\title{
Deposition nucleation viewed as homogeneous or immersion freezing in pores and cavities
}

\author{
C. Marcolli \\ Institute for Atmospheric and Climate Science, ETH Zurich, Switzerland \\ Correspondence to: C. Marcolli (claudia.marcolli@env.ethz.ch) \\ Received: 6 May 2013 - Published in Atmos. Chem. Phys. Discuss.: 19 June 2013 \\ Revised: 7 January 2014 - Accepted: 8 January 2014 - Published: 21 February 2014
}

\begin{abstract}
Heterogeneous ice nucleation is an important mechanism for the glaciation of mixed phase clouds and may also be relevant for cloud formation and dehydration at the cirrus cloud level. It is thought to proceed through different mechanisms, namely contact, condensation, immersion and deposition nucleation. Conceptually, deposition nucleation is the only pathway that does not involve liquid water, but occurs by direct water vapor deposition onto a surface. This study challenges this classical view by putting forward the hypothesis that what is called deposition nucleation is in fact pore condensation and freezing (PCF) occurring in voids and cavities that may form between aggregated primary particles and host water at relative humidity $\mathrm{RH}_{\mathrm{w}}<100 \%$ because of the inverse Kelvin effect. Homogeneous ice nucleation is expected to occur below $235 \mathrm{~K}$ when at least one pore is filled with water. Ice nucleation in pores may also happen in immersion mode but with a lower probability because it requires at least one active site in a water filled pore. Therefore a significant enhancement in ice nucleation efficiency is expected when temperature falls below $235 \mathrm{~K}$. For a deposition nucleation process from water vapor no discontinuous change in ice nucleation efficiency should occur at $T=235 \mathrm{~K}$ because no liquid water is involved in this process. Studies on freezing in confinement carried out on mesoporous silica materials such as SBA15, SBA-16, MCM-41, zeolites and KIT have shown that homogeneous ice nucleation occurs abruptly at $T=230$ $235 \mathrm{~K}$ in pores with diameters $(D)$ of $3.5-4 \mathrm{~nm}$ or larger but only gradually at $T=210-230 \mathrm{~K}$ in pores with $D=2.5-$ $3.5 \mathrm{~nm}$. Pore analysis of clay minerals shows that kaolinites exhibit pore structures with pore diameters $\left(D_{\mathrm{p}}\right)$ of 20 $50 \mathrm{~nm}$. The mesoporosity of illites and montmorillonites is characterized by pores with $D_{\mathrm{p}}=2-5 \mathrm{~nm}$. The number and
\end{abstract}

size of pores is distinctly increased in acid treated montmorillonites like K10. Water adsorption isotherms of MCM41 show that pores with $D_{\mathrm{p}}=3.5-4 \mathrm{~nm}$ fill with water at $\mathrm{RH}_{\mathrm{w}}=56-60 \%$ in accordance with an inverse Kelvin effect. Water in such pores should freeze homogeneously for $T<235 \mathrm{~K}$ even before relative humidity with respect to ice $\left(\mathrm{RH}_{\mathrm{i}}\right)$ reaches ice saturation. Ice crystal growth by water vapor deposition from the gas phase is therefore expected to set in as soon as $\mathrm{RH}_{\mathrm{i}}>100 \%$. Pores with $D>7.5 \mathrm{~nm}$ fill with water at $\mathrm{RH}_{\mathrm{i}}>100 \%$ for $T<235 \mathrm{~K}$ and are likely to freeze homogeneously as soon as they are filled with water. Given the pore structure of clay minerals, PCF should be highly efficient for $T<235 \mathrm{~K}$ and may occur at $T>235 \mathrm{~K}$ in particles that exhibit active sites for immersion freezing within pores. Most ice nucleation studies on clay minerals and mineral dusts indeed show a strong increase in ice nucleation efficiency when temperature is decreased below $235 \mathrm{~K}$ in accordance with PCF and are not explicable by the classical view of deposition nucleation. PCF is probably also the prevailing ice nucleation mechanism below water saturation for glassy, soot, and volcanic ash aerosols. No case could be identified that gives clear evidence of ice nucleation by water vapor deposition onto a solid surface.

\section{Introduction}

Ice is the stable phase of water below $273 \mathrm{~K}$ and forms readily by heterogeneous nucleation in the presence of surfaces that promote the formation of ice embryos. In the absence of such ice nuclei (IN) water can be supercooled to temperatures below $\sim 237 \mathrm{~K}$ when homogeneous nucleation sets in. There is evidence that, at least in water droplets with 
radii larger than $19 \mu \mathrm{m}$, homogeneous nucleation occurs in the volume of supercooled water (Duft and Leisner, 2004) and shows a strong increase in nucleation rate with decreasing temperature. Because IN are ubiquitous in large volumes of water, it is hardly possible to supercool large water drops to temperatures where homogeneous nucleation takes place (Mossop, 1955; Bigg, 1953; Pruppacher, 1995). Therefore, small volumes are needed to observe and analyze homogeneous ice nucleation. Airborne micrometer-sized particles can be investigated in electrodynamic balance experiments (Krämer et al., 1999; Duft and Leisner, 2004; Kabath et al., 2006), in continuous flow diffusion chambers (Hoyle et al., 2011) or in the large cloud chamber AIDA (Benz et al., 2005). On the other hand, small confined water volumes can be realized in water-in-oil emulsions (Marcolli et al., 2007; Liu et al., 2007) or in structured mesoporous materials (Findenegg et al., 2008; Janssen et al., 2004; Morishige and Kawano, 1999). There is ample evidence that cloud droplets or aqueous aerosol particles may supercool in the atmosphere until homogeneous nucleation sets in and leads to the glaciation of a liquid cloud or the formation of a cirrus cloud from aerosols, respectively (DeMott et al., 2003b; Hoyle et al., 2005; Peter et al., 2006; Krämer et al., 2009). In the presence of IN, cloud glaciation can occur at any temperature between ice melting at $273 \mathrm{~K}$ and the onset of homogeneous ice nucleation $(\sim 235 \mathrm{~K})$. Various insoluble particles such as mineral dust, soot, metallic particles, volcanic ash, or primary biological particles may act as IN (Pruppacher and Klett, 1997; Szyrmer and Zawadzki, 1997; Hoose et al., 2010; DeMott et al., 2010). The properties needed for a surface to be efficient as an IN are not well understood (Bartels-Rausch et al., 2012). For some of the best IN, a structural match with the ice lattice could be observed. Such materials include ice nucleation proteins expressed by bacterial species such as Pseudomonas syringae (Kajava and Lindow, 1993), and self-assembled crystalline monolayers of long-chain alcohols (Popovitz-Biro et al., 1994; Majewski et al., 1995; Zobrist et al., 2007). However, for other materials like mineral dusts, active sites that are usually associated with defects such as steps and cracks are suspected to induce ice nucleation (e.g., Fletcher, 1969; Marcolli et al., 2007).

Heterogeneous nucleation has been suggested to proceed via different mechanisms: contact nucleation (when an ice nucleus initiates freezing by contacting a supercooled droplet), condensation nucleation (when ice formation occurs during water condensation on a supercooled droplet), immersion nucleation (when freezing of a water droplet occurs on a foreign particle immersed in it), and deposition nucleation (when an ice embryo forms directly by water vapor condensation on a surface) (e.g., Murray et al., 2012; Pinti et al., 2012). While contact, condensation, and immersion nucleation all involve a liquid water phase, no liquid water is thought to be involved in deposition nucleation because it occurs at relative humidities $\left(\mathrm{RH}_{\mathrm{w}}\right)$ below water saturation. However, cracks and pores fill with water below water saturation due to the inverse Kelvin effect. This study puts forward the hypothesis that what is called deposition nucleation is in fact pore condensation and freezing (PCF) by homogeneous or immersion nucleation occurring in voids or cavities of aerosol particles, which may host liquid water at $\mathrm{RH}_{\mathrm{w}}<100 \%$. Ice nucleation in clay minerals and mineral dusts is taken as the prime example, because the database for these materials is best. The idea that capillary condensation of water is essential for the ice nucleation ability of clay minerals was already advanced in 1966 by Fukuta (1966) and taken up again very recently by Christenson (2013).

The structure, phase behavior and dynamics of water confined between closely spaced surfaces has attained considerable interest because of their relevance to areas such as frost heave, weathering of rocks and various man-made materials, the properties of porous media, oil recovery, ceramics and materials science in general (Christenson, 2001). With the development of new mesoporous materials of uniform pore size and shape like MCM-41 and SBA-15 (Findenegg et al., 2008; Kittaka et al., 2011), the investigation of freezing in narrow cylinders and cavities has become possible and much effort has been made to better understand how melting and freezing depend on the nature of the confining surfaces, their separation and geometry (Findenegg et al., 2008). To corroborate the hypothesis that pore condensation is the prevalent ice nucleation mechanism at $\mathrm{RH}_{\mathrm{w}}$ below water saturation, the recent findings of freezing in confinement are summarized and related to the pore structure.

This paper is structured as follows: Sect. 2 reviews water adsorption, melting, and freezing in pores. Section 3.1 relates the ice nucleation ability below water saturation to the pore structure of clay minerals and mineral dusts. The effect of coatings is discussed in Sect. 3.2. In Sect. 3.3, the analysis is extended to other types of IN like glasses, volcanic ash, and Snomax ${ }^{\mathrm{TM}}$. Section 4 concludes by making suggestions for studies to further explore the hypothesis of PCF. More detailed information on Sects. 2 and 3 is given in appendices A-D.

\section{Freezing in confinement}

Melting and freezing of water in confinement has been investigated since the early part of the 20th century (Christenson, 2001) and gained increased interest with the availability of new mesoporous materials and increased capabilities of molecular dynamic simulations. The materials that are most frequently used for experimental studies are mesoporous silica, zeolites, porous silicon, porous glass, and carbon nanotubes (Alba-Simionesco et al., 2006). The freezing and melting of water confined in mesoporous materials of different pore morphology and width has been studied by a variety of techniques, including calorimetry, NMR spectroscopy, and X-ray and neutron diffraction. The characterization of the porous structures is obtained by combining 
TEM, X-ray and neutron diffraction, and adsorption experiments.

\subsection{Materials}

Mesoporous silica materials of uniform pore size and shape exist in a large variety, such as MCM-41 (Mobil Composition of Matter), SBA-15 (Santa Barbara Amorphous type material), SBA-16, or KIT. They can be prepared by the controlled condensation of a silica precursor in aqueous media, using micellar aggregates of surfactants or amphiphilic block copolymers as structure-directing templates (Findenegg et al., 2008; Kittaka et al., 2011). The use of a template leads to a highly uniform pore shape and width as shown, e.g., in Beck et al. (1992). These porous materials exhibit amorphous pore walls, while, e.g., zeolites and carbon nanotubes are crystalline porous materials. MCM-41 is a porous oxide ceramic exhibiting hexagonal arrays of uniform cylindrical pores whose diameters may be engineered between 1 and $10 \mathrm{~nm}$. The porous structure becomes unstable for pore sizes larger than $5 \mathrm{~nm}$ due to constraints on the $0.5-1 \mathrm{~nm}$-thick silica walls (Alba-Simionesco et al., 2006; Beck et al., 1992). SBA-15 oxide ceramics exhibit a similar structure to that of MCM-41, but with thicker pore walls ( 3-4 nm), improving the stability of the porous structure (Alba-Simionesco et al., 2006) and can exhibit pores with diameters up to 10 or $20 \mathrm{~nm}$ that are connected via transverse microporous channels. SBA-16 exhibits cage-like pores in the size range from 6 to $11 \mathrm{~nm}$ diameters that are interconnected by channels whose dimensions depend on the hydrothermal treatment temperature during synthesis (Kittaka et al., 2011). The mesoporous KIT-5 silica has spherical cavities (10-20 nm diameters) arranged in a face-centered cubic array and connected through narrow necks (Morishige et al., 2007). Zeolites are microporous crystalline aluminosilicates with pore diameters $\left(D_{\mathrm{p}}\right)$ between 0.3 and $1.2 \mathrm{~nm}$. Mesopores with diameters between 2 and $50 \mathrm{~nm}$ can be created in the zeolites by steam and/or acid treatments. For steamed $\mathrm{Y}$ zeolites, up to $30 \%$ of these pores are connected to the external surface via the micropore system only (Janssen et al., 2004). The surfaces of the hydrophilic mesoporous silica can be turned hydrophobic by treatment with surfactants, as demonstrated by Deschamps et al. (2010) for MCM-41. To fill the hydrophobic pores with water, pressure has to be applied and the amount of water adsorbed by the hydrophobic material is drastically reduced (from $58 \% w / w$ to $2 \% w / w$ ). Singlewalled carbon nanotubes are hydrophobic carbon cylinders that can be filled with water when an external pressure is applied. The inner diameter of single-walled carbon nanotubes can be varied from 0.5 to $2.4 \mathrm{~nm}$ (Alba-Simionesco et al., 2006).

\subsection{Water adsorption}

Adsorption isotherms of MCM-41 and SBA-15 exhibit a relatively weak and nearly linear increase in the adsorbed amount of water up to the onset of pore condensation (Findenegg et al., 2008). In the case of MCM-41, pore condensation of water occurs when approximately one water molecule per surface silanol group has been adsorbed. SBA-15 has wider pores than MCM-41 and thus pore condensation starts at a significantly higher relative humidity when 3-4 statistical monolayers of water have been formed. Pore condensation of water in these materials is connected with a pronounced sorption hysteresis, indicating the existence of metastable regions of the liquid-like states in the pores. The mean density of water in completely filled pores is estimated as $0.93 \pm 0.03 \mathrm{~g} \mathrm{~cm}^{-3}$ at $20^{\circ} \mathrm{C}$ for water in MCM- 41 and in SBA-15 (Findenegg et al., 2008).

Morishige and Iwasaki (2003) discussed in detail water adsorption in the pores of SBA-15 as a function of pore filling $f=V_{\mathrm{w}} / V_{\mathrm{p}}$, where $V_{\mathrm{p}}$ is the mesopore volume and $V_{\mathrm{w}}$ the volume occupied by the adsorbed water. They developed the following conception for water adsorption at $270 \mathrm{~K}$ : at $f=0.2$, clusters of water form on the pore wall of the main channels. Capillary condensation starts above $f=0.4$. The liquid capillary condensate (the free water) coexists with the film water at $f=0.6$ and thin liquid bridges develop at this pore filling. At $f=0.8$ the thin liquid bridges grow into liquid domains and disappear close to a complete filling. A small amount of vapor bubbles still remains close to $f=1.0$ and eventually disappears beyond a complete filling.

Because of their small diameters, the pores of these materials fully fill with water well below a relative humidity $\mathrm{RH}_{\mathrm{w}}=100 \%$. Water uptake and release gives rise to hysteresis of 2-40\% in $\mathrm{RH}_{\mathrm{w}}$. The largest hysteresis is found for the cage-like pores of SBA-16 (Kittaka et al., 2011), while the narrow cylinders of MCM-41 exhibit a much smaller hysteresis (Kittaka et al., 2006). Adsorption and desorption in cylindrical capillaries both appear to be thermodynamically irreversible, with a delay in adsorption resulting from the presence of cylindrical menisci in open-ended pores being followed by a delay in desorption due to the retention of liquid behind narrow restrictions (Aylmore, 1974). Figure 1 compares the onset of water uptake for different mesoporous silica materials with the decreased water vapor pressure in capillaries predicted by the inverse Kelvin equation given by:

$$
\frac{p_{\mathrm{lc}}}{p_{1}}=\exp \left(\frac{-4 \gamma v_{1}}{D R T}\right)
$$

In this equation, $p_{\mathrm{lc}}$ is the water vapor pressure over the concave surface, $p_{1}$ the water vapor pressure over a flat water surface, $\gamma$ is the surface tension of water, $\nu_{1}$ the molar volume of liquid water, $D$ the diameter of the curved water surface, $R$ the ideal gas constant, and $T$ the absolute temperature. Since the water adsorption isotherms were mostly measured 


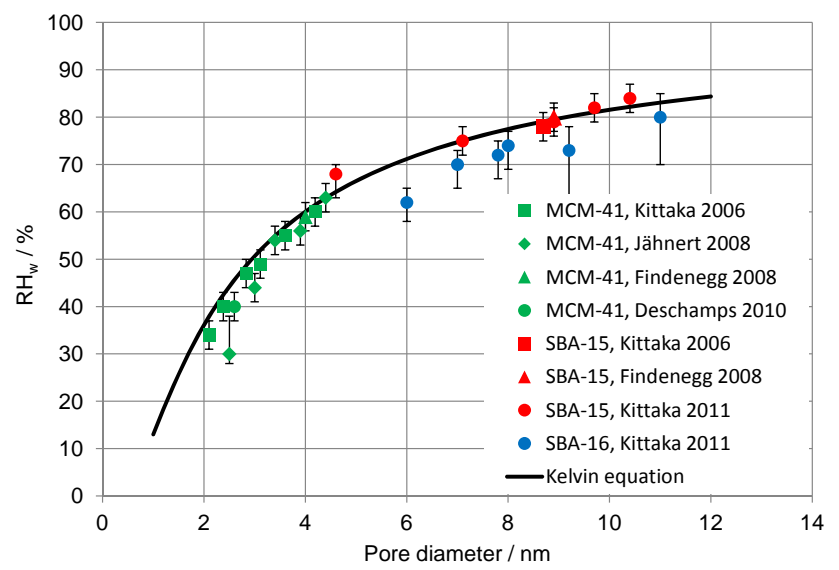

Fig. 1. Onset of capillary condensation of water in pores of different mesoporous silica materials as a function of relative humidity $\mathrm{RH}_{\mathrm{W}}$. Data is from Kittaka et al. (2006) (measured gravimetrically at $25^{\circ} \mathrm{C}$ ), Jähnert et al. (2008) (DVS (dynamic vapor sorption) at $20^{\circ} \mathrm{C}$ ), Findenegg et al. (2008) (measurements at $20^{\circ} \mathrm{C}$ ), Deschamps et al. (2010) (DVS), and Kittaka et al. (2011) (measured gravimetrically). The black solid line indicates capillary condensation predicted by the Kelvin equation (for $T=298 \mathrm{~K}$ ).

at ambient temperature, $T$ was taken as $298 \mathrm{~K}$ for the calculation in Fig. 1. Best agreement with pore filling due to the inverse Kelvin effect is obtained when $\mathrm{RH}_{\mathrm{w}}$ at the onset of capillary condensation is related to the pressure reduction in pores $\left(p_{\mathrm{lc}} / p_{1}\right)$ described by the Kelvin equation. The generally good agreement with pore filling shows that the Kelvin equation can be used to predict whether mesopores are filled with water or not.

\subsection{Melting and freezing in pores}

Completely filled pores. When water melts or freezes in pores, the melting as well as the freezing temperatures are depressed compared to the values measured in bulk water. Melting of water in completely filled pores of MCM-41 and SBA-15 gives rise to a single heat flow peak (Findenegg et al., 2008; Schreiber et al., 2001) in differential scanning calorimetry (DSC). Completely filled pores $(f \geq 1)$ are obtained by wetting the dry silica powders with an excess of water, so that water is also present on the external surfaces of the powder grains. This external water nucleates first when temperature is decreased and may initiate freezing in pores. Completely filled pores contain free (bulk) water in the middle of the pores and bound water adjacent to the pore walls (Morishige and Nobuoka, 1997; Morishige and Kawano, 1999; Schreiber et al., 2001). Properties of this bound water layer are discussed in Appendix A1. While the free water freezes to ice at temperatures in accordance with homogeneous ice nucleation, the bound water remains as a disordered "quasi-liquid" layer adjacent to the pore walls down to around or below $200 \mathrm{~K}$ (Webber and Dore, 2004; Web- ber et al., 2007). Crystal structures of ice in confinements have been intensely studied (Morishige and Nobuoka, 1997; Morishige and Iwasaki, 2003; Morishige and Uematsu, 2005; Morishige et al., 2009; Dore, 2000; Liu et al., 2006; Webber et al., 2007; Seyed-Yazdi et al., 2008). Results from these studies are summarized in Appendix A2. They have shown that nucleation of ice in pores with diameters $<30 \mathrm{~nm}$ leads to ice-I, which shows predominantly features of cubic ice rather than hexagonal ice, and contains numerous defects. Figures 2 and 3 summarize the melting and freezing temperatures, respectively, as a function of pore diameter for different mesoporous materials.

MCM-41. The lowest melting temperatures in DSC scans were observed in hydrophobically coated pores of MCM41 (2.3 nm pore diameter) by Deschamps et al. (2010) with melting onsets and maxima of $188 \mathrm{~K}$ and $206 \mathrm{~K}$, respectively. An X-ray diffraction study by Morishige and Nobuoka (1997) showed that freezing of water in pores with diameters of $4.2 \mathrm{~nm}$ occurs abruptly around $232 \mathrm{~K}$ and gives rise to cubic ice, while the water confined in pores with diameters of $2.4 \mathrm{~nm}$ freezes very gradually at lower temperatures. The hysteresis width between melting and freezing decreases for MCM-41 with decreasing pore diameter and vanishes for $D_{\mathrm{p}} \leq 2.9 \mathrm{~nm}$ (which is also evident from a comparison of Figs. 2 and 3). Findenegg et al. (2008) take this as evidence that freezing and melting lose their character as a first-order transition when water is confined in such narrow pores. They argue that the water and ice phases become more and more similar with decreasing pore size because the disorder in the ice phase and the short-range order in liquid water both increase. Ice crystallites in MCM-41 samples of pore size below $4 \mathrm{~nm}$ exhibit order only on a short-length scale and can be viewed as proto-crystallites, i.e., clusters of hydrogenbonded molecules without well-defined lattice planes.

SBA-15. Fully wetted SBA-15 samples showed two exothermic peaks in a DSC study performed by Kittaka at al. (2011), a sharp one due to freezing of external water with onsets between 268 and $256 \mathrm{~K}$ depending on the sample and a broader one with onsets between 253 and $260 \mathrm{~K}$ due to freezing of pore water. Melting of frozen pore water gave rise to endothermic peaks with onsets between 254 and $261 \mathrm{~K}$. The freezing and melting temperatures increased with increasing pore size. Schreiber et al. (2001) found similar results in their DSC study of SBA-15, with somewhat larger hysteresis between melting and freezing peaks of 4.4-15 K. Freezing of pore water in the cylindrical pores of SBA- 15 is initiated by the presence of the external ice. Findenegg et al. (2008) assume that the ice penetrates as a solid front into the pore and explain the hysteresis between melting and freezing by the existence of constrictions at the pore entrances.

SBA-16. All SBA-16 samples that were exposed to DSC cycles showed an exothermic peak around $232 \mathrm{~K}$ due to freezing of water in the cage-like pores and one melting peak in the temperature range $245-257 \mathrm{~K}$, which shifts to higher temperatures with increasing cage size (Kittaka et al., 2011). 
Two samples showed a complex freezing behavior because the cage-like pores are interconnected by cylindrical channels with diameters of 3.9 and $10.5 \mathrm{~nm}$, respectively, so that ice can propagate through the channels. The sample with interconnecting channels of $3.4 \mathrm{~nm}$ did not show such a behavior because the water remains unfrozen in these narrower channels. One can therefore assume that freezing occurred by homogeneous nucleation for those samples, in which the cage-like pores are not interconnected or when the connecting channels are too narrow for water to freeze within them.

KIT. For the KIT samples (Morishige et al., 2007) the freezing temperature depended on the hydrothermal treatment during synthesis, which influences the neck size of the pores. For samples that were hydrothermally treated only for one day, the neck size is smaller than $4 \mathrm{~nm}$ and the pore water in the spherical cavities of KIT is isolated from nucleation sites by the water remaining unfrozen in the narrow necks, and thus the freezing takes place via homogeneous nucleation at $232 \mathrm{~K}$. For samples with wider necks the external water acts as a nucleation site.

Zeolites. Similarly, Janssen et al. (2004) found that in mesoporous cavities inside the zeolite crystals water can be supercooled to ca. $-40^{\circ} \mathrm{C}$, at which point homogeneous nucleation occurred, while in mesopores that are connected to the external surface, nucleation of ice was initiated by the ice phase present on the surface of the crystals.

Microemulsions. Liu et al. (2007) measured the freezing of water in microemulsions to derive the critical nucleus size. They found a strong decrease in the freezing temperature for water pool radii smaller than $2 \mathrm{~nm}$ and freezing at the homogeneous nucleation temperature for larger droplets.

Partially filled pores. Melting and freezing in partially filled pores has been investigated by several groups (Morishige and Iwasaki, 2003; Schreiber et al., 2001; Findenegg et al., 2008; Kittaka et al., 2011). DSC scans of partially filled pores of SBA-15 (7.7 nm pore diameter) showed one melting peak at $\sim 260 \mathrm{~K}$ whose position did not significantly depend on the degree of pore filling (Schreiber et al., 2001) but several freezing peaks. At filling levels $f \geq 0.2$ two freezing peaks at $\sim 233 \mathrm{~K}$ and $\sim 236 \mathrm{~K}$ were present whose exact peak positions were almost independent of pore filling. For pore fillings of $f \geq 0.55$, an additional freezing peak at $\sim 245 \mathrm{~K}$ appeared whose exact position and shape showed a complex dependence on both pore size and relative pore filling. Schreiber et al. (2001) attributed the peak at $\sim 245 \mathrm{~K}$ to the freezing of pore water in completely filled sections of the pores and the one at $236 \mathrm{~K}$ to the freezing of a liquidlike film adsorbed on the pore walls and left the origin of the peak at $233 \mathrm{~K}$ open. A similar freezing pattern was observed by Findenegg et al. (2008) during DSC cooling scans for partially filled pores of SBA- 15 with a pore diameter of $9 \mathrm{~nm}$. They ascribed the peaks at 236 and $233 \mathrm{~K}$ at filling levels of $f=0.2-0.6$ to the delayering of the liquid-like film on the pore wall. At a pore filling of $f=0.6$, DSC scans exhibited an additional peak with a maximum at $\sim 245 \mathrm{~K}$, which they attributed to the freezing of pore water. Morishige and Iwasaki (2003) studied freezing in partially filled pores of SBA- 15 with $7.8 \mathrm{~nm}$ pore diameter by X-ray diffraction. For filling levels of $f=0.4$, they observed the formation of microscrystals with $\sim 4 \mathrm{~nm}$ diameter at $237 \mathrm{~K}$ and ascribed them to the freezing of film water on the pore walls. These microcrystals melted at $257 \mathrm{~K}$ upon heating. At $f=0.6$, freezing occurred in two steps at $\sim 242$ and $\sim 237 \mathrm{~K}$. At this pore filling, the film water seemed to coexist with free water filled in the pores. The freezing temperature of the free water increased to $248 \mathrm{~K}$ for $f=0.8$ and $250 \mathrm{~K}$ for $f=1.0$. Kittaka et al. (2011) investigated freezing in SBA-15 and SBA-16 as a function of relative pressure $p / p^{0}\left(\equiv \mathrm{RH}_{\mathrm{w}}\right)$ in a DSC study. For SBA-15 (8.9 nm diameter), they observed a small exothermic peak at around $230 \mathrm{~K}$ for water adsorbed at $\mathrm{RH}_{\mathrm{w}}=25-74 \%$. With an increase in the adsorbed amount $\left(\mathrm{RH}_{\mathrm{w}}=74\right.$ and $\left.80 \%\right)$, a second peak appeared at $235-240 \mathrm{~K}$. When approaching the relative pressure for capillary condensation, i.e., at $\mathrm{RH}_{\mathrm{w}}=80 \%$, a large amount of pore water started to freeze at a higher temperature of $252 \mathrm{~K}$. When the sample is desorbed to $\mathrm{RH}_{\mathrm{w}}=48 \%$, only a single exothermic peak at $\sim 232 \mathrm{~K}$ is seen. For the SBA-16 sample with no interconnecting channels, a small exothermic peak can be seen at $\sim 232 \mathrm{~K}$ for $\mathrm{RH}_{\mathrm{w}}=30 \%$ that increases in intensity with increasing pore filling. When water was desorbed at $\mathrm{RH}_{\mathrm{w}}=42-76 \%$, the freezing temperature and the peak intensity remained almost constant. For the desorbed sample at $\mathrm{RH}_{\mathrm{w}}=35 \%$ where about half the amount of pore water is removed, the freezing peak at $\sim 232 \mathrm{~K}$ is still clearly visible but reduced in intensity. This shows that freezing in partially filled pores is more complex than in completely filled pores. DSC curves of partially filled pores are therefore difficult to interpret and are discussed controversially.

Melting point depression. Most studies dealing with ice melting in confinement relate the observed melting temperatures to the thermodynamic equilibrium melting temperature defined as the temperature at which a small spherical particle $p$ confined by a foreign surface $f$ has the same Gibbs free energy in the solid $(s)$ and in the liquid $(l)$ phase, i.e., $G_{\mathrm{ps}}=G_{\mathrm{pl}}$ (Faivre et al., 1999). Assuming spherical shape of the solid and the liquid particles with radii $r_{\mathrm{ps}}$ and $r_{\mathrm{pl}}$, respectively, the equality of the Gibbs free energy can be expressed as:

$\frac{4 \pi r_{\mathrm{ps}}^{3}}{3 v_{\mathrm{s}}} \mu_{\mathrm{s}}+4 \pi r_{\mathrm{ps}}^{2} \gamma_{\mathrm{sf}}=\frac{4 \pi r_{\mathrm{pl}}^{3}}{3 v_{1}} \mu_{1}+4 \pi r_{\mathrm{pl}}^{2} \gamma_{\mathrm{lf}}$,

where $\mu_{\mathrm{s}}$ and $\mu_{1}$ stand for the chemical potential in the liquid and solid state, respectively. The interfacial tension between the foreign surface $f$ and the particle in the solid and in the liquid state is given by $\gamma_{\mathrm{sf}}$ and $\gamma_{\mathrm{lf}}$, respectively. Assuming that the molar volume in the solid and in the liquid state is the same, $v_{\mathrm{s}}=v_{\mathrm{l}}$ and $r_{\mathrm{ps}}=r_{\mathrm{pl}}=r$; this equation simplifies to

$\frac{r}{3 v_{\mathrm{s}}}\left(\mu_{\mathrm{s}}-\mu_{1}\right)=\gamma_{\mathrm{lf}}-\gamma_{\mathrm{sf}}$. 
Using Young's equation and assuming perfect wetting of ice by liquid water (i.e., $\cos (\alpha)=1$ ) yields $\gamma_{\mathrm{lf}}-\gamma_{\mathrm{sf}}=\gamma_{\mathrm{sl}}$, where $\gamma_{\mathrm{sl}}$ denotes the interfacial tension between the solid and the liquid phase. If the difference in chemical potentials is expressed as the vapor pressure ratio between the solid and the liquid phase, i.e., $\left(\mu_{1}-\mu_{\mathrm{s}}\right)=R T \ln \left(\mathrm{p}_{1} / p_{\mathrm{s}}\right)$, Eq. (3) transforms to

$\ln \frac{p_{1}}{p_{\mathrm{s}}}=\frac{3 v_{\mathrm{s}} \gamma_{\mathrm{s}}}{r R T}$

where $p_{1}$ is the equilibrium vapor pressure above the liquid and $p_{\mathrm{s}}$ the one above the solid phase. Using the ClausiusClapeyron equation, the vapor pressure ratio can be converted to a melting point depression $\Delta T$ for the thermodynamic equilibrium condition:

$$
\frac{\Delta T}{T_{0}}=-\frac{3 v_{\mathrm{s}} \gamma_{\mathrm{sl}}}{r \Delta H_{f}}
$$

where $T_{0}$ denotes the melting point of bulk ice and $\Delta H_{f}$ the molar enthalpy of melting. This equation is similar to the Gibbs-Thomson equation, but with a numerical coefficient of 3 instead of 2.

An analogous derivation can be performed for the melting point depression in a cylinder of radius $r$ and length $L$, neglecting the energies of the two ends (see Fig. 4a for illustration of the equilibrium condition):

$\frac{\pi L r_{\mathrm{ps}}^{2}}{v_{\mathrm{s}}} \mu_{\mathrm{s}}+2 \pi L r_{\mathrm{ps}} \gamma_{\mathrm{sf}}=\frac{\pi L r_{\mathrm{pl}}^{2}}{v_{1}} \mu_{1}+2 \pi L r_{\mathrm{pl}} \gamma_{\mathrm{lf}}$

yielding

$\ln \frac{p_{1}}{p_{\mathrm{s}}}=\frac{2 v_{\mathrm{s}} \gamma_{\mathrm{s} 1}}{r R T}$

and

$$
\frac{\Delta T}{T_{0}}=-\frac{2 v_{\mathrm{s}} \gamma_{\mathrm{sl}}}{r \Delta H_{f}}
$$

Equation (7) is identical to the Gibbs-Thomson (Kelvin) equation, although it is derived in a different way. This is the relationship that most studies treating pore melting use to explain the melting point depression in cylindrical pores (e.g., Schreiber et al., 2001; Christenson, 2001; Jähnert et al., 2008; Kittaka et al., 2011). For parameterization, this equation is usually brought into the following form:

$\Delta T=-\frac{C}{r}$ with $C=-\frac{2 T_{0} v_{\mathrm{s}} \gamma_{\mathrm{sl}}}{\Delta H_{f}}$.

Often the pore radius $r$ is replaced by the term $(r-t)$, which accounts for the quasi-liquid layer of width $t$ that forms at the pore wall and reduces the actual diameter of the ice phase in the pores (i.e., $\Delta T=-C /(r-t))$. Jähnert et al. (2008) calculated a value of $C=51.9 \pm 4 \mathrm{~K} \mathrm{~nm}$

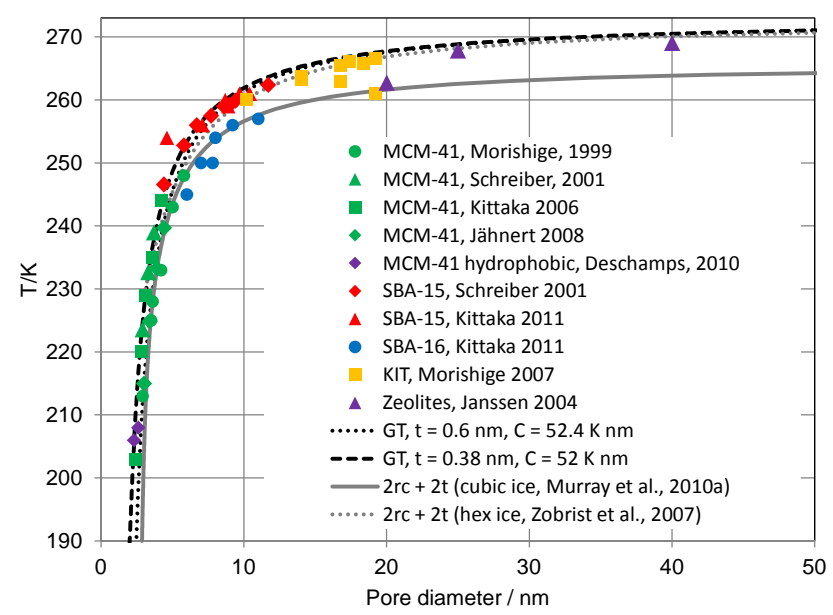

Fig. 2. Ice melting in completely filled pores of different mesoporous materials. Data is taken from Morishige and Kawano (1999) (X-ray diffraction patterns in ca. $2 \mathrm{~K}$ steps), Schreiber et al. (2001) (DSC curves at $0.5 \mathrm{~K} \mathrm{~min}^{-1}$, evaluation of peak maxima), Kittaka et al. (2006) (DSC curves at $5 \mathrm{~K} \mathrm{~min}^{-1}$, evaluation of peak onset), Jähnert et al. (2008) (DSC curves at $0.5 \mathrm{~K} \mathrm{~min}^{-1}$, evaluation of peak maxima), Deschamps et al. (2010) (DSC curves of hydrophobic pores at $0.5 \mathrm{~K} \mathrm{~min}^{-1}$, evaluation of peak maxima), Kittaka et al. (2011) (DSC curves at $5 \mathrm{~K} \mathrm{~min}^{-1}$, evaluation of peak onset), Morishige et al. (2007) (DSC curves at $0.5 \mathrm{~K} \mathrm{~min}^{-1}$, evaluation of peak onset), and Janssen et al. (2004) (DSC curves at $0.5 \mathrm{~K} \mathrm{~min}^{-1}$, evaluation of peak onset). Black dashed and dotted lines: melting point depression from the Gibbs-Thomson equation (GT). Grey dotted and solid lines: pore diameter needed to incorporate a critical cluster of hexagonal (calculated with values from parameterization by Zobrist et al., 2007) and cubic ice (calculated with values from parameterization by Murray et al., 2010a), respectively.

by inserting $T_{0}=273.15 \mathrm{~K}, \Delta H_{f}=6.01 \mathrm{~kJ} \mathrm{~mol}^{-1}$, $v_{\mathrm{s}}=18.02 \mathrm{~cm}^{3} \mathrm{~mol}^{-1}$ and $\gamma_{\mathrm{sl}}=31.7 \pm 2.7 \mathrm{~mJ} \mathrm{~m}^{-2}$ and determined empirically a very similar value of $C=52.4 \mathrm{~K} \mathrm{~nm}$ and $t=0.6 \mathrm{~nm}$ for their experiments on ice melting in fully filled pores of MCM-41 (dotted black line in Fig. 2). Schreiber et al. (2001) determined $C=52 \pm 2 \mathrm{~K} \mathrm{~nm}$ and $t=0.38 \mathrm{~nm}$, corresponding to $1-2$ monolayers of bound water (dashed black line in Fig. 2) by fitting the observed melting point depression of fully filled MCM-41 and SBA-15 pores. These values lead to a good description of the experimental data and are in agreement with the directly calculated value of $C=51.9 \pm 4 \mathrm{~K}$ and the assumption that 1-2 layers of bound water are present at the pore walls. The value of $t$ becomes important for pore radii $r<2 \mathrm{~nm}$ (Schreiber et al., 2001).

Interestingly, Eq. (7) corresponds to the Kelvin equation describing the pressure increase over small spherical particles, which is also of relevance in Classical Nucleation Theory (CNT, Pruppacher and Klett, 1997; see Fig. 4b for illustration). CNT formulates the Gibbs free energy to create a new solid phase from the liquid as the sum of a volume term accounting for the energy released when a molecule is 
incorporated from the liquid into the solid phase and a surface term accounting for the energy needed to build up the interface between the solid and the liquid phases. The Gibbs free energy $\left(G_{\mathrm{ps}}\right)$ to form a spherical solid cluster with radius $r$ within the liquid phase is given by

$G_{\mathrm{ps}}=\frac{4 \pi r^{3}}{3 v_{\mathrm{s}}} R T \ln \frac{p_{1}}{p_{\mathrm{s}}}+4 \pi r^{2} \gamma_{\mathrm{sl}}$

The critical radius $r_{\mathrm{c}}$ of the cluster is defined as the one where growth and shrinkage of the cluster of the solid phase both lead to a decrease in $G_{\mathrm{ps}}$ and can be determined by setting $\delta G_{\mathrm{ps}} / \delta r=0$ :

$r_{\mathrm{c}}=\frac{2 v_{\mathrm{s}} \gamma_{\mathrm{s}}}{R T \ln \frac{p_{1}}{p_{\mathrm{s}}}}$

Homogeneous nucleation rates of micrometer-sized droplets have been determined by many groups (e.g., Riechers et al. (2013) and Murray et al. (2010a) for a compilation of data) and can be used to parameterize CNT. Such parameterizations have been proposed recently by Zobrist et al. (2007) and Murray et al. (2010a) and provide values for all quantities in Eq. (11). The pore diameters needed to incorporate a critical cluster with a radius $r_{\mathrm{c}}$ and accounting for the presence of a non-freezing quasi-liquid layer between pore wall and nucleus with width $t$ are given by $D_{\mathrm{p}}=2 r_{\mathrm{c}}+2 t$ and shown as grey lines in Figs. 2 and 3 (for $t=0.6 \mathrm{~nm}$ ). If the pores are narrower, ice formation should be impeded during cooling and the ice in the pores should melt at the temperature where $2 r_{\mathrm{c}}+2 t>D_{\mathrm{p}}$. The dotted and solid grey lines give the pore diameters using the parameterization by Zobrist et al. (2007) for hexagonal and the parameterization by Murray et al. (2010a) for cubic ice, respectively. The temperature dependence of $D_{\mathrm{p}}=2 r_{\mathrm{c}}+2 t$ reflects the increase in the critical cluster size with temperature. Values taken from the parameterization by Zobrist et al. (2007) lead to good agreement with the measured melting point depressions in the pores but to too high freezing temperatures for most materials with $D_{\mathrm{p}}>4 \mathrm{~nm}$. The parameterization by Murray et al. (2010a) using the vapor pressure of cubic ice agrees well with the observed melting point depressions shown in Fig. 2 for $D_{\mathrm{p}} \leq 10 \mathrm{~nm}$ and the cage-like pores of SBA-16 (Kittaka et al., 2011). These findings are in agreement with XRD measurements by Kittaka et al. (2011), who showed that up to the melting temperature ice is present as cubic ice in the cages of SBA-16. Different XRD and neutron diffraction studies on SBA-15 further confirm that ice in pores with $D_{\mathrm{p}}=7.8 \mathrm{~nm}$ remains in its cubic form and that only for larger pore sizes does the hexagonal ice component seem to increase (Kittaka et al., 2011). Also shown in Fig. 3 are homogeneous ice nucleation temperatures for water in spherical pores with the diameters indicated on the $\mathrm{x}$ scale and assuming a cooling rate of $0.5 \mathrm{~K} \mathrm{~min}^{-1}$. The freezing temperatures are given for a nucleated fraction of $1 \%$ and should correspond to the reported onset of freezing in DSC experiments. The solid and dotted black lines give the parameterization by Murray et al. (2010a) with $n=0.3$ and the parameterization by Zobrist et al. (2007), respectively. The comparison of the calculated homogeneous ice nucleation temperatures with the freezing temperatures shows that homogeneous nucleation is not limited by the confinement for pore diameters larger than 3.5$4 \mathrm{~nm}$. For narrower pores, subcritical ice clusters may be produced at a high rate, but cannot grow to the critical size due to the confinement. This view is supported by experimental (Liu et al., 2007; Pradzynski et al., 2012) and modeling studies (Moore et al., 2012; Li et al., 2011; Reinhardt and Doye, 2012), which estimate that critical ice clusters consist of 70 to 275 molecules in the temperature range from 195 to $231 \mathrm{~K}$ corresponding to $r_{\mathrm{c}}=1.2-1.8 \mathrm{~nm}$ if one assumes a spherical shape of the critical clusters. Also for larger pores and at higher temperatures, the radius of a critical cluster with spherical shape seems to determine the melting and freezing temperatures in pores. Ice present on the external surfaces of mesoporous silica powders seems to initiate nucleation of the pore water (Schreiber et al., 2001; Liu et al., 2006) only when the temperature is lowered to a value so that $D_{\mathrm{p}} \geq 2 r_{\mathrm{c}}+2 t$. This is in agreement with XRD studies, which show that microcrystallites rather than ice cylinders grow in the pores. Analyzing the peak width of the X-ray diffraction patterns, Morishige and Iwasaki (2003) found that microcrystals with $\sim 4 \mathrm{~nm}$ diameter formed in partly filled pores of SBA-15 with diameters of $7.8 \mathrm{~nm}$. They concluded that microcrystals did not grow along the pore length but that many nuclei formed in each cylindrical pore. Freezing temperatures of KIT (Morishige et al., 2007) and SBA-16 samples (Kittaka et al., 2011) that lie between the solid grey and the dotted black lines in Fig. 3 are indicative of heterogeneous freezing within the cage-like pores initiated by ice that propagates through channels connecting the pores. The freezing temperature depends on the width of these channels, which can be influenced by the preparation procedure of the mesoporous materials. The presence of a quasi-liquid water layer between the pore wall and the critical cluster implies that the freezing/melting behavior should not be notably influenced by the surface properties of the pore walls. This is indeed confirmed by Deschamps et al. (2010), who investigated hydrophobically coated MCM-41, by Morishige and Nobuoka (1997), who incorporated aluminum into siliceous MCM-41 resulting in the formation of Bronsted-acid sites, and Findenegg et al. (2008), who investigated SBA-15 materials in which the pore walls had been decorated by propionic acid, phosphonic acid and sulfonic acid. In all these studies, the freezing/melting behavior of the free water confined in the pores was almost independent of the surface properties of the pore wall.

In summary, studies of water confined in mesoporous materials have shown that freezing occurs by homogenous nucleation as predicted by CNT in isolated pores with $D>3.5-$ $4 \mathrm{~nm}$, while freezing and melting temperatures drop off for smaller pore sizes. The resulting ice phase is a defective 


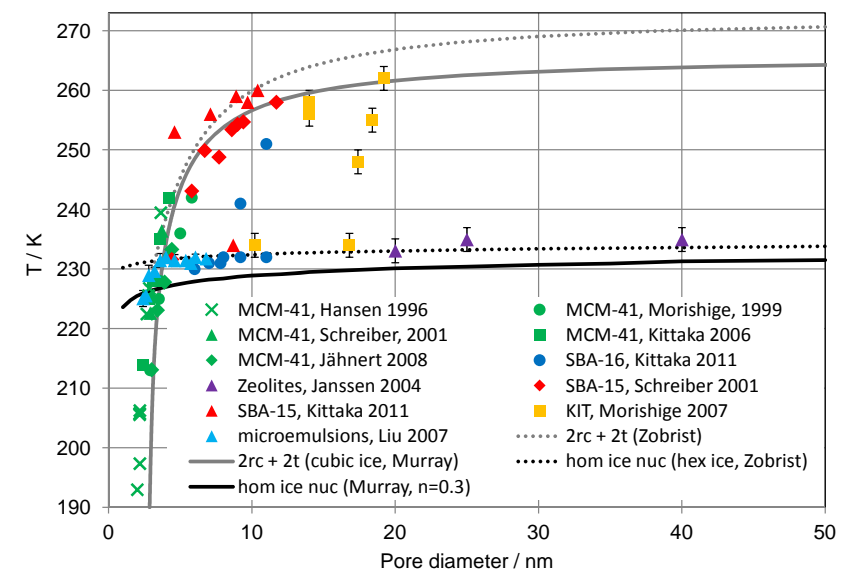

Fig. 3. Freezing in completely filled pores of different mesoporous materials. Data is taken from Hansen et al. (1996) (NMR spectra measured in $2 \mathrm{~K}$ steps), Morishige and Kawano (1999) (Xray diffraction patterns in ca. $2 \mathrm{~K}$ steps), Schreiber et al. (2001) (DSC curves at $0.5 \mathrm{~K} \mathrm{~min}^{-1}$, evaluation of peak maxima), Kittaka et al. (2006) (DSC curves at $5 \mathrm{~K} \mathrm{~min}^{-1}$, evaluation of peak onset), Jähnert et al. (2008) (DSC curves at $0.5 \mathrm{~K} \mathrm{~min}^{-1}$, evaluation of peak maxima), Kittaka et al. (2011) (DSC curves at $5 \mathrm{~K} \mathrm{~min}^{-1}$, evaluation of peak onset), Janssen et al. (2004) (DSC at $0.5 \mathrm{~K} \mathrm{~min}^{-1}$, evaluation of peak onset), Morishige et al. (2007) (DSC curves at $0.5 \mathrm{~K} \mathrm{~min}^{-1}$, evaluation of peak onset), Liu et al. (2007) (DSC curves at $5 \mathrm{~K} \mathrm{~min}^{-1}$, DTD (differential temperature difference) curves at $1 \mathrm{~K} \mathrm{~min}^{-1}$ ). Grey dotted and solid lines: pore diameter needed to incorporate a critical cluster of hexagonal (calculated with values from parameterization by Zobrist et al., 2007) and cubic ice (calculated with values from parameterization by Murray et al. (2010a), respectively. Black dotted and solid lines: parameterizations of homogeneous ice nucleation by Zobrist et al. (2007) and Murray et al. (2010a) with $n=0.3$, respectively.

form of ice-I, which has predominantly cubic ice rather than hexagonal ice features. The surface properties of the pore walls have little influence on the freezing and melting temperature because they are covered by a quasi-liquid layer of bound water.

\section{Deposition nucleation}

Deposition nucleation has been investigated for a variety of IN mainly by three different types of instruments: continuous flow diffusion chambers, the large cloud chamber AIDA, and static diffusion chambers. The working principles of these instruments are summarized in Appendix B.

Among the particle types that have been studied as potential IN, clay minerals and mineral dusts are probably the best investigated and characterized ones. Mineral dusts seem to be the most relevant IN in the atmosphere, since they are always enriched in residual particles of ice crystals (e.g., DeMott et al., 2003a, b; Cziczo et al., 2013). Clay minerals have been identified as major components of transported mineral dusts

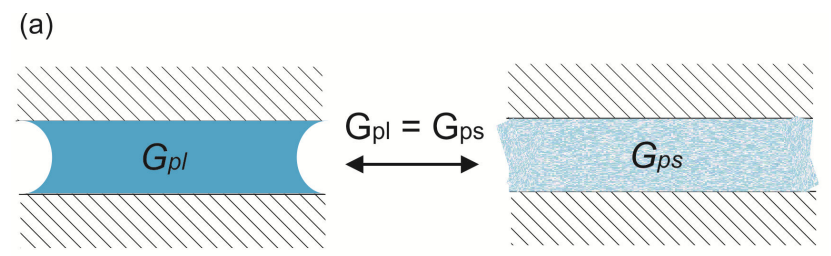

(b)

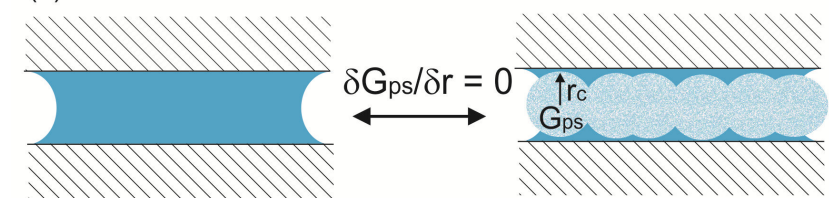

Fig. 4. (a) Scheme representing equilibrium condition between water phase (left) and ice phase (right) confined in a cylindrical pore as formulated in Eq. (6). (b) Ice crystals limited to critical size in cylindrical pores given by the critical radius $\left(r_{\mathrm{c}}\right)$ derived from CNT.

(Murray et al., 2012). They will therefore serve as the prime examples of PCF. A summary of sources and composition of clay minerals and mineral dusts is given in Appendix C1.

\subsection{Deposition nucleation on clay minerals and mineral dusts}

Deposition nucleation on clay minerals and mineral dusts offers the best source to investigate the importance of PCF because pore structures of clay minerals have been well characterized and can be used to predict the ice nucleation ability assuming that ice formation starts from pores filled with water. Clay minerals are hydrous aluminum silicates forming sheet-like structures of lamellae that may aggregate to lamellae stacks. The possible sources of porosity include crevices in the particle surface, staggered layer edges, voids created by the overlapping of stacked layers, and interlayer regions (Rutherford et al., 1997). Slit- and wedge-shaped pores result from the interleaving of crystal units of several lamellae in thickness. Depending on $\mathrm{RH}_{\mathrm{w}}$, mesopores $\left(D_{\mathrm{p}}=2-50 \mathrm{~nm}\right)$ fill with water due to capillary condensation. In slit-shaped pores water adsorption appears to occur largely by multilayer formation on the flat surfaces of the clay particles; desorption is then governed by the curvature of the semicylindrical menisci formed. In so-called "ink-bottle" pores with large chambers behind narrower pore openings, the adsorption branch shows a reversible filling of the pores, while the desorption branch is characterized by spontaneous emptying of the condensate governed by the curvature of the condensate meniscus (Aylmore and Quirk, 1967).

In kaolinites the stacking of lamellae leads to platy particles with pores resulting from the interleaving of the plates. The diameters of the pores are similar in size to the thickness of the particles, which varies from 15 to $100 \mathrm{~nm}$ with predominance in the range from 20 to $50 \mathrm{~nm}$ (Churchman et al., 1995; Sills et al., 1973). Illites tend to be an agglomerate 
of numerous individual crystals or clusters. Almost the entire porosity arises from the void spaces between nearly parallel aligned plates resulting in pore diameters of $2-5 \mathrm{~nm}$, with the maximum in the pore peak occurring at about $3 \mathrm{~nm}$ (Aylmore, 1974; Aylmore and Quirk, 1967). The porosity of montmorillonites is more dependent on the type of montmorillonite. Aylmore and Quirk (1967) showed for Redhill calcium montmorillonite (England) and Wyoming calcium bentonite (clay minerals consisting mostly of montmorillonite) that pores of $2-4 \mathrm{~nm}$ diameter predominate. Kumar et al. (1995) found that raw clays of bentonites have a pore size distribution with ca. $40 \%$ of the total volume of mesopores in the diameter range $2-5 \mathrm{~nm}$, while pores in the range $10-50 \mathrm{~nm}$ represent ca. $30 \%$. Acid treatment of montmorillonite enhances mesoporosity, making it an effective catalytic support. A more detailed discussion of the porosity of clay minerals is given in Appendix C2.

Water adsorption isotherms show that pores of mesoporous materials fill in accordance with an inverse Kelvin effect (Sect. 2.2). Completely filled pores contain free (bulk) water in the middle of the pores and bound water adjacent to the pore walls. The water in the middle of the pores freezes by homogeneous nucleation at $T=230-235 \mathrm{~K}$ for $D_{\mathrm{p}}>3.5$, as shown in Sect. 2.3. Since rates of homogeneous ice nucleation at these temperatures are high, the presence of one pore filled with water on a particle suffices to nucleate ice. For $T>235 \mathrm{~K}$, homogeneous ice nucleation rates decline rapidly and freezing in pores has to occur by immersion nucleation at active sites. The efficiency of immersion nucleation for PCF depends on the density of active sites within pores and is supposed to be drastically lower than the one of homogeneous nucleation. One can therefore assume that PCF occurs when aerosol particles contain one pore filled with water for $T<235 \mathrm{~K}$ and a pore with an active site immersed in water for $T>235 \mathrm{~K}$. This implies a strong increase in the ice nucleation efficiency when temperature is decreased below $235 \mathrm{~K}$. Such dependence of ice nucleation efficiency on temperature is not expected for deposition nucleation. PCF as the prevailing ice nucleation mechanism can therefore be assumed when particles become much better IN once the temperature is decreased below $235 \mathrm{~K}$.

\subsubsection{Clay minerals}

Deposition nucleation on clay minerals has been investigated by several groups using different measurement techniques. Figure 5 shows a compilation of literature data for kaolinite (a), illite (b), and montmorillonite (c). The symbols are color coded with respect to particle size $(d<1 \mu \mathrm{m}$, red; $d \approx 1 \mu \mathrm{m}$, purple; $d>1 \mu \mathrm{m}$, green) and indicate the onset of freezing as a function of temperature and relative humidity with respect to ice $\left(\mathrm{RH}_{\mathrm{i}}\right)$. The solid black lines indicate $\mathrm{RH}_{\mathrm{i}} / T$ conditions for water saturation (parameterization of Murphy and Koop, 2005). The dashed black line gives homogeneous ice nucleation for a nucleation rate of $10^{8} \mathrm{~cm}^{-3} \mathrm{~s}^{-1}$ (Koop et al.,
2000). The water activity scale given in Koop et al. (2000) is transformed to $\mathrm{RH}_{\mathrm{i}}$ using the parameterization by Murphy and Koop and assuming equality between water activity and $\mathrm{RH}_{\mathrm{w}}$. The light blue lines delimit the onset of pore filling with water for pores with diameters given on the lines calculated using the Kelvin equation (Eq. 1) and transforming from $\mathrm{RH}_{\mathrm{w}}$ to $\mathrm{RH}_{\mathrm{i}}$ using the parameterization by Murphy and Koop (2005). Pores with diameters indicated on the light blue lines are expected to be filled for $\mathrm{RH}_{\mathrm{i}}$ above the light blue lines and empty for $\mathrm{RH}_{\mathrm{i}}$ below the blue lines. The differently colored thick solid lines on the water vapor saturation line give the temperature ranges of immersion freezing reported by Pinti et al. (2012). There are differences between the different studies with respect to the definition of onset condition of nucleation, residence time, type and size of the clay minerals. The legend to the symbols therefore states the exact type of clay minerals, the particle diameter, and the active fraction for which ice nucleation is specified. The importance of the specified active fraction can be seen when comparing the large difference in freezing conditions reported by Salam et al. (2006) for the nucleation of the first crystal in their kaolinite sample (Fig. 5a, purple stars) and freezing of $15 \%$ of the particles (Fig. 5a, purple crosses), which only occurred at water saturation.

Ice nucleation results for kaolinite are summarized in Fig. 5a. Welti et al. (2009), Salam et al. (2006), Tobo et al. (2012), and Kulkarni et al. (2012) used a CFDC to investigate the submicrometer to micrometer particle fraction. The other studies employed static diffusion chambers and investigated supermicron-sized particles. Most studies investigated kaolinite from Sigma Aldrich (SA). Zimmermann et al. $(2007,2008)$ used kaolinite from the Clay Mineral Society (CMS), Salam et al. (2006) from City Chemicals (CC), other studies did not specify the source of their kaolinite. No obvious difference in ice nucleation between these clay types can be observed. However, there is a strong dependence on particle size. Micron-sized and supermicron particles nucleate ice at water saturation up to $263 \mathrm{~K}$ most probably in condensation-freezing mode. When temperature falls below $255 \mathrm{~K}$, supermicron particles start to nucleate ice in small fractions below water saturation and for $T<244 \mathrm{~K}$ submicron particles start to become efficient as IN below water saturation. Larger particles being better IN than smaller ones of the same material has also been observed by Gallavardin et al. (2008) from the analysis of ice residuals. Temperature ranges for immersion freezing on active sites of kaolinite from Sigma Aldrich (SA) reported by Pinti et al. (2012) are indicated by the differently colored thick solid lines on the water vapor saturation line of Fig. 5a. The brown and red segments are due to ice nucleation by standard and best sites, respectively, from DSC emulsion experiments. The orange segment represents the temperature range of freezing from DSC bulk experiments. The temperature range between the red and orange lines is neither accessible by emulsion nor bulk DSC experiments. Condensation freezing on kaolinites 

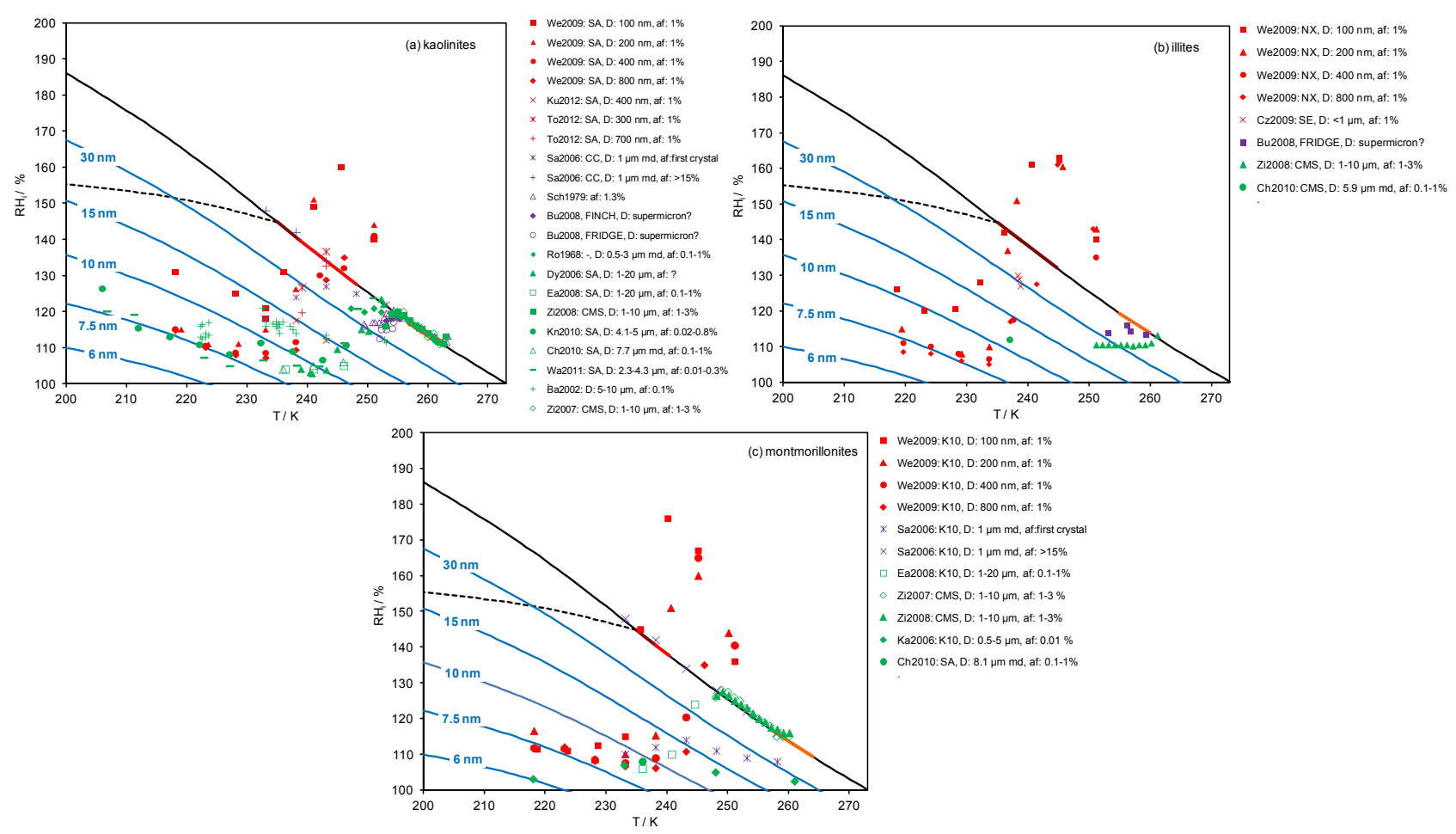

Fig. 5. Ice nucleation data as a function of temperature and relative humidity with respect to ice $\left(\mathrm{RH}_{\mathrm{i}}\right)$ for $(\mathbf{a}) \mathrm{kaolinites},(\mathbf{b})$ illites, and (c) montmorillonites. Red, purple and green symbols encode nucleation on submicron, micron, and supermicron particles, respectively. The solid and dashed black lines indicate liquid water saturation and homogeneous ice nucleation, respectively. The differently colored thick solid lines on the water vapor saturation line give the temperature range for which immersion freezing on standard (brown), special (red) and best sites (orange) has been observed by Pinti et al. (2012) for kaolinite SA (a), illite NX (b) and montmorillonite K10 (c). The solid light blue lines give pore filling in dependence on pore diameter. The legend lists the reference of the study, the diameter of the particles $(D)$ and the activated fraction (af). Abbreviations: md, mode diameter; SA, Sigma Aldrich; CC, City Chemicals; CMS, Clay Mineral Society. Compositions of kaolinites SA, illites NX and SE (Arginotec), and montmorillonite K10 are given in Pinti et al. (2012). References: We2009, Welti et al. (2009); Ku2012, Kulkarni et al. (2012); To2012, Tobo et al. (2012); Sa2006, Salam et al. (2006); Sch1979, Schaller and Fukuta (1979); Bu2008, Bundke et al. (2008); Ro1968, Roberts and Hallett (1968); Dy2006, Dymarska et al. (2006); Ea2008, Eastwood et al. (2008); Zi2008, Zimmermann et al. (2008); Kn2010, Knopf et al. (2010); Ch2010, Chernoff and Bertram (2010); Wa2011, Wang and Knopf (2011); Ba2002, Bailey and Hallett (2002); Zi2007, Zimmermann et al. (2007); Cz2009, Cziczo et al. (2009); Ka2006, Kanji and Abbatt (2006).

falls into the same temperature range as immersion freezing on best sites determined from bulk measurements performed by Pinti et al. (2012) (thick orange line). Ice nucleation below water saturation covers the temperature range for which Pinti et al. (2012) observed immersion freezing on average (thick brown line), special (thick red line) and best sites (thick orange line) and extends to conditions where ice nucleates homogeneously.

Freezing in pores is expected to occur by homogeneous ice nucleation for $T<235 \mathrm{~K}$ and by immersion freezing for $T>235 \mathrm{~K}$. Homogeneous ice nucleation should require only a small pore volume of $\sim 100 \mathrm{~nm}^{3}$ to be efficient (see Sect. 2.3), while heterogeneous ice nucleation needs larger pore structures to contain at least one active site. There is no reliable information available concerning the distribution of active sites within pores of clay minerals. It is therefore reasonable to assume that they are of similar abundance as on the outer surface of clay particles. Ice nucleation below wa- ter saturation at $T>250 \mathrm{~K}$ is expected to occur on the rare best sites (thick orange line), which seem to be abundant enough within pores of supermicron particles to shift the onset of ice nucleation below water saturation for $T<255 \mathrm{~K}$. Pores with $D>30 \mathrm{~nm}$ are the most common ones in kaolinites. At $T>250 \mathrm{~K}$, these pores start to fill up with water at $\mathrm{RH}_{\mathrm{i}}>120 \%$, which corresponds to the onset of heterogeneous nucleation observed for supermicron particles. The quite frequent standard sites are expected to induce freezing at $T<238 \mathrm{~K}$ and this corresponds to the temperature range for which deposition nucleation experiments performed with submicrometer-sized particles showed freezing below water saturation. It also agrees with the temperature range for which Lüönd et al. (2010) observed immersion freezing of submicrometer-sized kaolinite (SA). The higher $\mathrm{RH}_{\mathrm{i}}$ needed for smaller particles to activate ice may therefore reflect the lack of narrow pores in smaller kaolinite particles. For the studies that investigated particles on a substrate (all the green 
data points, the purple triangles, diamonds and circles) ice might also have formed by freezing of water that condensed in voids and gaps between the substrate and the particles. To account for ice nucleation under the observed $\mathrm{RH}_{\mathrm{i}}$ conditions at $T<235 \mathrm{~K}$, kaolinite particles should have pores with diameters down to $7.5 \mathrm{~nm}$. Pore structure analysis (see Appendix C2) showed that most pores in kaolinites are larger than $20 \mathrm{~nm}$. The lack of narrow pores in submicron kaolinite particles is the most probable reason for the quite high $\mathrm{RH}_{\mathrm{i}}$ needed for PCF. For $100 \mathrm{~nm}$ kaolinite particles (red squares in Fig. 5a) the measured onset of freezing would imply that less than $1 \%$ of the particles have pores with $D<10 \mathrm{~nm}$. $\mathrm{RH}_{\mathrm{i}}$ needed to fill a pore of a given size increases with decreasing temperature. This explains the shift of ice nucleation onsets to higher $\mathrm{RH}_{\mathrm{i}}$ with decreasing temperature. Given the pore structure of kaolinites, PCF is expected to be an efficient ice nucleation mechanism below water saturation. The steep increase in ice nucleation efficiency of submicrometer particles at temperatures where standard active sites become available and homogeneous ice nucleation sets in $(T=235$ $238 \mathrm{~K}$ ) is an indication that PCF is the prevailing mechanism for ice formation. A strong increase in the activated fraction of kaolinite (SA) particles for $T<235 \mathrm{~K}$ has been observed by Welti et al. (2014). They found that describing the ice nucleation activity by assuming deposition nucleation to be the governing mechanism below water saturation inadequate to represent the experimental data in the investigated temperature range.

Ice nucleation on illites is summarized in Fig. 5b. Temperature ranges for immersion freezing on active sites of illite NX reported by Pinti et al. (2012) are indicated by the differently colored thick solid lines on the water vapor saturation line. Supermicron particles from Clay Mineral Society (CMS) began to nucleate ice below water saturation for $T<261 \mathrm{~K}$ (Zimmermann et al., 2008; Chernoff and Bertram, 2010). If ice nucleation is assumed to occur within pores, the pore system of these particles needs to contain some of the rare best sites that are responsible for ice nucleation at these high temperatures. Alternatively, freezing in these studies might also have started from capillary water that condensed in voids between the substrate and the particles. Submicrometer particles of illite NX have been investigated by Welti et al. (2009) using a CFDC. These particles nucleate ice below water saturation for $T<242 \mathrm{~K}$. This is the temperature range for which Pinti et al. (2012) observed ice nucleation on the frequent standard sites of illite NX (thick brown line on water vapor saturation line). Such sites seem to be present in illite particles $>200 \mathrm{~nm}$ but missing in smaller particles. 100 and $200 \mathrm{~nm}$ particles need $T<236 \mathrm{~K}$ for ice nucleation below water saturation, which is indicative of the onset of homogeneous ice nucleation occurring within pores.

Pore structure analysis of illites showed that most of the porosity of this clay type arises from pores of $2-5 \mathrm{~nm}$ equivalent plate separation (see Appendix C2). Studies on freezing in confinement (Sect. 2.3) have shown that homogeneous ice nucleation occurs abruptly for $T=230-235 \mathrm{~K}$ in pores with diameters of $3.5-4 \mathrm{~nm}$ but only gradually at $T=220-230 \mathrm{~K}$ in pores with $D=2.5-3.5 \mathrm{~nm}$. Therefore, for freezing to occur during the limited residence times in CFDCs (4-12 s), the wider pores with $D_{\mathrm{p}}>3.5 \mathrm{~nm}$ should be responsible. For temperatures above $200 \mathrm{~K}$, these pores are already filled with water when supersaturation with respect to ice is reached. Assuming a PCF mechanism, ice crystal growth should therefore start immediately when $\mathrm{RH}_{\mathrm{i}}=100 \%$ is reached. In all experiments the onset of ice freezing was observed at $\mathrm{RH}_{\mathrm{i}} \approx 105 \%$ or higher in accordance with a PCF mechanism. The relatively high ice supersaturation $\left(\mathrm{RH}_{\mathrm{i}}=120 \%\right)$ needed for activated fractions of $1 \%$ for $100 \mathrm{~nm}$ illite particles (red squares) might be an indication that only a fraction of these small particles have pores in the right diameter range. In summary, the sharp increase in ice nucleation activity for $T<235 \mathrm{~K}$ for illite particles with $D_{\mathrm{p}}=100-200 \mathrm{~nm}$ observed by Welti et al. (2009) together with the pore structure reported for this clay mineral is strong evidence that PCF is the prevailing ice nucleation mechanism for illite particles.

Figure $5 \mathrm{c}$ shows the onsets of freezing of all studies that investigated montmorillonites. The differently colored thick lines on the water vapor saturation line give the ranges of immersion freezing for montmorillonite K10 determined by Pinti et al. (2012). Most studies used the acid-treated K10 as representative montmorillonite, which contains pores with $D_{\mathrm{p}}=4-50 \mathrm{~nm}$ (see Appendix C2). At $T<235 \mathrm{~K}$ the pore volume of pores with $D_{\mathrm{p}}>4 \mathrm{~nm}$ should be large enough for PCF to be highly efficient. Ice is expected to form by homogeneous nucleation in pores and induce ice crystal growth as soon as $\mathrm{RH}_{\mathrm{i}}=100 \%$ is reached. Most experiments showed onsets of freezing at $\mathrm{RH}_{\mathrm{i}}=110-120 \%$ for $T<235 \mathrm{~K}$ in accordance with a PCF mechanism. Slow growth of ice crystals to detectable sizes within the CFDC at $\mathrm{RH}_{\mathrm{i}}$ close to $100 \%$ might explain why the onset of ice nucleation was not observed at even lower supersaturation with respect to ice. At $T>235 \mathrm{~K}$, larger particles nucleated ice at lower $\mathrm{RH}_{\mathrm{i}}$, indicating that the availability of water-covered active sites within pores determined the onset of ice nucleation. There is also a distinct difference between montmorillonite K10 investigated by Kanji et al. (2008) and Salam et al. (2006) and the montmorillonites from the Clay Mineral Society (CMS) studied by Zimmermann et al. (2007, 2008 ). For $T>250 \mathrm{~K}$ the clays from CMS needed water saturation for freezing while K10 already showed first ice crystal formation at $\mathrm{RH}_{\mathrm{i}}<110 \%$. This can be explained by the increased pore volume in the acid-treated K10 compared with the natural samples. The pore structure of montmorillonite particles and the low ice supersaturation needed to nucleate ice at $T<235 \mathrm{~K}$ points to PCF as the prevailing ice nucleation mechanism below watersaturation. However, the low $\mathrm{RH}_{\mathrm{i}}$ needed to activate 400 and $800 \mathrm{~nm}$ particles by Welti et al. (2009) at $243 \mathrm{~K}$ is rather unexpected given the ice nucleation activity of montmorillonite K10 in immersion mode observed by Pinti et al. (2012). 
In summary, studies performed on submicrometer particles provide the best support for PCF as the dominating mechanism for ice formation below water saturation (Welti et al., 2009; Kulkarni et al., 2012; Tobo et al., 2012), since these studies clearly show a strong increase in ice nucleation efficiency when temperature falls below $235 \mathrm{~K}$.

\subsubsection{Arizona test dust (ATD)}

ATD from Powder Technology Inc. (Minnesota, USA) is produced by grinding samples of sand from Arizona. It has been used by different groups for comparison of results and methods of ice nucleation. The mineralogical composition of ATD is dominantly quartz, feldspars and a substantial proportion of unidentified clay minerals (Broadley et al., 2012; Murray et al., 2012). Many of the supermicron particles consist predominantly of Si. Connolly et al. (2009) present an ESEM image of a typical ATD sample, showing granular and smooth faceted morphologies. The ESEM image also reveals aggregates of submicron particles and submicron particles sticking to larger particles. Transmission electron microscope images of submicrometer particles presented by Niedermeier et al. (2011) show ragged surfaces featuring both crystalline and amorphous structures. Water uptake isotherms at $298 \mathrm{~K}$ exhibited coverages of $\sim 4$ monolayers at $80 \%$ RH (Gustafsson et al., 2005).

Figure 6a summarizes results of ice nucleation studies investigating ATD in deposition mode. The solid black lines indicate $\mathrm{RH}_{\mathrm{i}} / T$ conditions for water saturation (parameterization of Murphy and Koop, 2005). The dashed black line gives homogeneous ice nucleation (Koop et al., 2000) for a nucleation rate of $10^{8} \mathrm{~cm}^{-3} \mathrm{~s}^{-1}$. The light blue lines delimit the onset of pore filling with water for pores with diameters given on the lines calculated using the Kelvin equation (Eq. 1). While many studies report ice nucleation below water saturation for $T<241 \mathrm{~K}$, water saturation was required in most studies to induce ice nucleation at higher temperatures. All studies show ice nucleation below water saturation for $T<235 \mathrm{~K}$. If ice crystal formation at $T<235 \mathrm{~K}$ is attributed to homogeneous ice nucleation in pores, pores with diameters of $\sim 6 \mathrm{~nm}$ are required to account for the $\mathrm{RH}_{\mathrm{i}}$ at which freezing occurred in the studies by Möhler et al. (2006) and Mangold et al. (2005). Ice nucleation reported by Welti et al. (2009) and Koehler et al. (2010) is in accordance with freezing in pores with diameters of $7-10 \mathrm{~nm}$. Considering the mineralogical composition and morphology of ATD, the share of clay minerals and aggregated particles should indeed be sufficient to account for activated fractions of 1-10\% or even higher at the observed conditions. With their setup, Knopf and Koop (2006) optically monitored individual ice nucleation events on ATD particles spread on a hydrophobic substrate. The nucleation events occurred over a large $\mathrm{RH}_{\mathrm{i}}$ range that might be representative of the spread of pore diameters in the sample.
Ice nucleation occurring on the water vapor saturation line in Fig. 6a should be due to immersion or condensation freezing and can be compared with the active site parameterization of immersion freezing on ATD by Marcolli et al. (2007). Kanji and Abbatt (2010) observed immersion nucleation of $100 \mathrm{~nm}$ ATD particles at temperatures up to $243 \mathrm{~K}$. The data point at $251 \mathrm{~K}$ probably arises from water droplets, which cannot be discriminated from ice with the employed setup. Ice nucleation at water saturation by $200-800 \mathrm{~nm}$ diameter particles was observed by Welti et al. (2009) at $\sim 246 \mathrm{~K}$ as the highest temperature. The data points reported at $255-$ $256 \mathrm{~K}$ and $250-251 \mathrm{~K}$ are at or close to the breakthrough line of the instrument where liquid droplets can still be present and mistaken for ice crystals. Koehler et al. (2010) observed ice nucleation at water saturation at highest temperatures of $237-243 \mathrm{~K}$ for $200-400 \mathrm{~nm}$ particles. An activated fraction of $0.1 \%$ at water saturation at $\sim 251 \mathrm{~K}$ was observed by Jones et al. (2011) for an aerosol containing ATD particles with diameters $<1 \mu \mathrm{m}$. The data point at $256 \mathrm{~K}$ is uncertain because it was measured at a supersaturation with respect to water of $5 \%$. Connolly et al. (2009) reported freezing of a normally distributed ATD aerosol with average mean diameter of $350 \mathrm{~nm}$ and standard deviation of 1.65 (which includes particles with diameters up to $2 \mu \mathrm{m}$ ) when water saturation was reached at $255 \mathrm{~K}$, but no freezing at $261 \mathrm{~K}$. Ice nucleation on ATD was observed by Knopf and Koop (2006) at $T=260 \mathrm{~K}$ as the highest temperature for particles in the size range $0.7-10 \mu \mathrm{m}$ in diameter.

Based on the active site parameterization of Marcolli et al. (2007), ATD particles with diameters of $200 \mathrm{~nm}$ should exhibit on average active sites with contact angles of $98^{\circ}$ or larger. Such active sites would induce heterogeneous freezing at $\sim 234 \mathrm{~K}$ within $\sim 10 \mathrm{~s}$, which is below the homogeneous freezing threshold of $\sim 235 \mathrm{~K}$. This means that water droplets containing an ATD particle that is smaller than $200 \mathrm{~nm}$ rather freeze homogeneously than heterogeneously. Particles with diameters of $300 \mathrm{~nm}, 400 \mathrm{~nm}, 1 \mu \mathrm{m}, 2 \mu \mathrm{m}$ and $10 \mu \mathrm{m}$ are expected to freeze within $10 \mathrm{~s}$ at $237 \mathrm{~K}$ (contact angle $\left.\geq 84^{\circ}\right), 240 \mathrm{~K}$ (contact angle $\left.\geq 77^{\circ}\right), 245 \mathrm{~K}$ (contact angle $\geq 65^{\circ}$ ), $248 \mathrm{~K}$ (contact angle $\geq 60^{\circ}$ ), and $251 \mathrm{~K}$ (contact angle $\geq 54^{\circ}$ ), respectively. Monodisperse aerosols of 100 , 200, 300, 400, 1000, and $2000 \mathrm{~nm}$ diameters are expected to yield activated fractions of $1 \%$ at $239,245,247,249$, 251 , and $252 \mathrm{~K}$, respectively. This shows that the temperatures for condensation/immersion freezing of ATD reported by the different groups are largely consistent when the size distribution of ATD, residence time in the instrument, and activated fraction are taken into account and can be described by the Marcolli et al. (2007) active site parameterization. This is in accordance with the ICIS2007 intercomparison that showed general agreement of ice formation for polydisperse ATD with particle sizes up to $1-2 \mu \mathrm{m}$ between measurements performed with different types of CFDC setups, the AIDA chamber and the FRIDGE instrument (DeMott et al., 2011). 

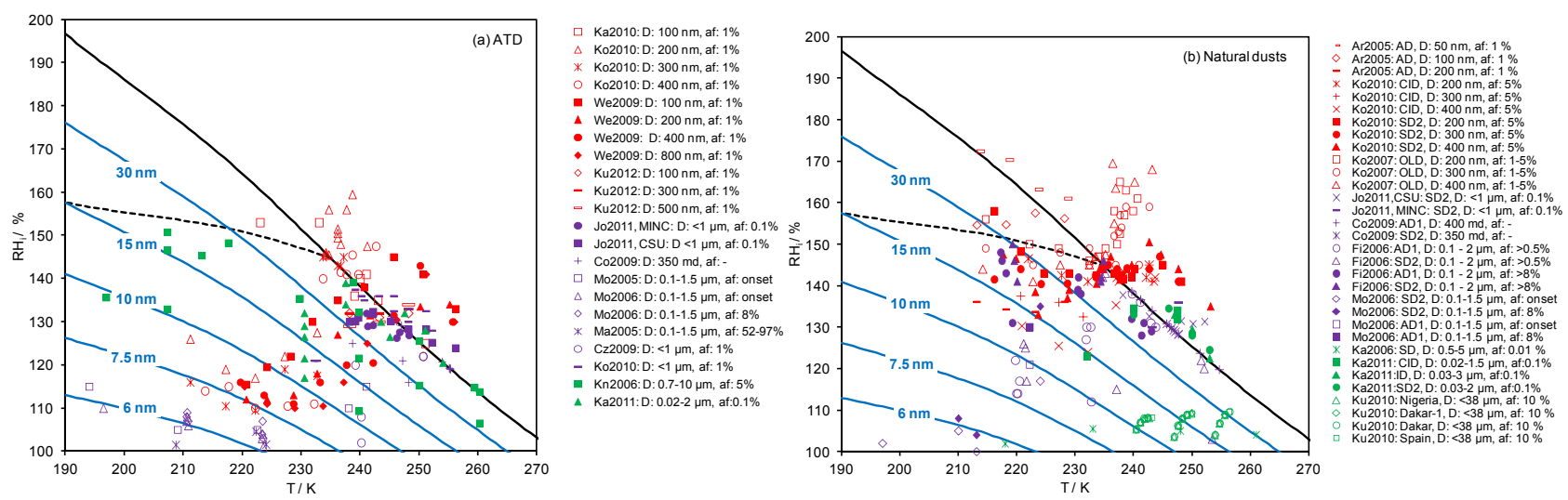

Fig. 6. Ice nucleation data as a function of temperature and relative humidity with respect to ice $\left(\mathrm{RH}_{\mathrm{i}}\right)$ for (a) Arizona Test Dust (ATD) and (b) natural dusts. Red, purple and green symbols encode nucleation on submicron, micron, and supermicron particles, respectively. The solid and dashed black lines indicate liquid water saturation and homogeneneous ice nucleation, respectively. The solid light blue lines give pore filling in dependence on pore diameter. The legend lists the reference of the study, the source of the dust in the case of natural dusts, the diameter of the particles $(D)$ and the active fraction (af). Abbreviations: AD, Asian Dust; CID, Canary Island Dust; SD2, Saharan Dust from Cairo; OLD: Owen Lake Dust; AD1, Asian Dust; SD, Saharan Dust; ID, Isreali Dust. References: Ka2010, Kanji and Abbatt (2010); Ko2010, Koehler et al. (2010); We2009, Welti et al. (2009); Ku2012, Kulkarni et al. (2012); Jo2011, Jones et al. (2011); Co2009, Connolly et al. (2009); Mo2005, Möhler et al. (2005b); Mo2006, Möhler et al. (2006); Ma2005, Mangold et al. (2005); Cz2009, Cziczo et al. (2009); Kn2006, Knopf and Koop (2006); Ka2011, Kanji et al. (2011); Ar2005, Archuleta et al. (2005); Ko2007, Koehler et al. (2007); Fi2006, Field et al. (2006); Ka2006; Kanji and Abbatt (2006); Ku2010, Kulkarni and Dobbie (2010).

When the active site occurrence probability is applied to the surface of cylindrical pores, the total length of pores in a particle required to initiate immersion freezing at a given temperature can be calculated. Connolly et al. (2009) measured deposition freezing at $248 \mathrm{~K}$ and $\mathrm{RH}_{\mathrm{i}}=116 \%$ and at $247 \mathrm{~K}$ and $\mathrm{RH}_{\mathrm{i}}=121 \%$. Under these conditions, pores with diameters $\leq 30 \mathrm{~nm}$ are filled. Applying the active site occurrence probability given by Marcolli et al. (2007) to a cylindrical pore with $d=30 \mathrm{~nm}$, a pore length of $30 \mu \mathrm{m}$ is needed to provide on average an active site that induces freezing at $T \geq 248 \mathrm{~K}$. This would imply that at least a part of the ATD particles used in the experiments by Connolly et al. (2009) (fraction $<2 \mu \mathrm{m}$ ) must exhibit quite porous structures. Koehler et al. (2010) observed no ice nucleation below water saturation at $T>235 \mathrm{~K}$ for ATD particles in the size range from 100 to $400 \mathrm{~nm}$. Welti et al. (2009) report ice nucleation below water saturation at $\sim 240 \mathrm{~K}$ for submicron ATD particles, which implies the presence of cylindrical pores with a total length of 16 and $5 \mu \mathrm{m}$ for pore diameters of 10 and $30 \mathrm{~nm}$, respectively. These examples indicate that immersion freezing in pores of ATD particles is limited by the availability of active sites within pores. The strong increase in $\mathrm{RH}_{\mathrm{i}}$ needed to initiate ice nucleation with decreasing particle size provides a further indication that the density of active sites within pores is low. ATD becomes much more efficient as an IN at $T<235 \mathrm{~K}$ because the pore volume needed for homogeneous ice nucleation is much smaller than the one for heterogeneous ice nucleation. The increase in ice nucleation efficiency at $T<240 \mathrm{~K}$ for submicron ATD particles with diameters $D_{\mathrm{p}}<400 \mathrm{~nm}$ is an indication that PCF is the prevailing nucleation mechanism in this temperature range. Moreover, most studies did not observe ice nucleation activity at $T>240 \mathrm{~K}$, which is in accordance with PCF because the density of active sites in pores seems to be rather low if one applies the parameterization by Macolli et al. (2007) to the pores of ATD.

\subsubsection{Natural dust samples}

Figure $6 \mathrm{~b}$ summarizes ice nucleation measurements performed on different samples of natural dusts. All studies except that performed on $50 \mathrm{~nm}$ particles (Archuleta et al., 2005) report ice nucleation below water saturation for temperatures below $235 \mathrm{~K}$. For $T>235 \mathrm{~K}$, only few samples showed ice nucleation below water saturation, but most froze in immersion/condensation mode at water saturation.

Many studies (Connolly et al., 2009; Field et al., 2006; Möhler et al., 2006; Koehler et al., 2010; Kanji et al., 2011) used a dust sample collected in the Saharan desert near Cairo (SD2) for their ice nucleation experiments. X-ray fluorescence analysis indicated that the bulk fraction of this sample (diameter $<20 \mu \mathrm{m})$ is rich in silicon $(26.8 \%)$, calcium oxides $(22.9 \%)$, and aluminum oxide $(8.5 \%)$, indicative of the presence of layer silicates and quartz. Electron micrographs showed mineral particles with irregular and partly aggregate-like structures (Möhler et al., 2006). Koehler et al. (2010) investigated size-selected particles of this sample with diameters of $200-400 \mathrm{~nm}$ in a CFDC. All samples nucleated ice below water saturation for $T<233 \mathrm{~K}$, but required cloud droplet activation for $T>237 \mathrm{~K}$. 200-300 nm particles 
showed immersion/condensation freezing up to $248 \mathrm{~K}$ and the $400 \mathrm{~nm}$ sample up to $253 \mathrm{~K}$. Field et al. (2006), Möhler et al. (2006), and Connolly et al. (2009) studied ice nucleation on the fraction of the SD2 sample with $D<2 \mu \mathrm{m}$ (normal distribution with average mean diameter of $350 \mathrm{~nm}$ and an average standard deviation of 1.85). For temperatures between 234 and $252 \mathrm{~K}$, droplets formed at the same time as ice, implying condensation freezing. Kanji et al. (2011) observed immersion/condensation freezing up to $253 \mathrm{~K}$ investigating the size range up to $2 \mu \mathrm{m}$. This is evidence that larger Saharan dust particles contain more active sites and freeze at higher temperatures than smaller ones. No clear case of freezing below water saturation for $T>235 \mathrm{~K}$ has been observed. In the temperature range $220-235 \mathrm{~K}$, ice nucleation occurred over a large $\mathrm{RH}_{\mathrm{i}}$ range, which would imply homogeneous freezing in pores with diameters of 7-30 nm. For higher activated fractions and smaller particle sizes ice nucleation occurred at higher $\mathrm{RH}_{\mathrm{i}}$. The large range over which ice nucleation was observed suggests a large range of pore sizes present in this sample. For temperatures below 213 K, Möhler et al. (2006) observed ice nucleation close to ice saturation (100-110\%). Asian dust (AD1) collected in the easterly parts of the Takla Makan Desert has been investigated in the AIDA chamber (Field et al., 2006; Möhler et al., 2006; Connolly et al., 2009) using the aerosol fraction $D<2 \mu \mathrm{m}$ (normal distribution with average mean diameter of $400 \mathrm{~nm}$ and an average standard deviation of 1.70). X-ray fluorescence analysis indicated that the bulk fraction of this sample (diameter $<20 \mu \mathrm{m}$ ) is rich in silicon $(70.2 \%)$ with minor shares of calcium oxide (11.5\%) and aluminum oxide $(8.5 \%)$, indicating quartz as the major component and minor contributions of layer silicates. AD1 showed freezing below water saturation for $T<235 \mathrm{~K}$ and freezing at water saturation for $T=235-255 \mathrm{~K}$. Dust samples that are rich in quartz are expected to have low densities of active sites and pores (Eastwood et al., 2008). The surface within pores is therefore most probably not large enough to contain an active site on average per particle. Therefore freezing in pores only becomes efficient when temperature is decreased below $235 \mathrm{~K}$ and homogeneous nucleation sets in. Ice nucleation in the temperature range $217-233 \mathrm{~K}$ occurred over a large $\mathrm{RH}_{\mathrm{i}}$ range corresponding to freezing in pores with diameters between 7 and $30 \mathrm{~nm}$. The large difference in $\mathrm{RH}_{\mathrm{i}}$ between onset of freezing and a frozen fraction of $8 \%$ suggests that only a minor fraction of AD1 particles - probably the layer silicates - contains pores narrow enough to be filled with water at low $\mathrm{RH}_{\mathrm{i}}$ (Field et al., 2006).

The Asian dust sample used by Archuleta et al. (2005) was collected from the Tengger desert of China. The composition of the $<10 \mu \mathrm{m}$ fraction contained the elements $\mathrm{Si}, \mathrm{Al}, \mathrm{Fe}$, $\mathrm{P}, \mathrm{K}, \mathrm{Ca}$ and $\mathrm{Mg}$. Transmission electron microscope images of $200 \mathrm{~nm}$ diameter particles revealed aggregate structures. Pores and slits that form at the interfaces of such aggregated particles could account for the observed activated fraction of $1 \%$ at $T=210-230 \mathrm{~K}$ and $\mathrm{RH}_{\mathrm{i}}=133-137 \%$. The absence of ice nucleation below water saturation for $50 \mathrm{~nm}$ diameter particles could be due to a low fraction of aggregated particles for this small size class. As another difference, the 50 and $100 \mathrm{~nm}$ particles contained relatively more soluble matter than the larger $200 \mathrm{~nm}$ particles (Archuleta et al., 2005).

Koehler et al. (2010) and Kanji et al. (2011) investigated Canary Island dust (CID) collected on the Canary Island of Lanzarote, which receives large annual deposits of Saharan dust. It also likely contains beach sand and small ancient coral. This sample showed ice nucleation close to water saturation for $T=237-247 \mathrm{~K}$ and distinctly below water saturation for $T=220-232 \mathrm{~K}$, indicative of the transition from immersion/condensation to homogeneous ice nucleation within pores when the temperature is decreased below the homogeneous ice nucleation threshold at $T \approx 235 \mathrm{~K}$. Kanji et al. (2011) investigated in addition a dust collected from Ramat Hashron, Israel, following a dust storm (ID). This sample needed water saturation for ice formation in the investigated temperature range ( $T=247-253 \mathrm{~K})$.

Koehler et al. (2007) investigated a sample collected at various locations around the dry lake bed of the Owens Lake region (OLD). The dominant elements of the bulk sample $(\leq 300 \mu \mathrm{m})$ are $\mathrm{Na}, \mathrm{Ca}, \mathrm{Fe}$, and $\mathrm{K}$. No significant activity as IN was observed for $T>236 \mathrm{~K}$. For $T=214-236 \mathrm{~K}$, all investigated size classes $(200,300$, and $400 \mathrm{~nm})$ induced ice nucleation below water saturation at $\mathrm{RH}_{\mathrm{i}}$ indicative of freezing in pores and cracks with diameters of $15-30 \mathrm{~nm}$.

Bulk elemental composition revealed silicon as the major component in the Dakar, Dakar-1, and Nigeria samples investigated by Kulkarni and Dobbie (2010). The sample from Spain was dominated by Ca $(80 \%)$. Electron micrographs showed irregularities in the dust surface, including cracks, steps or pores. The investigated sample fraction with diameters up to $38 \mu \mathrm{m}$ showed an activated fraction of $1 \%$ at $\mathrm{RH}_{\mathrm{i}}<110 \%$ and temperatures up to $256 \mathrm{~K}$. Similarly low $\mathrm{RH}_{\mathrm{i}}$ for an activated fraction of $0.01 \%$ at $T=218-261 \mathrm{~K}$ exhibited a Saharan dust sample from the Cape Verde islands with diameters up to $5 \mu \mathrm{m}$, which was composed of quartz and smectite clay minerals such as montmorillonite and potassic feldspars (Kanji and Abbatt, 2006). This low nucleation threshold might be due to the large particle sizes and the applied nucleation onset criterion of only $0.01 \%$.

Most ice nucleation experiments with natural mineral dusts have shown a significant increase in ice nucleation efficiency when temperature is decreased below $235 \mathrm{~K}$, which is a clear indication that PCF is the prevailing nucleation mechanism below water saturation. Most of the investigated natural dust samples do not seem to be rich enough in active sites and/or pores, so that heterogeneous freezing within pores is not effective enough to lead to detectable nucleated fractions below water saturation for $T>235 \mathrm{~K}$. The only studies that observed ice nucleation well below water saturation for $T>235 \mathrm{~K}$ were performed on very large natural dust particles deposited onto a substrate (Kulkarni and Dobbie, 2010; Kanji et al., 2011). An aggregated structure of these large particles or water condensed between the particles 
and the substrate might explain the low ice nucleation onsets $\left(\mathrm{RH}_{\mathrm{i}}<110 \%\right)$ in these studies.

Almost all ice nucleation studies performed on natural dust samples shown in Figure 6b observed ice nucleation below water saturation only when temperature was below the homogeneous ice nucleation threshold, with the only exception of the studies performed by Kulkarni and Dobbie (2010) and Kanji and Abbatt (2006) on large particles deposited onto a substrate. They can therefore be considered as direct evidence of PCF as the dominating mechanism for ice formation below water saturation.

\subsection{Coatings}

Airborne mineral dust particles may acquire coatings during transport by deposition of semivolatile or nonvolatile compounds such as sulfates, nitrates, and organic material that form by oxidation of gas-phase species in the atmosphere (Murphy and Thomson, 1997; Grassian, 2002; Murphy, 2005). If the particles contain pores and cracks, these fill up first due to the inverse Kelvin effect (e.g., Sjogren et al., 2007) before the particles acquire an external coating. Pores containing water-soluble materials fill with an aqueous solution when $\mathrm{RH}_{\mathrm{w}}$ is increased. $\mathrm{RH}_{\mathrm{w}}$ of complete filling is lowered compared with the pure water case and depends on pore diameter and the water activity of the solution (e.g., Sjogren et al., 2007). When the deposited semivolatile materials are viscous, water uptake and release may be delayed (e.g., Zobrist et al., 2008b). The presence of a solution instead of pure water within pores has consequences for ice nucleation because aqueous solutions freeze at lower temperatures than pure water. Such a freezing point depression occurs for homogeneous ice nucleation and for heterogeneous ice nucleation in immersion mode and can be parameterized as a function of water activity (Koop et al., 2000; Zobrist et al., 2008a). If the active sites on mineral dusts are deactivated because of specific interactions with the solutes such as chemical reactions or surface adsorption, the freezing point depression may be larger than that predicted by a water activity-based parameterization. If the pores are completely filled with viscous organic matter, ice nucleation in pores might be completely impeded because the presence of the organic material slows down or even inhibits water condensation in pores. Once the particles have obtained a full coating the significance of freezing within pores should be minor.

Several studies investigated the influence of coatings on IN efficiencies, some studies observed a decrease in IN efficiency, and other studies found no effect. Zobrist et al. (2008b) provide data on immersion freezing of aqueous solutions of ammonium sulfate, sulfuric acid, and organic compounds containing ATD particles. They observed freezing point depressions compared with the pure water suspensions that could be parameterized as a function of the solution water activity. Similar freezing point depressions have also been observed by Zuberi et al. (2002) for kaolinite and montmorillonite particles coated with ammonium sulfate. Möhler et al. (2008a) and Cziczo et al. (2009) investigated ice nucleation on ATD and illite particles coated with sulfuric acid (15-20 wt\%), ammonium sulfate (15-20 wt\%), and SOA (from $\alpha$-pinene ozonolysis; $17 \mathrm{wt} \%$ for ATD and $41 \mathrm{wt} \%$ for illite) in AIDA cloud expansion experiments. Analysis of ice residues at the single particle level suggests that coating thickness shows large variations between particles (Cziczo et al., 2009). The ice nucleation efficiency of ATD and illite particles coated with SOA was markedly suppressed for expansion runs at $T=210-205 \mathrm{~K}$. Almost all uncoated ATD and illite particles acted as IN between 105 and $120 \% \mathrm{RH}_{\mathrm{i}}$, but only about $20 \%$ of the coated ATD particles were ice-active (at $\mathrm{RH}_{\mathrm{i}}$ between 115 and $130 \%$ ) and $10 \%$ of the coated illite particles $\left(\right.$ at $\mathrm{RH}_{\mathrm{i}}$ between 160 and $170 \%$ ). This might indicate that the lower coating level of ATD (17\%) was not sufficient to fill up all pores with SOA, while the higher coating level of illite $(41 \%)$ led to mineral particles completely immersed in SOA, leading to ice nucleation at conditions even above the $\mathrm{RH}_{\mathrm{i}}$ threshold for homogeneous ice nucleation of solution particles. Eastwood et al. (2009) and Chernoff and Bertram (2010) found that $\mathrm{RH}_{\mathrm{i}}$ for ice nucleation of different clay mineral and quartz particles was increased by $20-30 \%$ in the temperature range from 233 to $248 \mathrm{~K}$ when coated with aqueous sulfuric acid layers of $0.2-0.7 \mu \mathrm{m}$ but still below water saturation. This may indicate that nucleation occurs in pores filled with $\mathrm{H}_{2} \mathrm{SO}_{4}$ solutions. Archuleta et al. (2005) studied metal oxide particles with diameters between 50 and $200 \mathrm{~nm}$, with and without $\mathrm{H}_{2} \mathrm{SO}_{4}$ coatings at $T=213-228 \mathrm{~K}$. No clear effect of the coatings emerged, possibly because of the low level of coating that corresponds to 2.9-7.1 monolayers assuming spherical particles. Also, Knopf and Koop (2006) did not observe a clear influence of $\mathrm{H}_{2} \mathrm{SO}_{4}$ coatings with estimated thickness of 67-1100 monolayers on ice nucleation of ATD particles for $T=200-260 \mathrm{~K}$. Again at these coating levels, pores fill with dilute $\mathrm{H}_{2} \mathrm{SO}_{4}$ solutions leading to a slight freezing point depression, which is however difficult to detect given the large scatter of freezing temperatures.

Koehler et al. (2007, 2010) observed that the IN efficiency of different mineral dusts (ATD, CID, OLD) that were wet generated by atomizing an aqueous suspension of particles was reduced compared to the one of dry-generated particles. They ascribe this effect to soluble components that were present in the dust samples and are likely to redistribute and transform insoluble particles that were not initially associated with soluble material into internally mixed particles. Wet-generated CID and OLD particles initiated ice formation at conditions similar to those required for homogeneous solution freezing at temperatures colder than $237 \mathrm{~K}$. This indicates that the CID and OLD samples contained enough soluble material to completely fill up the pores and coat the mineral dust surface. Wet-generated ATD froze at higher $\mathrm{RH}_{\mathrm{i}}$ 
than dry-generated ATD but below the conditions required for homogeneous solution freezing.

\subsection{Other ice nuclei}

This study has so far focused on heterogeneous ice nucleation on clay minerals and mineral dusts. To explore whether PCF is in general responsible for ice nucleation below water saturation, the ice nucleation characteristics of other types of IN are critically reviewed in Appendix D and summarized in this section.

Soot. There is no clear case of heterogeneous ice nucleation on soot aerosols below water saturation for $T>235 \mathrm{~K}$ (e.g., Dymarska et al., 2006), while the ice nucleation ability below $235 \mathrm{~K}$ seems to depend strongly on the type and pretreatment of the soot. The ice nucleation ability of pure soot is distinctly improved when temperature drops below $235 \mathrm{~K}$, but clearly deteriorates when the soot has acquired an organic coating. The occurrence of ice nucleation below water saturation only for $T \leq 235 \mathrm{~K}$ points to PCF as an explanation. Empty spaces between aggregated primary particles may fill with water due to capillary forces and freeze homogeneously at $\mathrm{RH}_{\mathrm{w}}$ below water saturation. Coatings may fill up the empty space between particles and compact the aggregates, leading to decreased ice nucleation ability of the soot. Freezing of water in carbon nanotubes produces ice-like structures (Maniwa et al., 2005; Kyakuno et al., 2011), which might be of significance for ice nucleation by soot aerosols (for more information see Appendix D1).

Snomax ${ }^{\mathrm{TM}}$. Pseudomonas syringae, a bacterial species that expresses a protein with a close lattice match with ice is responsible for the ice nucleation activity of Snomax ${ }^{\mathrm{TM}}$. This clearly defines the ice nucleation site of Snomax ${ }^{\mathrm{TM}}$ as an extended surface. Pores should therefore not be involved in ice nucleation on Snomax ${ }^{\mathrm{TM}}$ particles. Considering the soluble material such as carbohydrates and nucleic acids that have been identified in Snomax ${ }^{\text {TM }}$ pellets (Lagriffoul et al., 2010), the ice active proteins should be immersed in an aqueous solution layer with bulk properties. In this case, ice nucleation on Snomax ${ }^{\mathrm{TM}}$ would also occur by an immersion freezing mechanism in the reported cases of deposition freezing (Chernoff and Bertram, 2010; Jones et al., 2011; Kanji et al., 2011). See Appendix D2 for more details.

Glassy aerosols. Zobrist et al. (2008b) predicted that the smooth convex surfaces of glassy aerosols would be unsuitable to nucleate ice heterogeneously. However, different studies have shown that heterogeneous ice nucleation is a general feature of glassy aerosols but occurs only on a small subset of these particles (Murray et al., 2010b; Wilson et al., 2012; Wang and Knopf, 2011; Knopf et al., 2010; Wang et al., 2012). This experimental evidence suggests that some glassy particles have special properties that render them active as IN. These properties might be cracks or slits that may form during glass transition and absorb water below water saturation by capillary forces as discussed in further detail in Appendix D3.

Volcanic ash. Hoyle et al. (2011) and Steinke et al. (2011) investigated heterogeneous freezing on an ash sample collected during the eruption of the Icelandic volcano Eyjafjallajökull in April 2010. This material proved to be a rather poor IN at temperatures above $235 \mathrm{~K}$ but similarly efficient as ATD at low temperatures $(T<233 \mathrm{~K})$. Typical volcanic ash samples exhibit pore size distributions centered at pore diameters $D_{\mathrm{p}} \cong 5 \mathrm{~nm}$ and comparatively low numbers of pores of larger diameter (Delmelle et al., 2005). If one assumes a similar pore structure for the ash sample of Eyjafjallajökull, PCF can indeed account for the observed ice nucleation activity below water saturation (see also Appendix D4).

Inorganic salts and dicarboxylic acids. Analysis of ice nucleation data from aerosol particles consisting of dicarboxylic acids, AS or AgI, indicates that a nucleation mechanism by direct deposition of water molecules from the gas phase is unlikely. Rather, ice nucleation starts from a liquid water phase that gathers in pores or at steps and consists of an aqueous solution rather than pure water. This liquid phase is expected to be a solution of the dicarboxylic acids and AS, respectively, if crystallization of these solutes during efflorescence was not complete. In the case of AgI, the solutes are probably hygroscopic impurities. It is therefore not clear whether the pore structure, stabilizing the liquid phase against water subsaturation by the inverse Kelvin effect or the solutes present in the solution stabilizing the liquid phase by the Raoult effect is more important for preserving a liquid phase as medium for homogeneous or immersion ice nucleation at $\mathrm{RH}_{\mathrm{w}}<100 \%$ (for more information, see Appendix D5).

\section{Conclusions and outlook}

This study challenges the classical view that ice nucleation below water saturation occurs by direct water vapor deposition onto a surface and puts forward the hypothesis that what is called deposition nucleation is in fact homogeneous or immersion nucleation occurring in pores and cavities that may form between aggregated primary particles. These voids fill with water at $\mathrm{RH}_{\mathrm{w}}<100 \%$ because of the inverse Kelvin effect. Ice nucleation in clay minerals and mineral dusts offers the prime example to corroborate this hypothesis, because these materials are characterized best with respect to pore structures. The recent findings of freezing in confinement were therefore reviewed and related to the pore structure of clay minerals. This analysis showed that ice nucleation within pores of the clay minerals kaolinite, montmorillonite and illite should indeed occur at temperature and $\mathrm{RH}_{\mathrm{w}}$ conditions that were so far taken as indicative of deposition freezing. Pores with diameters $<5 \mathrm{~nm}$ are filled with water at ice saturation for temperatures $T>200 \mathrm{~K}$. Freezing in such pores is expected to occur by homogeneous ice 
nucleation for $T<235 \mathrm{~K}$ and by immersion freezing on active sites present in the pores for $T>235 \mathrm{~K}$. Many clay minerals and mineral dusts indeed show a strong increase in ice nucleation efficiency when temperature is decreased below $235 \mathrm{~K}$. Such an increase is difficult to explain when ice nucleation is supposed to occur by a deposition mechanism but evident when assuming freezing in pores because only small pore volumes are needed for homogeneous ice nucleation below $235 \mathrm{~K}$, while heterogeneous ice nucleation needs larger pore structures to contain at least one active site for immersion nucleation. All this evidence taken together leads to the conclusion that pore condensation and freezing (PCF) should be the prevailing freezing mechanism of clay minerals and mineral dusts for $\mathrm{RH}_{\mathrm{w}}$ below water saturation. Extending the analysis to other types of IN showed that freezing in pores and cracks is probably the prevailing ice nucleation mechanism for glassy and volcanic ash aerosols at $\mathrm{RH}_{\mathrm{w}}$ below water saturation. No case could be identified that gives clear evidence of ice nucleation by direct water vapor deposition onto a solid surface. Inspection of IN with a close lattice match to ice like silver iodide and Snomax ${ }^{\mathrm{TM}}$ show that for a high ice nucleation efficiency the presence of water soluble impurities on the surface may be essential.

Further work is needed to test and corroborate the hypothesis that ice nucleation below water saturation occurs predominantly in water-filled pores and cavities. Ice nucleation studies should be conceived that allow a direct correlation of ice nucleation efficiency with pore structures of a material. Therefore, materials that are investigated as IN should be characterized with respect to their porosity. So far, freezing and melting properties of mesoporous silica materials like SBA-15, MCM-41, or zeolites have mostly been characterized for powders such that freezing in pores was initiated by ice that had nucleated on the external surface of the particles. If these materials were investigated as aerosols at $\mathrm{RH}_{\mathrm{w}}$ below water saturation, nucleation should start from pore water. Such studies could help to establish what degree of pore filling is needed for homogeneous ice nucleation and freezing in pores. Freezing of water in carbon nanotubes might be of significance for ice nucleation by soot aerosols. Further studies could reveal whether a high share of nanotubes improves the ice nucleation potential of soot.

If such studies corroborate the hypothesis of PCF, model parameterization that is based on the pore structure of an IN as the relevant property that determines ice nucleation efficiency below water saturation should be elaborated. Pore structure analysis would then be essential for a reliable parameterization.

\section{Appendix A}

\section{A1 Interfacial water}

Completely filled pores of, e.g., MCM-41 and SBA-15 contain two phases of water, termed "free" and "bound", with free water in the middle of the pores and bound water adjacent to the pore walls (Morishige and Nobuoka, 1997; Morishige and Kawano, 1999; Schreiber et al., 2001). When the water freezes to ice, a disordered "quasi-liquid" layer remains adjacent to the pore walls down to around or below $200 \mathrm{~K}$ (Webber and Dore, 2004; Webber et al., 2007). The diffraction profile obtained after the freezing of the free water suggests that the bound water possesses little short-range order and consists of randomly displaced water molecules (Morishige and Nobuoka, 1997). The thickness of this layer ranges from one to three molecular layers and its structure is different from that of both the bulk crystal and liquid, but is often considered as "liquid-like" or "quasi-liquid" based on NMR relaxation times. The pore walls may therefore be considered as wetted by the liquid phase and not by the solid phase (Denoyel and Pellenq, 2002). The existence of a quasiliquid layer is also confirmed by molecular dynamics studies. Solveyra et al. (2011) showed that above the melting temperature partially filled hydrophilic and hydrophobic nanopores of $3 \mathrm{~nm}$ diameter contain two water phases in coexistence: a condensed liquid plug and a surface-adsorbed phase. They found that only the liquid plug crystallizes on cooling, producing ice I with stacks of hexagonal and cubic layers. The confined ice is wetted by a premelted liquid layer that persists in equilibrium with ice down to temperatures well below its melting point. Moore et al. (2012) used molecular dynamics simulations to investigate the coexistence between confined ice and liquid water for a series of cylindrical nanopores, with water-wall interactions ranging from strongly hydrophilic to very hydrophobic. They found that the ice formed in the nanopores is a hybrid ice I with stacks of cubic and hexagonal layers and that the melting temperature of the nanoconfined ice is strongly dependent on the radius of the pore but rather insensitive to the hydrophilicity of the pore surface. A premelted liquid layer in coexistence with the confined ice was present down to the lowest investigated temperature, $50 \mathrm{~K}$ below the melting temperatures of the confined ice.

X-ray diffraction showed that the thickness and mobility of the quasi-liquid layer gradually changes with decreasing temperature after the water in the middle of the pores has crystallized and seems to undergo complete freezing very gradually between 220 and $180 \mathrm{~K}$, independent of pore dimension (Morishige and Nobuoka, 1997). Hansen et al. (1996) attribute a transition below $209 \mathrm{~K}$ that is apparent from NMR spectra and does not show any hysteresis effect on the freezing of the interfacial water layer, for which they estimate a thickness of $0.54 \mathrm{~nm}$. In a neutron diffraction and NMR relaxation study, Liu et al. (2006) give further evidence that this disordered ice-water interfacial region can be 
incorporated into the ice phase provided that the temperature is low enough. It seems to be in an equilibrium state that is primarily dependent on temperature but not on sample history. Its thickness decreases by $0.9 \mathrm{~nm}$ between $250 \mathrm{~K}$ and $150 \mathrm{~K}$, corresponding to two or three monolayers of water molecules. It grows in thickness with increasing temperature and leads to melting of the entire pore solid at a depressed pore melting point (Jähnert et al., 2008).

\section{A2 Ice crystal structures}

Structural properties of ice in confinements have been intensely studied by X-ray (Morishige and Nobuoka, 1997; Morishige and Iwasaki, 2003; Morishige and Uematsu, 2005; Morishige et al., 2009) and neutron diffraction (Dore, 2000; Liu et al., 2006; Webber et al., 2007; Seyed-Yazdi et al., 2008). These studies have shown that nucleation of ice in pores with diameters $<30 \mathrm{~nm}$ leads to ice-I, which shows predominantly features of cubic ice rather than hexagonal ice, and contains numerous defects. The regular ABABAB stacking of hexagonal ice does not form. It has been suggested (Webber and Dore, 2004; Findenegg et al., 2008) that in this initial phase a proto-crystal develops, which is effectively a disordered hydrogen-bonded cluster of water molecules that does not possess well-defined crystallographic axes. As the hydrogen-bonded cluster grows into a small crystallite, the competition between the different growth axes in interaction with the pore walls leads to stacking faults instead of a regular formation of hexagonal $(\mathrm{ABABAB})$ or cubic (ABCABC) lattice planes. Ice crystallites in MCM-41 samples $D_{\mathrm{p}}<4 \mathrm{~nm}$ do not significantly exceed the size of the smallest proto-crystallites (Findenegg et al., 2008). Webber and Dore (2004) therefore hypothesize that all ice crystals start their life as a defective cubic ice crystallite and that this behavior is revealed in the confined geometry only because the eventual size of the crystal is restricted to the limits imposed by the pore dimensions. Morishige et al. (2009) found that the stability of cubic ice in mesopores depends on the pore geometry. Cubic ice confined to the interconnected spherical cavities of KIT-5 (diameter $>10 \mathrm{~nm}$ ) is metastable with respect to hexagonal ice. On the other hand, cubic ice confined to the cylindrical pores of SBA- $15\left(D_{\mathrm{p}}=8 \mathrm{~nm}\right)$ is stable up to the melting point of the ice. This is in agreement with a study by Johari (2005), who used the known enthalpy and interfacial energy of hexagonal and cubic ice to calculate the relative stability of the two ice forms. They found that water droplets smaller than $15 \mathrm{~nm}$ radius and films thinner than $10 \mathrm{~nm}$ would freeze to cubic ice in the $160-220 \mathrm{~K}$ range, and only bigger droplets and thicker films would prefer freezing to hexagonal ice. Water present on the external surfaces of powders with completely filled pores nucleates to hexagonal ice and may initiate the nucleation of the pore water, which then grows as defective cubic ice along the center of the cylindrical pore, possibly surrounded by a layer of disordered ice (Schreiber et al., 2001; Liu et al., 2006).

\section{Appendix B}

\section{Working principles of the different instrument types}

\section{B1 Continuous flow diffusion chambers (CFDC)}

One instrument type in use for the study of deposition nucleation are continuous flow diffusion chambers, which allow real-time measurements of IN concentration from an aerosol flow. An ice nucleus counter of this type consists of a main chamber where the aerosols are exposed to an environment with a defined temperature and supersaturation with respect to ice $\left(\mathrm{RH}_{\mathrm{i}}\right)$, an optional evaporation section, and a detector that counts the ice crystals that have formed in the chamber. An ice supersaturation profile with a maximum roughly in the center of the main chamber is maintained by holding two opposing ice-covered walls with a gap between them (10$20 \mathrm{~mm}$ ) at different temperatures (e.g., Stetzer et al., 2008; Koehler et al., 2007; Kanji and Abbatt, 2009). In some setups, the opposing walls are arranged in a concentric cylinder geometry (Salam et al., 2006; Koehler et al., 2007; Jones et al., 2011); others have a flat parallel plate design like the Zurich Ice Nucleating Chamber (ZINC, Stetzer et al., 2008; Welti et al., 2009), the UT-CFDC (Kanji and Abbatt, 2009) and the Compact Ice Chamber (CIC, Friedman et al., 2011; Kulkarni et al., 2012). By increasing the temperature gradient between the plates, supersaturation increases while the temperature in the central aerosol location is held relatively constant. Typical residence times of the aerosols in the chamber are 4-12 s (Koehler et al., 2007; Welti et al., 2009; Kanji and Abbatt, 2009, Friedman et al., 2011). The optional evaporation section is held at ice saturation in order to evaporate water droplets that might condense in the nucleation section when experimenting at relative humidities above water saturation (Welti et al., 2009; Koehler et al., 2007, Kanji and Abbatt, 2009; Jones et al., 2011; Friedman et al., 2011).

A continuous, stable aerosol flow is either generated dry in a fluidized bed (e.g., Welti et al., 2009) or with a smallscale powder disperser (e.g., Kulkarni et al., 2012) or wet by atomization from solution followed by diffusion drying (e.g., Kanji and Abbatt, 2010). Generation of the aerosol flow from solution carries the risk that insoluble particles that were not initially associated with soluble material may transform into internally mixed particles (Koehler et al., 2007). Submicron particles are size-selected from the aerosol stream in a differential mobility analyzer (DMA) and introduced into the CFDC (e.g., Welti et al., 2009). Due to multiple charges, larger particles with the same mobility are also present in a size-selected sample, especially in the $100 \mathrm{~nm}$ and $200 \mathrm{~nm}$ size range (Archuleta et al., 2005; Welti et al., 2009).

At the outlet of the CFDC, particles are measured and binned by size with an optical particle counter (OPC) (e.g., Koehler et al., 2007; Stetzer et al., 2008). Ice crystals that are nucleated in the CFDC are detected by their growth to relatively large sizes $(>2 \mu \mathrm{m})$ compared with wet aerosol 
particles in equilibrium with the relative humidity conditions and liquid droplets that may form when the humidity condition in the main chamber is above water saturation (e.g., Archuleta et al., 2005; Stetzer et al., 2008). The activated ice fraction is determined by comparing the ice crystal count with a total particle count and referenced typically to the temperature and $\mathrm{RH}_{\mathrm{i}}$ conditions at which $1 \%$ of the particles activate as ice nuclei.

The FINCH (Fast Ice Nuclei Counter) instrument described by Bundke et al. (2008) has a similar working principle as a CFDC, but supersaturation is produced by the mixing of humidified and dry air, allowing higher flow rates and rapid changes in temperature and supersaturation. Ice crystal detection occurs optically. Ice crystals can be directly discriminated from cloud droplets based on their different depolarization of scattered light.

\section{B2 Large AIDA cloud chamber}

The AIDA aerosol vessel is an $84 \mathrm{~m}^{3}$ actively cooled cylindrical aluminum chamber with a diameter of $4 \mathrm{~m}$ that can be operated as an expansion cloud chamber to investigate microphysical processes at simulated cloud conditions. This chamber was used for the studies by Jones et al. (2011), Connolly et al. (2009), Möhler et al. (2006, 2008a), Field et al. (2006), Cziczo et al. (2009), Wagner et al. (2011), and Mangold et al. (2005). A description of the design and operation principle can be found, e.g., in Möhler et al. (2006) and Connolly et al. (2009). The aerosol vessel is brought to atmospheric pressure by adding water vapor and synthetic air. A fan within the vessel ensures well-mixed conditions with sample temperatures within the volume varying by $\pm 0.2 \mathrm{~K}$. For ice nucleation experiments the interior wall of the AIDA chamber is ice coated such that humidity conditions are near the saturation pressure of ice at the wall temperature at the start of an experiment. Aerosol samples are prepared dry with a PALAS rotating brush generator, piped through a dispersion nozzle and introduced into the chamber. The size distribution of the added aerosol typically covers the range from 0.1 to $2 \mu \mathrm{m}$ with a median diameter of $0.3-0.5 \mu \mathrm{m}$. The number concentrations are about 500 to $700 \mathrm{~cm}^{-3}$ (Field et al., 2006; Mangold et al., 2005). To simulate the adiabatic cooling of rising air parcels, the pressure within the chamber is reduced by controlled pumping from $1000 \mathrm{hPa}$ to $800 \mathrm{hPa}$ over typical periods of $5 \mathrm{~min}$. After pumping starts, the gas temperature drops almost adiabatically due to volume expansion. The cooling in the aerosol vessel is not purely adiabatic because the chamber wall temperatures remain approximately constant throughout the expansion and as a consequence there is a heat flux from the vessel wall into the chamber. With the highest pumping speed, maximum initial cooling rates of about $4 \mathrm{Kmin}^{-1}$ can be achieved and the relative humidity with respect to ice increases by up to $50 \% \mathrm{~min}^{-1}$. Mean cooling rates (close to the time of nucleation) are typically 1$2 \mathrm{~K} \mathrm{~min}^{-1}$. The onset of ice formation is detected by the in- creasing intensity and depolarization of laser light backscattered by the growing ice particles. The concentration of total water (gas and condensed phase) is measured with a fastscanning chilled mirror hygrometer and the FISH Lyman- $\alpha$ fluorescence hygrometer. Both instruments are located outside the cold box and take their sample flow through a stainless steel tube. Simultaneously, the water vapor concentration in the AIDA vessel is measured in situ at $1370 \pm 2 \mathrm{~nm}$ by a tunable diode laser (TDL) absorption spectrometer. Ice particle number concentrations and mean sizes are retrieved from FTIR extinction spectra. The ice water content (IWC) is directly obtained by subtracting the gas-phase water vapor concentration measured by the TDL absorption from the total water concentration measured by the FISH instrument. The IWC is also retrieved from the FTIR extinction spectra. Number concentrations and optical diameters of growing ice crystals are determined with two optical particle spectrometers. The total aerosol number concentration is measured with a condensation particle counter. The ice crystal number concentration reaches its maximum shortly after ice nucleation. Subsequently, the number concentration decreases continuously due to the ongoing pumping and ice particle sedimentation (Mangold et al., 2005).

\section{B3 Static diffusion chambers}

In this type of chamber, particles are deposited onto a substrate and detected optically, usually with an optical microscope. Typically, the investigated IN are particles of micrometer sizes. The setups differ in substrate size and material and the way supersaturation with respect to ice is generated. Depositing particles onto a substrate always carries the danger of artifact due to sample-substrate interactions, e.g., water vapor sorption at the particle-substrate interface and ice nucleation induced by the substrate or at the particle-substrate interface.

The studies by Dymarska et al. (2006), Eastwood et al. (2008, 2009), Chernoff and Bertram (2010), Knopf et al. (2010), Wang and Knopf (2011), and Wang et al. (2012) employed a flow cell setup consisting of a cell with controlled temperature and humidity and a reflected light microscope. Particles were deposited onto the bottom of the flow cell, consisting of a glass cover slide treated with dichlorodimethylsilane to make a hydrophobic layer. A typical sample held 200 to 800 micrometer-sized particles. The flow cell was located on a cooling stage, ensuring that the coldest portion of the flow cell is the glass substrate. In a typical experiment, temperature was decreased at a rate of $0.1 \mathrm{~K} \mathrm{~min}^{-1}$ at a constant water vapor pressure provided by a controlled humidified $\mathrm{N}_{2}$ (g) flow leading to an increase in $\mathrm{RH}_{\mathrm{i}}$ of around $1-2 \% \mathrm{~min}^{-1}$. From the optical images the $\mathrm{RH}_{\mathrm{i}}$ at which water droplets or ice particles first formed (i.e., onset of water or ice nucleation) was determined. Baustian et al. (2010) and Wise et al. (2010) employed a similar setup 
with a Raman microscope for detection and hydrophobically treated quartz discs as sample holders.

Kanji and Abbatt (2006) and Kanji et al. (2008) deposited solid particles onto a Teflon-coated copper cold stage that was housed in a temperature controlled vacuum chamber with a constant flow of water vapor transiting through the sample chamber. The cold stage was exposed to constant partial pressure of water while its temperature was reduced to increase $\mathrm{RH}_{\mathrm{i}}$ by $1 \%$ every $6 \mathrm{~s}$. The entire surface of the cold stage was under observation by a digital camera to capture ice nucleation onset given when the first ice crystal had grown to $100 \mu \mathrm{m}$, the minimum size needed for detection. By varying the number of particles on the stage (up to $10^{5}$ ), ice onsets down to 1 particle in $10^{5}$ could be measured.

The Thermal Gradient Diffusion Chamber (TGDC) employed by Kulkarni and Dobbie (2010) consisted of an optical microscope for ice crystal detection and a chamber made up of two parallel horizontal plates with the inside of both plates coated with ice. Heating of the top plate produced a thermal and vapor diffusion gradient between the plates. Particles were deposited onto a hydrophobic teflon substrate (500 particles per $\mathrm{mm}^{2}$ ) affixed to a sample holder rod, which could be raised to predefined heights that correspond to calibrated temperatures and humidities. The total number of dust particles counted in the field of view varied between 5 and 15 , giving a nucleation threshold for ice formation of around $10 \%$.

Roberts and Hallett (1968) scattered their samples (up to $10^{4}$ micrometer-sized particles) on a glass cover slip within a cold stage with ice-coated walls. Supersaturation with respect to ice was achieved by cooling the glass cover slip.

The setup employed by Knopf and Koop (2006) consisted of a microscope for optical observation of ice formation and a vacuum cell with an upper temperature stage, which held the hydrophobically coated quartz plate on which the sample was wet dispersed, and a lower temperature stage, which controlled the temperature of a water reservoir. About 20 particles in the size range of $1-10 \mu \mathrm{m}$ were observed simultaneously during an experiment. Before an ice nucleation experiment started, the lower temperature stage was set to $20 \mathrm{~K}$ below the temperature of the upper stage such that $\mathrm{RH}_{\mathrm{i}}$ at the sample ranged between 5 and $40 \%$. To reach supersaturation, the water reservoir was heated at $0.2-1 \mathrm{~K} \mathrm{~min}^{-1}$, giving an increase in $\mathrm{RH}_{\mathrm{i}}$ at a rate of about $2-20 \% \mathrm{~min}^{-1}$.

The FRIDGE static vacuum vapor diffusion chamber employed by Bundke et al. (2008) was designed to measure ice nucleation activity of aerosols sampled on filter substrates ( $47 \mathrm{~mm}$ diameter cellulose nitrate membrane filters). Filters were placed on top of a Peltier cooled plate housed within a vacuum chamber connected to an external water vapor source. Ice crystals were observed by a CCD camera and counted by automatic picture analysis software. In a typical experiment, the chamber was closed, evacuated (1 min), and cooled to the desired temperature ( $2 \mathrm{~min})$. Water vapor was introduced by opening the connection to the vapor source.
The resulting water vapor supersaturation over the substrate surface was calculated from the pressure in the chamber and the temperature of the surface.

Schaller and Fukuta (1979) used a wedge-shaped ice thermal chamber in which aerosols were introduced. The top and bottom plates were covered with ice. A temperature difference between the plates was maintained by heating of the top plate and cooling of the bottom plate leading to a profile of supersaturation with respect to ice that can be calculated. Ice crystals were visually counted with respect to their positions in the chamber. At least $50-100$ ice crystals in $1 \mathrm{~cm}^{3}$ of air containing 5000 particles were observed at the defined threshold supersaturation.

The thermal diffusion chamber used by Bailey and Hallett (2002) consisted of two ice-coated stainless steel plates separated by $2.8 \mathrm{~cm}$, in which a glass filament was inserted vertically. Glass filaments were coated with IN by drawing them through finely powdered samples. The detectable particles left adhering to the filament were 5 to $10 \mu \mathrm{m}$ in size and were visible as tiny dark spots on the filament. To achieve supersaturation with respect to ice, the temperatures of the top and bottom plate were increased and decreased, respectively, at a rate of approximately $0.3 \mathrm{~K} \mathrm{~min}^{-1}$ until one or two crystals were observed to nucleate, corresponding to a nucleated fraction of $0.1 \%$. Initial nucleation on the coated filaments usually occurred in a few places simultaneously near the middle of the chamber. This involved a temperature span of about $1-2 \mathrm{~K}$ and a variation in supersaturation of $1-2 \%$.

Environmental scanning electron microscopy (ESEM) enables in situ observation of interactions between water vapor and aerosol particles in the submicrometer range. By varying the water vapor pressure and using a Peltier element to realize temperatures below the freezing point it is possible to obtain supersaturated conditions relative to ice in the sample chamber. In the studies by Zimmermann et al. (2007, 2008) the chamber gas consisted of almost pure water vapor at variable pressures. Between approximately 200 and 400 micrometer-sized particles of a sample were spread on a silicon plate $(5 \times 5 \mathrm{~mm})$, which was placed in a silanized $\mathrm{Cu}$ adaptor (Zimmermann et al., 2007). Blank experiments with this substrate showed no ice formation up to approximately $140 \% \mathrm{RH}_{\mathrm{i}}$. Ice nucleation experiments were performed by changing the temperature in steps of $1 \mathrm{~K}$, and increasing at each temperature the $\mathrm{H}_{2} \mathrm{O}$ vapor pressure in steps of $0.1 \mathrm{hPa}$ from subsaturation to supersaturation with respect to ice. These steps in pressure regulation are equivalent to a change in the supersaturation on the order of $2 \%$ at a temperature of $273 \mathrm{~K}$, and about $12 \%$ at lower temperatures around $250 \mathrm{~K}$. Therefore, precise determination of ice activation by ESEM was restricted to temperatures above $250 \mathrm{~K}$. 


\section{Appendix C}

\section{C1 Sources and composition of mineral dust}

The main source of airborne mineral dust is the global dust belt, which covers the Sahara, the deserts of the Arabian Peninsula, the Caspian Sea and Aral Sea regions in Central Asia, and the Gobi and the Taklimakan in China. Sources outside the global dust belt are located in the USA and Mexico, Australia, Botswana and the Namibia desert, Bolivia, and desert areas in western Argentina (Formenti et al., 2011). Recent model estimates indicate that global mineral dust emissions by wind-driven erosion range between 1000 and $3000 \mathrm{Tg} \mathrm{yr}^{-1}$ (Zender et al., 2004; Cakmur et al., 2006; Textor et al., 2007). The Saharan sources are considered by far the most active ones in the world (Engelstaedter et al., 2006). Dust from North African sources is transported across the Atlantic Ocean to the United States, the Caribbean and South America and towards the Mediterranean, Europe and the Middle East.

Clay minerals have been identified as major components of transported mineral dusts (Murray et al., 2012). Composition analysis of particles that originated from dust storms over the western deserts of the Tibesti mountains and were transported over Israel showed high concentrations of montmorillonite and mixed-layer minerals. In aerosols from storms that originated in the Chad and Lybian plateau deserts and the Great Sand Sea of the Ahaggar Massif, high concentrations of illite were found (Ganor, 1991). Scanning electron microscopy showed that most of the supermicron aerosol particles collected in Tel Aviv after a dust storm contained $\mathrm{Si}, \mathrm{Al}, \mathrm{Mg}, \mathrm{K}, \mathrm{Ca}, \mathrm{S}$, and $\mathrm{Fe}$ as the dominant elements and consisted of aggregates of different minerals including calcite, quartz, dolomite, feldspar, gypsum, and the clay minerals illite and kaolinite. Less than $10 \%$ of the particles were pure minerals that contained only quartz, calcite or dolomite. Sulfur was found in $\sim 65 \%$ of the particles and resided almost always on the surface of the particles (Falkovich et al., 2001). Mineral dust advected to Cape Verde was found to be in the size range from 2 to $4 \mu \mathrm{m}$ and to consist of kaolinite (25-5 wt\%), K-feldspar (20-25 wt \%), illite (10-14 wt $\%)$, quartz $(\sim 10 \mathrm{wt} \%)$, smectites $(\sim 5 \mathrm{wt} \%)$, plagioclase $(1-6 \mathrm{wt} \%)$, gypsum $(\sim 5 \mathrm{wt} \%)$, halite $(2-17 \mathrm{wt} \%)$ and calcite $(\sim 3 \mathrm{wt} \%)$ (Kandler et al., 2011a, b). This composition is similar to the one of mineral dust measured by $\mathrm{X}$-ray powder diffraction in southern Morocco with quartz, K-feldspar, plagioclase, calcite, hematite, chlorite, and the clay minerals illite and kaolinite as major constituents (Kandler et al., 2009). The clay minerals were found to be present as large aggregates, which did not have a platy morphology. Dust samples from rainfall residues collected in southeast Italy revealed median diameter values between 1.7 and $2.4 \mu \mathrm{m}$ (Blanco et al., 2003). The mineral composition was similar to the one found during red rain events in Spain (Avila et al., 1997), with illite > quartz > smectite > paly- gorskite $>$ kaolinite $>$ calcite $>$ dolomite $>$ feldspars as the main constituents. These examples show that atmospheric mineral dust particles are typically micrometer-sized aggregates consisting of a mixture of minerals with clay minerals as an important component.

\section{C2 Pore structure of clay minerals}

Clay minerals are hydrous aluminum silicates with a layer (sheet-like) structure of lamellae. Depending on type and size, airborne clay mineral particles may consist of a stack of lamellae often with a high degree of parallel alignment or an aggregate of lamellae stacks. The possible sources of porosity include crevices in the particle surface, staggered layer edges, voids created by the overlapping of stacked layers and interlayer regions (Rutherford et al., 1997). Slit- and wedgeshaped pores result from the interleaving of crystal units of several lamellae in thickness, giving rise to discrete differential pore-size distribution peaks at or near plate-thickness values (Aylmore and Quirk, 1967). The following classes of voids can be discriminated, in agreement with the IUPAC nomenclature: micropores, corresponding to the cations containing interlayer space with spacing $<2 \mathrm{~nm}$; mesopores, corresponding to the free space existing between particles, in the range $2-50 \mathrm{~nm}$; and macropores, corresponding to the interaggregate voids $>50 \mathrm{~nm}$. The interlamellar space may be considered as an intraparticular porosity (Salles et al., 2008, 2009).

The sorption of $\mathrm{N}_{2}$ and other inert gases at temperatures near their boiling points has been used by many workers to study the nature and extent of void spaces within microporous systems. The Brunauer, Emmett, and Teller (BET) method of estimating the specific surface area from such adsorption isotherms has received general acceptance (Aylmore and Quirk, 1967). Estimations of pore sizes and their volume distribution are usually based on the phenomenon of capillary condensation and the application of the Kelvin equation to either the complete adsorption or desorption isotherm after correcting for the thickness of the physically adsorbed layer (Aylmore and Quirk, 1967).

Water adsorption to clay minerals is thought to occur in different steps (Salles et al., 2008): for $\mathrm{RH}_{\mathrm{w}}$ typically $<10 \%$ of the particle surfaces are hydrated with one layer water molecules. For $\mathrm{RH}_{\mathrm{w}}>10 \%$, water enters the interlayer space and hydrates both the cations and the "internal" surfaces (the oxygen atom layers forming the walls of the interlamellar space) with a discrete number (1,2 or 3) of layers of water molecules. For swelling clays like montmorillonite, concomitant with the hydration of the interlamellar space, a stepwise increase in the interlamellar spacing is observed. Increasing further $\mathrm{RH}_{\mathrm{w}}$ is thought to lead to capillary condensation in the inter-particle mesopores and, in the case of montmorillonites, to the onset of the so-called osmotic swelling regime in the interlamellar space and the 
inter-particle mesopores. Osmotic swelling is an entropic phenomenon and depends on the local ion concentration.

In slit-shaped pores adsorption appears to occur largely by multilayer formation on the flat surfaces of the clay particles. With the filling of the pores, desorption is then governed by the curvature of the semicylindrical menisci formed. Hysteresis in such systems thus results at least partly from a delay in the formation of a meniscus during the adsorption process (Aylmore, 1974). When irregular tubular and so-called "inkbottle" pores predominate, spontaneous emptying of condensate retained in larger chambers behind narrower pore openings produces irreversibility in the desorption branch of an isotherm. The adsorption branch, on the other hand, corresponds to a reversible filling of the pores, governed by the curvature of the condensate meniscus (Aylmore and Quirk, 1967). In systems where the porous structure is such that meniscus formation is delayed until the adsorbed multilayers merge in the narrowest part of the void space, pore-filling may occur by spontaneous nucleation at these points, thus giving rise to irreversibility on the adsorption branch. This "open-pore" concept (Foster, 1932) seems most applicable to the open-sided, slit-shaped pores that occur in many systems (de Boer, 1958). On the desorption branch, the meniscus is present and, provided there are no bottle-shaped pores, the relative pressure in the pore, and hence evaporation, is governed solely by the curvature of the meniscus and the correct pore radii can be obtained by applying the Kelvin equation to the desorption branch of the isotherm (Aylmore and Quirk, 1967). In a system containing cylindrical capillaries, adsorption and desorption processes appear both to be thermodynamically irreversible with a delay in adsorption resulting from the presence of cylindrical menisci in open-ended pores being followed by a delay in desorption due to the retention of liquid behind narrow restrictions (Aylmore, 1974).

Kaolinite. Kaolinites belong to the phyllosilicate group and are represented by the chemical formula $\mathrm{Al}_{2} \mathrm{Si}_{2} \mathrm{O}_{5}(\mathrm{OH})_{4}$. Their lamellae consist of a tetrahedral sheet linked through oxygen atoms to an octahedral sheet of alumina octahedrals (a so-called TO structure) (Pinti et al., 2012). They form platy particles. Pores are likely to occur from the interleaving of the plates and should be similar in size to the thickness of the particles, without a marked concentration in any particular size range (Churchman et al., 1995).

Aylmore and Quirk (1967) investigated the pore size distribution $(<10 \mathrm{~nm})$ of two kaolinites by means of lowtemperature $\mathrm{N}_{2}$ sorption. The majority of the porosity was contained in relative large plate separations of $>10 \mathrm{~nm}$ for Rocky Gully kaolinite (Western Australia) and $20 \mathrm{~nm}$ for the Merck kaolinite (Merck Chemical Company, Germany: labeled DAB-6), and falls outside the range to be examined by $\mathrm{N}_{2}$ sorption. With the relatively large crystals in kaolinites, surface separations of the order of $10 \mathrm{~nm}$ at least could arise from steps in the crystal surface as well as from separations between neighboring crystals (Aylmore and Quirk,
1967). Diamond (1970) investigated Macon kaolinite (Georgia) using the method of mercury intrusion, which can cover a pore diameter range from several hundred microns down to approximately $15 \mathrm{~nm}$. Pores that were intruded under a given pressure were referred to an "equivalent" cylindrical diameter. They found that the bulk of the pores are about 30 to $200 \mathrm{~nm}$ in equivalent diameter with virtually no pores $<30 \mathrm{~nm}$. Sills et al. (1973) investigated mixtures of API-9 kaolinite (New Mexico) and Willalooka illite (South Australia) using $\mathrm{N}_{2}$ sorption and mercury injection. For the $100 \%$ kaolinite sample, they found plate separations from 15 to $100 \mathrm{~nm}$ with a predominance in the range from 20 to $50 \mathrm{~nm}$ (Sills et al., 1973).

Illite. Illites belong to the phyllosilicate and mica groups and tend to be an agglomerate of numerous individual crystals or clusters. Their structure is given by the repetition of an octahedral layer sandwiched between two tetrahedral layers (TOT) (Pinti et al., 2012). Electron microscopy of Willalooka illite (South Australia) revealed this material to consist of plate-shaped particles of $100 \mathrm{~nm}$ across the planar surfaces and an average thickness of around $4 \mathrm{~nm}$ (Aylmore, 1974). Gas sorption measurements showed that most of the porosity of this clay arises from pores of $2-5 \mathrm{~nm}$ equivalent plate separation, with the maximum in the pore peak occurring at about $3 \mathrm{~nm}$ (Aylmore, 1974; Aylmore and Quirk, 1967). Since almost the entire porosity arises from pores of less than $6 \mathrm{~nm}$, the porosity must result largely from the void spaces between nearly parallel aligned plates (Aylmore and Quirk, 1967). Mercury intrusion of Fithian illite was only able to penetrate less than one-third of the pore volume (Diamond, 1970). The pore space that had been intruded was distributed over the full range of pore sizes explored, with an upturn in pore volume for $D<30 \mathrm{~nm}$. It seems likely that most of the residual pore space not assayed by this method is in pores $<16 \mathrm{~nm}$ in diameter.

Montmorillonite. Montmorillonites belong to the phyllosilicate group and are members of the smectite family. They present a TOT structure containing interlamellar cations that compensate for the negative charge of the silicate layers and are responsible for the ability of these clays to swell (Salles et al., 2009; Pinti et al., 2012). Aylmore and Quirk (1967) investigated the pore structure of Redhill calcium montmorillonite (England) and Wyoming calcium bentonite using $\mathrm{N}_{2}$ sorption. They found that in both montmorillonites, pores of $2-4 \mathrm{~nm}$ diameter predominate. In Redhill calcium montmorillonite almost all of the porosity was contained in pore dimensions of $<6 \mathrm{~nm}$. By contrast, only ca. $60 \%$ of the porosity of the Wyoming calcium bentonite is held in pores of $<10 \mathrm{~nm}$. Diamond (1970) found comparatively little intrusion by mercury for Clay Spur montmorillonite (Wyoming) until pressure sufficient to intrude pores of $65 \mathrm{~nm}$ diameter was reached. About three-quarters of the total pore space could be intruded, i.e., existed in pores larger in equivalent diameter than about $14 \mathrm{~nm}$. Most of the residual 
unintruded pore space would be expected to lie in diameter classes just beyond the limit (Diamond, 1970).

Salles et al. (2008) investigated the swelling of sodium montmorillonite in the presence of water vapor using thermoporometry, a calorimetric technique in which the sample was exposed to freezing/melting cycles. They found that water froze in pores with equivalent cylindrical pore diameters of $4.5-5 \mathrm{~nm}$ at $54 \% \mathrm{RH}_{\mathrm{w}}$. At 75 and $90 \% \mathrm{RH}_{\mathrm{w}}$, freezing was observed in pores with diameters up to 6 and $8 \mathrm{~nm}$, respectively. The equilibrium between the filling of the mesopores and the filling of the interlayer space seemed to be strongly dependent on the interlayer cation. For $\mathrm{K}^{+}$and other alkali cations, the filling of the mesopores takes place only at high $\mathrm{RH}_{\mathrm{w}}(97 \%)$, and for cesium montmorillonite, the complete filling of mesopores was not observed in the available experimental range ( $<97 \% \mathrm{RH}_{\mathrm{w}}$ ) (Salles et al., 2009).

Acid treatment of montmorillonite enhances mesoporosity, making it an effective catalytic support (Kumar et al., 1995). $\mathrm{N}_{2}$ sorption showed that untreated bentonite clay containing $90 \%$ of montmorillonite possesses little porosity in the range of ca. $2 \mathrm{~nm}$ radii, but following $1-4 \mathrm{~N}$ sulfuric acid treatment there is an increase in the volumes of these pores. Acid concentration beyond 5-6 N causes distinct enhancement of mesoporosity and the pore radii increase from 2 to $5 \mathrm{~nm}$ (Kumar et al., 1995). It is thought that treatment with acid $(3-4 \mathrm{~N})$ results in the broadening of slits or voids between the layers due to depleted cation concentration and interlamellar attraction as well as destruction of octahedral layers. Acid attack on the tetrahedral silica layer leads to free silica, which may produce spheroidal ink bottle type pores by depositing at pore openings. Similar results were obtained for bentonites (clay minerals consisting mostly of montmorillonite). For raw clay and clay activated with $1.5 \mathrm{M}$ $\mathrm{HCl}$, pores in the diameter range $2-5 \mathrm{~nm}$ represented approx. $40 \%$ of the total volume of mesopores, while pores in the range $10-50 \mathrm{~nm}$ represented approx. $30 \%$. Activation with 3-6 $\mathrm{M} \mathrm{HCl}$ increased the contribution of small mesopores $(2-5 \mathrm{~nm})$ up to $52-55 \%$ and decreased the contribution of coarser mesopores $(10-50 \mathrm{~nm})$ down to $22 \%$. The highest concentration used for activation $(7.5 \mathrm{M} \mathrm{HCl})$ had a lower effect on the transformation of coarser mesopores into smaller ones (Vuković et al., 2005). Treatment with sulfuric acid (1.5-6 M) strongly increased the pore volume and size of the pores, resulting in pore size distributions with radii up to $10 \mathrm{~nm}$ and a predominance of radii $<4 \mathrm{~nm}$ (Tomić et al., 2011).

\section{Appendix D}

\section{Other ice nuclei}

\section{D1 Soot}

Results of ice nucleation studies with soot aerosols are summarized in Kärcher et al. (2007) and Hoose and Möhler (2012). There is no clear case of heterogeneous ice nucleation below water saturation for $T>235 \mathrm{~K}$ (e.g., Dymarska et al., 2006), while the ice nucleation ability below $235 \mathrm{~K}$ seems to depend strongly on the type and pretreatment of the soot. Untreated Degussa lamp black soot particles and those with monolayer $\mathrm{H}_{2} \mathrm{SO}_{4}$ coverage activated ice only at a relative humidity close to water saturation in the temperature range 213-233 K (DeMott et al., 1999). The Degussa lamp black soot particles were aggregates of primary particles of an average size of $95 \mathrm{~nm}$ with mean mobility equivalent diameters of about $240 \mathrm{~nm}$. Only a multilayer $\mathrm{H}_{2} \mathrm{SO}_{4}$ coverage rendered the Degussa lamp black soot particles more efficient as IN than liquid solution particles. On the other hand, soot particles from a graphite spark generator showed nucleated fractions from $\mathrm{RH}_{\mathrm{i}}=130 \%$ at $186 \mathrm{~K}$ to $\mathrm{RH}_{\mathrm{i}}=140 \%$ at $240 \mathrm{~K}$, with minimum values of about $\mathrm{RH}_{\mathrm{i}}=110 \%$ at $215 \mathrm{~K}$ (Möhler et al., 2005a). These particles had a fractal-like, agglomerate structure with mean mobility equivalent diameters of 70-140 nm consisting of primary particles with diameters between 4 and $8 \mathrm{~nm}$ (Crawford et al., 2011). Coatings with $\mathrm{H}_{2} \mathrm{SO}_{4}$ (volume fractions between 20 and $80 \%$ ) increased their nucleation threshold to $\mathrm{RH}_{\mathrm{i}}=155 \%$ at $T=185 \mathrm{~K}$ and $\mathrm{RH}_{\mathrm{i}}=140 \%$ at $230 \mathrm{~K}$. Similarly, increasing organic carbon content (OC) made the soot particles more hydrophobic and decreased their ice nucleation ability. Flame soot aerosol particles with an OC mass content of $16 \%$ showed ice nucleation onset at $\mathrm{RH}_{\mathrm{i}}=145 \%$ at $T=207 \mathrm{~K}$ (Möhler et al., 2005b).

Kanji et al. (2011) found activation below water saturation for graphite spark generated soot at $T<235 \mathrm{~K}$. At warmer temperatures soot only activated via condensation freezing at or above water saturation. Koehler et al. (2009) investigated the ice nucleation behavior of soot aerosols with different hydrophilicity. Soots from natural gas pyrolysis required relative humidity well in excess of water saturation at $-40{ }^{\circ} \mathrm{C}$ for ice formation. At -51 to $-57^{\circ} \mathrm{C}$, ice formation occurred in up to 1 in 1000 particles (with $D \approx 200 \mathrm{~nm}$ ) for soot from natural gas pyrolysis and from TCI kerosene flame soot at relative humidities below those required for homogeneous freezing in aqueous solutions. Oxidized soot from natural gas pyrolysis showed a nucleated fraction of $1 \%$ under the same conditions. Soot from a turbulent diffusion flame in an aircraft engine combustor nucleated ice near the conditions for homogeneous freezing of water from aqueous solutions. This suggests that heterogeneous ice nucleation is favored on oxidized hydrophilic soot of intermediate polarity. Crawford et al. (2011) studied the ice nucleation efficiency of propane 
flame soot particles with varying OC content in the AIDA cloud chamber. The aerosol consisted of soot aggregates with small individual particles of ca. $30 \mathrm{~nm}$ diameter, with larger spherical particles of up to $120 \mathrm{~nm}$ also being present. For the soot with the lowest OC content, ice nucleation occurred at a minimum threshold of $\mathrm{RH}_{\mathrm{i}}=122 \%$ at $T=227 \mathrm{~K}$. Soot with OC content of 30 and $70 \%$ required supersaturation with respect to water for ice formation. Friedman et al. (2011) found no ice nucleation below water saturation at temperatures of $243 \mathrm{~K}$ and $253 \mathrm{~K}$ for $100-400 \mathrm{~nm}$ core soot particles generated in a diffusion flame with propane as fuel under lean conditions to keep organic content low. At $T=233 \mathrm{~K}$, the particles showed homogeneous ice nucleation.

The occurrence of ice nucleation below water saturation only for $T \leq 235 \mathrm{~K}$ points to PCF as an explanation. Empty spaces between aggregated primary particles may fill with water due to capillary forces and freeze homogeneously at $\mathrm{RH}_{\mathrm{w}}$ below water saturation. Coatings may fill up the empty space between particles and compact the aggregates, leading to a decreased ice nucleation ability of the soot.

Soot is composed of primary particles that can be amorphous carbon, fullerenic or quasi-crystalline carbon or graphene (hexagonal graphitic) sheets, as well as curved graphene layers forming closed-shell structures, including concentric fullerene polyhdera, onions or nanotubes (Murr and Soto, 2005). Soot structure depends on fuel identity, temperature of combustion and combustion kinetics and chemistry. While near optimally burning blue-flame combustion sources appear to produce a preponderance of carbon nanotubes and related carbon nanopolyhedra, richerburning combustion regimes producing yellow flames typically form the more classical soot aggregates (Murr and Soto, 2005). Aggregates of carbon nanotubes and other concentric, fullerenic polyhedra have been observed in the exhausts of fuel-gas-air combustion sources, including natural gas and propane kitchen stove-top burners, natural gas home water heaters, furnaces, and industrial fuel gas-air combustion processes, but also in the combustion of wood soot. Diesel soots have generally amorphous microstructures (Murr et al., 2004; Murr and Soto, 2005; Murr and Guerrero, 2006; Bang et al., 2004).

Single-walled carbon nanotubes (SWCNTs) crystallize into bundles with nanotube diameters typically in the range of 1.1-2.4 nm. Although SWCNTs are made of hydrophobic graphene sheets, experimental and theoretical/computational studies showed that water can be drawn into open-ended nanotubes by capillary suction (Koga et al., 2001; Maniwa et al., 2005). Water confined in SWCNTs undergoes a liquidsolid-like transition below room temperature and forms ordered tubular ice structures, so-called ice nanotubes. In ice nanotubes water molecules form a polygon through hydrogen bonds and are then stacked one-dimensionally. In ideal polygonal ice nanotubes, each water molecule is bonded to the four nearest-neighbor water molecules through a hydrogen bond, as in bulk ice. The melting/freezing temperature of ice nanotubes decreases from 300 to $190 \mathrm{~K}$ with increasing nanotube diameters from 1.09 to $1.52 \mathrm{~nm}$ (Maniwa et al., 2005). Kyakuno et al. (2011) showed that water inside nanotubes with diameters from 1.68 to $2.40 \mathrm{~nm}$ undergoes a wet-dry type transition with the lowering of temperature. Below the transition temperature water is ejected from the nanotubes. The wet-dry transition and the freezing of water inside the SWCNTs seem to take place simultaneously. Water probably becomes unstable inside the SWCNTs when it freezes and is ejected from inside the nanotubes. The wetdry transition temperature increased from 218 to $237 \mathrm{~K}$ with an increasing nanotube diameter from 1.68 to $2.4 \mathrm{~nm}$. This shows that ice-like structures form in nanometer-sized pores of carbonaceous materials and may serve as ice nuclei for cubic or hexagonal ice.

\section{D2 $\operatorname{Snomax}^{\mathrm{TM}}$ and bacteria}

A good summary of ice nucleation studies performed with Snomax $^{\mathrm{TM}}$ and ice-active living bacteria is presented in Hoose and Möhler (2012). All studies performed with living bacteria explored immersion mode ice nucleation and found freezing temperatures between 252 and $271 \mathrm{~K}$. Ice nucleation properties of Snomax ${ }^{\mathrm{TM}}$ have been studied in immersion and deposition mode. Möhler et al. (2008b) investigated the IN activities of the bacterial strains Pseudomonas syringae, Pseudomonas viridiflava, and Erwinia herbicola bacterial species and of Snomax ${ }^{\mathrm{TM}}$ in the AIDA cloud chamber. In the investigated temperature range between -5 and $-15^{\circ} \mathrm{C}$ the bacterial cells and Snomax ${ }^{\mathrm{TM}}$ needed water saturation to act as heterogeneous ice nuclei either in the condensation or the immersion mode. The size distribution of the Snomax ${ }^{\mathrm{TM}}$ aerosol revealed a bimodal distribution of an almost monodisperse peak of intact cells with diameters around $0.8 \mu \mathrm{m}$ and a polydisperse mode of smaller particles with diameters between about 0.01 and $0.5 \mu \mathrm{m}$, probably composed of cell fragments. Chernoff and Bertram (2010) measured ice nucleation onset values between 110 and $120 \%$ at temperatures ranging from 234 to $247 \mathrm{~K}$ for $\operatorname{Snomax}^{\mathrm{TM}}$ deposited onto a hydrophobic substrate. The Snomax ${ }^{\mathrm{TM}}$ particles had average sizes of 6-7 $\mu \mathrm{m}$ and were most likely agglomerates of several Snomax ${ }^{\mathrm{TM}}$ cells and/or cell fragments. Covering the Snomax ${ }^{\mathrm{TM}}$ particles with a sulfuric acid coating with an estimated weight fraction of $0.17 \mathrm{did}$ not change their ice nucleation ability. Similar ice nucleation thresholds of $\mathrm{RH}_{\mathrm{i}}=120 \%$ at $247 \mathrm{~K}$ have also been observed by Jones et al. (2011) and Kanji et al. (2011). Interestingly, these freezing conditions in terms of water activity and temperature align with the ones found by Koop and Zobrist (2009) for immersion freezing of solution droplets containing Snomax ${ }^{\mathrm{TM}}$, as shown in Fig. 5a of Hoose and Möhler (2012).

Snomax $^{\text {TM }}$ is used in artificial snow making with spray guns and produced from strain Pseudomonas syringae 31R1 grown under conditions (proprietary information) to maximize the ice nucleation activity (Möhler et al., 2008b). The 
product is obtained by the culturing of the bacterial cells, which are then centrifuged, frozen, lyophilisated, exposed to $\gamma$ radiation and pressed into pellets consisting of bacteria cells, cell debris and a dried culture medium (Lagriffoul et al., 2010; Koop and Zobrist, 2009). The pellets are predominantly composed of proteins (30 to $50 \%$ ), carbohydrates (15\%), nucleic acids (10 to $11 \%$ ), metals (5 to $9 \%$ ) with alkaline earth salts $(\mathrm{Ca}, \mathrm{Fe}, \mathrm{K}, \mathrm{Mg}, \mathrm{Na}$ and $\mathrm{P})$ and transition metals ( $\mathrm{Zn}, \mathrm{Mn}, \mathrm{Cu}$, and Ni) (Lagriffoul et al., 2010).

A protein is responsible for the ice nucleation activity of Pseudomonas syringae. This protein is located on the outer membrane of the bacterium, with monomers of about 150 $\mathrm{KDa}$ (Lagriffoul et al., 2010). It contains a central repetitive region (around 1000 amino acids), which shows a close lattice match with ice and seems essential in the ice-producing activity (Kajava and Lindow, 1993). The protein monomers can bind together on the cell membrane to form larger ice nucleation sites. The ice nucleation temperature increases with increasing number of monomers building up the nucleation sites. This clearly defines the ice nucleation site of Snomax $^{\mathrm{TM}}$ as an extended surface. Pores should therefore not be involved in ice nucleation on Snomax ${ }^{\mathrm{TM}}$ particles. Considering the almost equal shares of proteins $(30-50 \%)$ and soluble components ( $25 \%$ carbohydrates and nucleic acids) contained in Snomax ${ }^{\mathrm{TM}}$ pellets, the Snomax particles should indeed possess a thick water soluble coating that takes up water when relative humidity is increased. The ice nucleating proteins should therefore be totally immersed in an aqueous solution and induce ice nucleation in immersion mode below water saturation. This would explain the agreement in terms of $\mathrm{RH}_{\mathrm{i}} / a_{\mathrm{w}}$ and the temperature of the deposition freezing conditions reported by Chernoff and Bertram (2010) and Jones et al. (2011), and the immersion freezing conditions observed by Koop and Zobrist (2009) shown in Fig. 5a of Hoose and Möhler (2012). Moreover, the fact that the sulfuric acid coating applied by Chernoff and Bertram (2010) did not influence the freezing behavior of Snomax ${ }^{\mathrm{TM}}$ particles is a further indication that the soluble material present in the pellets is sufficient for a full coating with an aqueous solution. In this case ice nucleation on Snomax ${ }^{\mathrm{TM}}$ would also occur by an immersion freezing mechanism in the reported cases of deposition freezing (Chernoff and Bertram, 2010; Jones et al., 2011; Kanji et al., 2011).

\section{D3 Glassy aerosols}

Different studies have shown that glassy aerosols nucleate ice heterogeneously, however, with a low activated fraction. Murray et al. (2010b) and Wilson et al. (2012) found in AIDA cloud chamber experiments that citric acid, raffinose, 4-hydroxy-3-methoxy-DL-mandelic acid, and levoglucosan aerosols nucleate ice heterogeneously when they were in a glassy state. Heterogeneous ice nucleation started typically in the range $120-140 \% \mathrm{RH}_{\mathrm{i}}$ and continued gradually until homogeneous nucleation set in. Typically, the fraction of aerosol particles that nucleated ice heterogeneously increased slowly with increasing $\mathrm{RH}_{\mathrm{i}}$ up to values of 0.003 . Secondary organic aerosol generated from the oxidation of naphtalene with $\mathrm{OH}$ radicals and investigated on a hydrophobically coated substrate started to nucleate ice at $\mathrm{RH}_{\mathrm{i}} 10-$ $15 \%$ below the homogeneous ice nucleation limit of solution droplets (Wang et al., 2012). Similarly, a small fraction $(0.01-0.2 \%)$ of humic acid reference samples (Suwannee River standard fulvic acid and leonardite) had the ability to nucleate ice heterogeneously (Wang and Knopf, 2011; Kanji et al., 2008). Further analysis showed that these aerosols were indeed in a glassy state. Therefore, heterogeneous ice nucleation seems to be a general feature of glassy aerosols, but occurs only on a small subset of these particles. Zobrist et al. (2008b) predicted that the smooth convex surfaces of glassy aerosols would be unsuitable for nucleating ice heterogeneously. However, experimental evidence suggests that some glassy particles have special properties that render them active as IN. These properties might be cracks or slits that absorb water below water saturation by capillary forces. If this is the case, drying and/or cooling conditions during vitrification might be decisive for the fraction of particles that act as IN, since they influence the probability of cracking or splitting of particles. However, since no detailed characterization of the surfaces of glassy aerosols is available, a direct relationship between pores and ice nucleation ability of particles is not possible.

\section{D4 Volcanic ash}

Heterogeneous ice nucleation on volcanic ash samples has been mostly investigated in immersion mode at temperatures above $250 \mathrm{~K}$. Based on a review of literature values and their own measurements, Durant et al. (2008) suggested that fine-ash particles $(1-1000 \mu \mathrm{m})$ from the majority of volcanoes exhibit immersion freezing onsets between $250 \mathrm{~K}$ and $260 \mathrm{~K}$. Hoyle et al. (2011) and Steinke et al. (2011) investigated heterogeneous freezing on an ash sample collected on 15 April 2010, at a distance of $58 \mathrm{~km}$ from the eruption of the Icelandic volcano Eyjafjallajökull. This ash sample can be regarded as representative of material produced in most volcanic eruptions involving explosive interaction with an external water source (Hoyle et al., 2011). ESEM images (Steinke et al., 2011) of the volcanic ash revealed particles with relatively sharp edges, with smaller particles being attached to the particle's surface and also particles consisting of several small particles (with sizes of $\sim 0.2 \mu \mathrm{m}$ ). The most abundant components were silicates along with aluminium oxide. The sulfate content was low (approximately $0.1 \mathrm{~g}$ per $\mathrm{kg}$ of ash mass). Hoyle et al. (2011) investigated ice nucleation of this sample with a cutoff diameter $<1 \mu \mathrm{m}$ at $\mathrm{RH}_{\mathrm{w}}$ conditions below water saturation at $T=223-248 \mathrm{~K}$ employing the ZINC CFDC and found that the ice nucleation efficiency below water saturation strongly increased for $T<238 \mathrm{~K}$ in accordance with PCF as the prevailing 
ice nucleation mechanism. Steinke et al. (2011) performed AIDA cloud chamber experiments on the same sample, selecting the fraction with diameters between 0.1 and $5 \mu \mathrm{m}$ and a median diameter of $\sim 0.4 \mu \mathrm{m}$. They observed freezing below water saturation at $242 \mathrm{~K}$ and $\mathrm{RH}_{\mathrm{i}}=126 \%$ with a low nucleated fraction so that $\mathrm{RH}_{\mathrm{w}}$ reached water saturation leading to immersion freezing. At around $233 \mathrm{~K}$ ice nucleation onset was observed at $\mathrm{RH}_{\mathrm{i}}=116 \%$ with an ice fraction of $0.1 \%$, and continued, gradually reaching a nucleated fraction of $1 \%$ at $\mathrm{RH}_{\mathrm{i}}=128 \%$. An expansion run performed at around $224 \mathrm{~K}$ showed ice nucleation onset at $\mathrm{RH}_{\mathrm{i}}=105 \%$ with an ice fraction of $0.1 \%$, and a nucleated fraction of $40 \%$ at $\mathrm{RH}_{\mathrm{i}}=117 \%$. This strong increase in ice nucleation activity with decreasing temperature is in line with PCF as the dominating ice nucleation mechanism. Delmelle et al. (2005) performed nitrogen and water vapor adsorption/desorption experiments on six fine-ash samples $(<100 \mu \mathrm{m})$ from different volcanoes. The ash samples had isotherms characteristic of materials with unrestricted monolayer-multilayer adsorption and a low density of pores. The pore size distribution was similar for all samples, with a small peak centered around $5 \mathrm{~nm}$ and comparatively low amounts of pores of larger diameters. They concluded that fine-ash particles collected from different volcanoes have relatively undifferentiated surface textures, irrespective of the chemical composition and eruption type. If we assume a similar pore structure for the ash sample of Eyjafjallajökull, PCF can indeed account for the observed ice nucleation activity at $\mathrm{RH}_{\mathrm{w}}$ below water saturation.

\section{D5 Inorganic salts and dicarboxylic acids}

Inorganic salts and dicarboxylic acids are water-soluble substances that fully dissolve at high dilution and can be crystallized from supersaturated solutions. Therefore, to judge their ice nucleation ability it has to be made sure that they are indeed present in a solid state. If particles of these substances are exposed to water vapor of varying $\mathrm{RH}_{\mathrm{w}}$, their deliquescence and efflorescence properties have to be considered. Numerous studies have been dedicated to the ice nucleation properties of these substances.

Dicarboxylic acids. Zobrist et al. (2006) investigated immersion freezing of emulsified water droplets containing insitu crystallized oxalic, adipic, succinic, phthalic and fumaric acids with a differential scanning calorimeter. Out of these, only the dihydrate of oxalic acid acted as a heterogeneous IN with an increase in freezing temperature of $2 \mathrm{~K}$ compared with homogeneous ice nucleation of solution droplets. Parsons et al. (2004) did not observe any ice formation on saturated 2-40 $\mu \mathrm{m}$ sized particles of C3-C6 dicarboxylic acids when exposed to increasing $\mathrm{RH}_{\mathrm{w}}$ at $T>243 \mathrm{~K}$, rather, the particles underwent deliquescence to form solution droplets. Conversely, Shilling et al. (2006) found that a small fraction of maleic acid particles deposited onto a gold substrate nucleated ice heterogeneously below their deliquescence $\mathrm{RH}_{\mathrm{w}}$ with onset $\mathrm{RH}_{\mathrm{i}}$ ranging from about 1.05 at $220 \mathrm{~K}$ to 1.30 at $190 \mathrm{~K}$. The spray-deposited particles were micrometer-sized (1-10 $\mu \mathrm{m}$ diameter) and contained numerous defects and extensive surface structure. The authors therefore hypothesized that ice nucleation was likely to be initiated at these defect sites. Baustian et al. (2010) observed that the nucleation activity of micrometer-sized glutaric acid particles deposited onto a hydrophobic substrate declined with decreasing temperature from $\mathrm{RH}_{\mathrm{i}}=120 \%$ at $235 \mathrm{~K}$ to $\mathrm{RH}_{\mathrm{i}}=160 \%$ at $218 \mathrm{~K}$. Ice nucleation was highly selective and occurred preferentially on just a few glutaric acid particles in each sample.

Wagner et al. $(2010,2011)$ performed AIDA cloud chamber experiments to investigate the heterogeneous ice nucleation potential of oxalic acid dihydrate. They observed that solid oxalic acid dihydrate aerosols exhibited a remarkably high variability in their ice nucleation ability from very efficient to almost inactive depending on the crystallization conditions of the injected oxalic acid solution droplets. The ice nucleation ability was also dependent on whether the crystallized particles were exposed to preceding droplet activation and evaporation cycles or not. They found that an oxalic acid dihydrate aerosol with diameters of about $800 \mathrm{~nm}$ that had crystallized within $2000 \mathrm{~s}$ from a concentrated oxalic acid solution (62-67 wt \%) at conditions close to ice saturation at $244 \mathrm{~K}$ showed ice nucleation when reaching a threshold ice saturation ratio $\mathrm{RH}_{\mathrm{i}}=103 \%$ at $244 \mathrm{~K}$ and a nucleated fraction of 0.1 at $\mathrm{RH}_{\mathrm{i}}=107 \%$. However, oxalic acid dihydrate particles $(40-120 \mathrm{~nm})$ that were crystallized slowly at $266 \mathrm{~K}$ (within $6.5 \mathrm{~h}$ ) from solution droplets with estimated concentrations of $35 \mathrm{wt} \%$ proved to be a much less efficient IN that nucleated ice close to water saturation at $T=244 \mathrm{~K}$. Experiments performed at $244 \mathrm{~K}$ with sodium oxalate particles $(400 \mathrm{~nm})$ formed by immediate crystallization at $244 \mathrm{~K}$ led to very few ice crystals before water saturation was reached and a dense cloud of water droplets formed. With droplet cloud formation, a clear and continuous increase in the ice particle number concentrations was monitored, showing that sodium oxalate was not completely dissolved during CCN activation and subsequent droplet growth. Directly after the evaporation of the cloud droplets, an ice nucleation event occurred on the recrystallized sodium oxalate particles. In a succeeding expansion run the modified sodium oxalate crystals acted as efficient ice nuclei in the deposition mode with $\mathrm{RH}_{\mathrm{i}}=106 \%$ and a nucleated fraction of 0.07. Kanji et al. (2008) investigated the ice formation on micrometer-sized oxalic acid dihydrate particles deposited as a dilute aqueous solution onto a Teflon-coated, copper cold stage at $233 \mathrm{~K}$ and crystallized under dry conditions. These particles nucleated ice at $\mathrm{RH}_{\mathrm{i}}=110-125 \%$.

Wagner et al. (2010) hypothesize that the discrepancy in the ice nucleation ability between the various experiments is caused by differences in the crystal structure and morphology of the particles. Rapid crystallization could lead to the formation of a surface microstructure with numerous defects like 
cracks, steps, or dislocations, in which water can condense and freeze. The slow growth of oxalic acid dihydrate crystals from less supersaturated oxalic acid solution droplets lead to a more regular surface microstructure with fewer defects.

Ammonium sulfate (AS). A compilation of results for ammonium sulfate (AS) can be found in Hoose and Möhler (2012). Ammonium sulfate has been investigated by Zuberi et al. (2001) in immersion mode using optical microscopy and differential scanning calorimetry. They found a large variability of ice nucleation activity depending on the way the freezing/cooling cycles were performed and on the resulting morphologies of the AS crystals. If the crystallized solid was in the form of microcrystals, the heterogeneous ice-freezing temperature was close to the eutectic temperature and the critical saturation with respect to ice was close to 1 . However, if the solid was in the form of one or two large crystals, the heterogeneous freezing temperature was close to the homogeneous freezing temperature. Shilling et al. (2006) found that spray-deposited solid ammonium sulfate particles on a gold substrate nucleated ice at saturation ratios ranging from $\mathrm{RH}_{\mathrm{i}}=142 \pm 4 \%$ at $190 \mathrm{~K}$ to $\mathrm{RH}_{\mathrm{i}}=104 \pm 5 \%$ at $240 \mathrm{~K}$, with an estimated nucleated fraction of 1 in $10^{5}$ particles at $240 \mathrm{~K}$. The investigated particles $(1-10 \mu \mathrm{m}$ in diameter) were polycrystalline and contained a significant number of defects. An aqueous AS solution might form and freeze in these defects. Baustian et al. (2010) observed ice nucleation of micrometer-sized AS particles deposited onto a hydrophobic substrate for freezing temperatures between $214 \mathrm{~K}$ and $235 \mathrm{~K}$ at an average ice saturation ratio $\mathrm{RH}_{\mathrm{i}}=110 \pm 7 \%$. Relative humidity measured at the onset of ice formation ranged from 61 to $78 \%$, which is below the deliquescence $\mathrm{RH}_{\mathrm{w}}$ of AS. Ice nucleation was highly selective and occurred preferentially on just a few ammonium sulfate particles. Optical images of the solid ammonium sulfate particles revealed rough surfaces. Wise et al. (2010) investigated ice nucleation on AS particles with typical diameters close to $5 \mu \mathrm{m}$ that were deposited onto a hydrophobic substrate using an atomizer. At $235 \mathrm{~K}$, ice nucleated on a small fraction of dry particles while other particles deliquesced. For temperatures between 220 and $230 \mathrm{~K}$ ice nucleation on solid AS particles occurred at $\mathrm{RH}_{\mathrm{i}}$ of approximately $110 \%$. In contrast to the findings of Baustian et al. (2010), the same particle did not nucleate ice twice if ice nucleation experiments were repeated. One can therefore conclude that a nucleation mechanism by direct deposition of water molecules from the gas phase is unlikely. Rather, ice nucleation starts from an aqueous AS solution that gathers in pores or at steps when crystallization during efflorescence was not complete.

Silver iodide (AgI). The maximum temperature at which silver iodide particles serve as IN is $\sim 269 \mathrm{~K}$ for particles one micron in diameter, and $265 \mathrm{~K}$ for particles $10 \mathrm{~nm}$ in diameter. Ice formation below water saturation was observed to be a relatively inefficient process. DeMott (1995) measured $1 \%$ activation at water saturation at $253 \mathrm{~K}$ for AgI$\mathrm{AgCl}$ aerosols of sizes typically generated for cloud modifi- cation. Detwiler and Vonnegut (1981) observed $\mathrm{RH}_{\mathrm{i}}=106 \%$ at $257 \mathrm{~K}$ to $123 \%$ at $206 \mathrm{~K}$ for activated fractions of $1 \%$ of AgI particles with estimated diameters of $100 \mathrm{~nm}$ generated from a ventilated hot wire. However, for ice nucleation at $257 \mathrm{~K}$ water saturation was needed and the ice particles probably formed by a condensation freezing process. Schaller and Fukuta (1979) found ice nucleation below water saturation at $\mathrm{RH}_{\mathrm{i}}<110 \%$ for nucleated fractions of $6.4 \%$ at $T=261-$ $248 \mathrm{~K}$ for AgI particles with diameters of $\sim 300 \mathrm{~nm}$ generated from a smoke.

The unit cells of AgI and ice are the same to within approximately one percent. Vonnegut (1947) considered this close match as the reason for the ice nucleation ability of $\mathrm{AgI}$ and postulated that ice nucleation can be attributed to an epitactic effect. However, closer investigation showed that only a small fraction of the AgI surface is active as IN. Anderson and Hallett (1976) observed by microscopy that nucleation of ice crystals on large cleaved crystals of solutiongrown AgI reproducibly formed at specific nucleation sites. Several groups investigated water adsorption isotherms of AgI (Tcheurekdjian et al., 1964; Corrin and Nelson, 1968; Bassett et al., 1970; Barchet and Corrin, 1972), revealing that the AgI surface is largely hydrophobic with isolated hydrophilic sites. Barchet and Corrin (1972) assumed that water vapor, which distributed patchwise on the AgI surface, forms the foundations for nucleation embryos, while the remainder of the silver iodide surface is relatively inactive in the adsorption process and that the presence of a liquid-like film at $T>263 \mathrm{~K}$ is supposed to inhibit direct nucleation of ice from the vapor. Tcheurekdjian et al. (1964) related the hydrophilic patches to hygroscopic impurities mostly located in geometrical heterogeneous locations such as steps. This notion is in accordance with the observation that the surface of "pure" silver iodide is a poor ice nucleant, while the surface of contaminated silver iodide differs markedly in its interaction with water vapor and is an excellent ice nucleant (Corrin and Nelson, 1968).

Acknowledgements. The author thanks T. Peter, U. Lohmann and $\mathrm{U}$. Krieger for reading of the manuscript and helpful discussions.

Edited by: O. Möhler

\section{References}

Alba-Simionesco, C., Coasne, B., Dosseh, G., Dudziak, G., Gubbins, K. E., Radhakrishnan, R., and Sliwinska-Bartkowiak, M.: Effects of confinement on freezing and melting, J. Phys.Condens. Mat., 18, R15-R68, doi:10.1088/0953-8984/18/6/R01, 2006.

Anderson, B. J. and Hallett, J.: Supersaturation and time dependence of ice nucleation from the vapor on single crystal substrates, J. Atmos. Sci., 33, 822-832, doi:10.1175/15200469(1976)033<0822:SATDOI>2.0.CO;2, 1976. 
Archuleta, C. M., DeMott, P. J., and Kreidenweis, S. M.: Ice nucleation by surrogates for atmospheric mineral dust and mineral dust/sulfate particles at cirrus temperatures, Atmos. Chem. Phys., 5, 2617-2634, doi:10.5194/acp-5-2617-2005, 2005.

Avila, A., Queralt-Mitjans, I., and Alarcon, M.: Mineralogical composition of African dust delivered by red rains over northeastern Spain, J. Geophys. Res, 102, 21977-21996, doi:10.1029/97JD00485, 1997.

Aylmore, L. A. G.: Gas sorption in clay mineral systems, Clay. Clay Miner., 22, 175-183, doi:10.1346/CCMN.1974.0220205, 1974.

Aylmore, L. A. G. and Quirk, J. P.: The micropore size distributions of clay mineral systems, J. Soil Sci., 18, 1-17, 1967.

Bailey, M. and Hallett, J.: Nucleation effects on the habit of vapour grown ice crystals from -18 to $-42{ }^{\circ} \mathrm{C}$, Q. J. Roy. Meteor. Soc., 128, 1461-1483, doi:10.1256/00359000260247318, 2002.

Bang, J. J., Guerrero, P. A., Lopez, D. A., Murr, L. E., and Esquivel, E. V.: Carbon nanotubes and other fullerene nanocrystals in domestic propane and natural gas combustion streams, J. Nanosci. Nanotechno., 4, 716-718, doi:10.1166/jnn.2004.095, 2004.

Barchet, W. R. and Corrin M. L.: Water vapor adsorption by pure silver iodide above ice saturation, J. Phys. Chem., 76, 22802285, doi:10.1021/j100660a018, 1972.

Bartels-Rausch, T., Bergeron, V., Cartwright, J. H. E., Escribano, R., Finney, J. L., Grothe, H., Gutiérrez, P. J., Haapala, J., Kuhs, W. F., Petterson, J. B. C., Price, S. D., Sainz-Díaz, C. I., Stokes, D. J., Strazzulla, G., Thomson, E. S., Trinks, H., and Uras-Aytemiz, N.: Ice structures, patterns, and processes: A view across the icefields, Rev. Mod. Phys., 84, 885-944, doi:10.1103/RevModPhys.84.885, 2012.

Bassett, D. R., Boucher, E. A., and Zettlemoyer, A. C.: Adsorption studies on ice-nucleating substrates. Hydrophobed silicas and silver iodide, J. Colloid Interf. Sci., 34, 436-446, doi:10.1016/0021-9797(70)90203-1, 1970.

Baustian, K. J., Wise, M. E., and Tolbert, M. A.: Depositional ice nucleation on solid ammonium sulfate and glutaric acid particles, Atmos. Chem. Phys., 10, 2307-2317, doi:10.5194/acp-10-23072010, 2010.

Beck, J. S., Vartuli, J. C., Roth, W. J., Leonowicz, M. E., Kresge, C. T., Schmitt, K. D., Chu C. T.-W., Olson, D. H., Sheppard, E. W. McCullen, S. B., Higgins, J. B., and Schlenker, J. L.: A new family of mesoporous molecular sieves prepared with liquid crystal templates, J. Am. Chem. Soc., 114, 10834-10843, doi:10.1021/ja00053a020, 1992.

Benz, S., Megahed, K., Möhler, O., Saathoff, H., Wagner, R., and Schurath, U.: T-dependent rate measurements of homogeneous ice nucleation in cloud droplets using a large atmospheric simulation chamber, J. Photoch. Photobio. A, 176, 208-217, doi:10.1016/j.jphotochem.2005.08.026, 2005.

Bigg, E. K.: The supercooling of water, P. Phys. Soc. Lond. B, 66, 688-694 doi:10.1088/0370-1301/66/8/309, 1953.

Blanco, A., Dee Tomasi, F., Filippo, E., Manno, D., Perrone, M. R., Serra, A., Tafuro, A. M., and Tepore, A.: Characterization of African dust over southern Italy, Atmos. Chem. Phys., 3, 21472159, doi:10.5194/acp-3-2147-2003, 2003.

Broadley, S. L., Murray, B. J., Herbert, R. J., Atkinson, J. D., Dobbie, S., Malkin, T. L., Condliffe, E., and Neve, L.: Immersion mode heterogeneous ice nucleation by an illite rich powder representative of atmospheric mineral dust, Atmos. Chem. Phys., 12, 287-307, doi:10.5194/acp-12-287-2012, 2012.
Bundke, U., Nillius, B., Jaenicke, R., Wetter, T., Klein, H., and Bingemer, H.: The fast Ice Nucleus chamber FINCH, Atmos. Res., 90, 180-186, doi:10.1016/j.atmosres.2008.02.008, 2008.

Cakmur, R. V., Miller, R. L., Perlwitz, J., Geogdzhayev, I. V., Ginoux, P., Koch, D., Kohfeld, K. E., Tegen, I., and Zender, C. S.: Constraining the magnitude of the global dust cycle by minimizing the difference between a model and observations, J. Geophys. Res., 111, D06207, doi:10.1029/2005jd005791, 2006.

Chernoff, D. I. and Bertram, A. K.: Effects of sulfate coatings on the ice nucleation properties of a biological ice nucleus and several types of minerals, J. Geophys. Res., 115, D20205, doi:10.1029/2010JD014254, 2010.

Christenson, H. K.: Confinement effects on freezing and melting, J. Phys.-Condens. Mat., 13, R95-R133, doi:10.1088/09538984/13/11/201, 2001.

Christenson, H. K.: Two-step crystal nucleation via capillary condensation, CrystEngComm, 15, 2030-2039, doi:10.1039/c3ce26887j, 2013.

Churchman, G. J., Davy, T. J., Aylmore, L. A. G., Gilkes, R. J., and Self, P. G.: Characteristics of fine pores in some halloysites, Clay Miner., 30, 89-98, 1995.

Connolly, P. J., Möhler, O., Field, P. R., Saathoff, H., Burgess, R., Choularton, T., and Gallagher, M.: Studies of heterogeneous freezing by three different desert dust samples, Atmos. Chem. Phys., 9, 2805-2824, doi:10.5194/acp-9-2805-2009, 2009.

Corrin, M. L. and Nelson, J. A.: Energetics of the adsorption of water vapor on "pure" silver iodide. J. Phys. Chem., 72, 643645, doi:10.1021/j100848a043, 1968.

Crawford, I., Möhler, O., Schnaiter, M., Saathoff, H., Liu, D., McMeeking, G., Linke, C., Flynn, M., Bower, K. N., Connolly, P. J., Gallagher, M. W., and Coe, H.: Studies of propane flame soot acting as heterogeneous ice nuclei in conjunction with single particle soot photometer measurements, Atmos. Chem. Phys., 11, 9549-9561, doi:10.5194/acp-11-9549-2011, 2011.

Cziczo, D. J., Froyd, K. D., Gallavardin, S. J., Möhler, O., Benz, S., Saathoff, H., and Murphy, D. M.: Deactivation of ice nuclei due to atmospherically relevant surface coatings, Environ. Res. Lett., 4, 044013, doi:10.1088/1748-9326/4/4/044013, 2009.

Cziczo, D. J., Froyd, K. D., Hoose, C., Jensen, E. J., Diao, M., Zondlo, M. A., Smith J. B., Twohy, C. H., and Murphy, D. M.: Clarifying the dominant sources and mechanisms of cirrus cloud formation, Science, 340, 1320-1324, 2013.

De Boer, J. H.: The shapes of capillaries, in: The structure and properties of porous materials, Butterworths, London, p. 68, 1958.

Delmelle, P., Villiéras, F., and Pelletier, M.: Surface area, porosity and water adsorption properties of fine volcanic ash particles, B. Volcanol., 67, 160-169, doi:10.1007/s00445-004-0370-x, 2005.

DeMott, P. J.: Quantitative descriptions of ice formation mechanisms of silver iodide-type aerosols, Atmos. Res., 38, 63-99, doi:10.1016/0169-8095(94)00088-U, 1995.

DeMott, P. J., Chen, Y., Kreidenweis, S. M., Rogers, D. C., and Sherman, D. E.: Ice formation by black carbon particles, Geophys. Res. Lett., 26, 2429-2432, doi:10.1029/1999GL900580, 1999.

DeMott, P. J., Sassen, K., Poellot, M. R., Baumgardner, D., Rogers, D. C., Brooks, S. D., Prenni, A. J., and Kreidenweis, S. M.: African dust aerosols as atmospheric ice nuclei, Geophys. Res. Lett., 30, 1732, doi:10.1029/2003GL017410, 2003a. 
DeMott, P. J., Cziczo, D. J., Prenni, A. J., Murphy, D. M., Kreidenweis, S. M., Thomson, D. S., Borys, R., and Rogers, D. C.: Measurements of the concentration and composition of nuclei for cirrus formation, P. Natl. Acad. Sci. USA, 100, 14655-14660, doi:10.1073/pnas.2532677100, 2003b.

DeMott, P. J., Prenni, A. J., Liu, X., Kreidenweis, S. M., Petters, M. D., Twohy, C. H., Richardson, M. S., Eidhammer, T., and Rogers, D. C.: Predicting global atmospheric ice nuclei distributions and their impacts on climate, P. Natl. Acad. Sci. USA, 107, 1121711222, doi:10.1073/pnas.0910818107, 2010.

DeMott, P. J., Möhler, O., Stetzer, O., Vali, G., Levin, Z., Petters, M. D., Murakami, M., Leisner, T., Bundke, U., Klein, H., Kanji, Z. A., Cotton, R., Jones, H., Benz, S., Brinkmann, M., Rzesanke, D., Saathoff, H., Nicolet, M., Saito, A., Nillius, B., Bingemer, H., Abbatt, J., Ardon, K., Ganor, E., Georgakopoulos, D. G., and Saunders, C.: Resurgence in ice nuclei measurement research, B. Am. Meteorol. Soc., 92, 1623-1635, doi:10.1175/2011BAMS3119.1, 2011.

Denoyel, R. and Pellenq, R. J. M.: Simple phenomenological models for phase transitions in a confined geometry. 1: Melting and solidification in a cylindrical pore, Langmuir, 18, 2710-2716, doi:10.1021/la015607n, 2002.

Deschamps, J., Audonnet, F., Brodie-Linder, N., Schoeffel, M., and Alba-Simionesco, C.: A thermodynamic limit of the melting/freezing processes of water under strongly hydrophobic nanoscopic confinement, Phys. Chem. Chem. Phys., 12, 14401443, doi:10.1039/b920816j, 2010.

Detwiler, A. G. and Vonnegut, B.: Humidity required for ice nucleation from the vapor onto silver iodide and lead iodide aerosols over the temperature range -6 to $-67^{\circ} \mathrm{C}$, J. Appl. Meteorol., 20, 1006-1012, doi:10.1175/15200450(1981)020<1006:HRFINF>2.0.CO;2, 1981.

Diamond, S.: Pore size distributions in clays, 18, Clay. Clay Miner., 7-23, doi:10.1346/CCMN.1970.0180103, 1970.

Dore, J.: Structural studies of water in confined geometry by neutron diffraction, Chem. Phys., 258, 327-347, doi:10.1016/S03010104(00)00208-1, 2000.

Duft, D. and Leisner, T.: Laboratory evidence for volumedominated nucleation of ice in supercooled water microdroplets, Atmos. Chem. Phys., 4, 1997-2000, doi:10.5194/acp-4-19972004, 2004.

Durant, A. J., Shaw, R. A., Rose, W. I., Mi, Y., and Ernst, G. G. J.: Ice nucleation and overseeding of ice in volcanic clouds, J. Geophys. Res., 113, D09206, doi:10.1029/2007JD009064, 2008.

Dymarska, M., Murray, B. J., Sun, L., Eastwood, M. L., Knopf, D. A., and Bertram, A. K.: Deposition ice nucleation on soot at temperatures relevant for the lower troposphere, J. Geophys. Res., 111, D04204, doi:10.1029/2005JD006627, 2006.

Eastwood, M. L., Cremel, S., Gehrke, C., Girard, E., and Bertram, A. K.: Ice nucleation on mineral dust particles: Onset conditions, nucleation rates and contact angles, J. Geophys. Res., 113, D22203, doi:10.1029/2008JD010639, 2008.

Eastwood, M. L., Cremel, S., Wheeler, M., Murray, B. J., Girard, E., and Bertram, A. K.: Effects of sulfuric acid and ammonium sulfate coatings on the ice nucleation properties of kaolinite particles, Geophys. Res. Lett., 36, L02811, doi:10.1029/2008GL035997, 2009.
Engelstaedter, S., Tegen, I., and Washington, R.: North African dust emissions and transport, Earth-Sci. Rev., 79, 73-100, doi:10.1016/j.earscirev.2006.06.004, 2006.

Faivre, C., Bellet, D., and Dolino, G.: Phase transitions of fluids confined in porous silicon: A differential calorimetry investigation, Eur. Phys. J. B, 7, 19-36, doi:10.1007/s100510050586, 1999.

Falkovich, A. H., Ganor, E., Levin, Z., Formenti, P., and Rudich, Y.: Chemical and mineralogical analysis of individual mineral dust particles, J. Geophys. Res., 106, 18029-18036, doi:10.1029/2000jd900430, 2001.

Field, P. R., Möhler, O., Connolly, P., Krämer, M., Cotton, R., Heymsfield, A. J., Saathoff, H., and Schnaiter, M.: Some ice nucleation characteristics of Asian and Saharan desert dust, Atmos. Chem. Phys., 6, 2991-3006, doi:10.5194/acp-6-2991-2006, 2006.

Findenegg G. H., Jähnert, S., Akcakayiran D., and Schreiber, A.: Freezing and melting of water confined in silica nanopores, Chem. Phys. Chem., 9, 2651-2659, doi:10.1002/cphc.200800616, 2008.

Fletcher, N. H.: Active sites and ice crystal nucleation, J. Atmos. Sci., 26, 1266-1271, doi:10.1175/15200469(1969)026<1266:ASAICN>2.0.CO;2, 1969.

Formenti, P., Schütz, L., Balkanski, Y., Desboeufs, K., Ebert, M., Kandler, K., Petzold, A., Scheuvens, D., Weinbruch, S., and Zhang, D.: Recent progress in understanding physical and chemical properties of African and Asian mineral dust, Atmos. Chem. Phys., 11, 8231-8256, doi:10.5194/acp-11-8231-2011, 2011.

Foster, A. G.: The sorption of condensible vapours by porous solids. Part I. The applicability of capillary theory, T. Faraday Soc., 28, 645-657, doi:10.1039/tf9322800645, 1932.

Friedman, B., Kulkarni, G., Beránek, J., Zelenyuk, A., Thornton, J. A., and Cziczo, D. J.: Ice nucleation and droplet formation by bare and coated soot particles, J. Geophys. Res., 116, D17203, doi:10.1029/2011JD015999, 2011.

Fukuta, N.: Activation of atmospheric particles as ice nuclei in cold and dry air, J. Atmos. Sci., 23, 741-750, doi:10.1175/15200469(1966)023<0741:AOAPAI>2.0.CO;2, 1966.

Gallavardin, S. J., Froyd, K. D., Lohmann, U., Moehler, O., Murphy, D. M., and Cziczo, D. J.: Single particle laser mass spectrometry applied to differential ice nucleation experiments at the AIDA chamber, Aerosol Sci. Tech., 42, 773-791, doi:10.1080/02786820802339538, 2008.

Ganor, E.: The composition of clay minerals transported to Israel as indicators of Saharan dust emission, Atmos. Environ., 25A, 2657-2664, doi:10.1016/0960-1686(91)90195-D, 1991.

Grassian, V. H.: Chemical reactions of nitrogen oxides on the surface of oxide, carbonate, soot, and mineral dust particles: implications for the chemical balance of the troposphere, J. Phys. Chem. A, 106, 860-877, doi:10.1021/jp012139h, 2002.

Gustafsson, R. J., Orlov, A., Badger, C. L., Griffiths, P. T., Cox, R. A., and Lambert, R. M.: A comprehensive evaluation of water uptake on atmospherically relevant mineral surfaces: DRIFT spectroscopy, thermogravimetric analysis and aerosol growth measurements, Atmos. Chem. Phys., 5, 3415-3421, doi:10.5194/acp-5-3415-2005, 2005.

Hansen, E. W., Stöcker, M., and Schmidt, R.: Low-temperature phase transition of water confined in mesopores probed by NMR. 
Influence on pore size distribution, J. Phys. Chem., 100, 21952200, doi:10.1021/jp951772y, 1996.

Hoose, C. and Möhler, O.: Heterogeneous ice nucleation on atmospheric aerosols: a review of results from laboratory experiments, Atmos. Chem. Phys., 12, 9817-9854, doi:10.5194/acp-12-98172012, 2012.

Hoose, C., Kristjánsson, J. E., and Burrows, S. M.: How important is biological ice nucleation in clouds on a global scale?, Environ. Res. Lett., 5, 024009, doi:10.1088/1748-9326/5/2/024009, 2010.

Hoyle, C. R., Luo, B. P., and Peter, T.: The origin of high ice crystal number densities in cirrus clouds, J. Atmos. Sci., 62, 2568-2579, doi:10.1175/JAS3487.1, 2005.

Hoyle, C. R., Pinti, V., Welti, A., Zobrist, B., Marcolli, C., Luo, B., Höskuldsson, Á., Mattsson, H. B., Stetzer, O., Thorsteinsson, T., Larsen, G., and Peter, T.: Ice nucleation properties of volcanic ash from Eyjafjallajökull, Atmos. Chem. Phys., 11, 9911-9926, doi:10.5194/acp-11-9911-2011, 2011.

Jähnert, S., Chávez, F. V., Schaumann, G. E., Schreiber, A., Schönhoff, M., and Findenegg, G. H.: Melting and freezing of water in cylindrical silica nanopores, Phys. Chem. Chem. Phys., 10, 6039-6051, doi:10.1039/b809438c, 2008.

Janssen, A. H., Talsma, H., van Steenbergen, M. J., and de Jong, K. P.: Homogeneous nucleation of water in mesoporous zeolite cavities, Langmuir, 20, 41-45, doi:10.1039/b809438c, 2004.

Johari, G. P.: Water's size-dependent freezing to cubic ice, J. Chem. Phys., 122, 194504, doi:10.1063/1.1900723, 2005.

Jones, H. M., Flynn, M. J., DeMott, P. J., and Möhler, O.: Manchester Ice Nucleus Counter (MINC) measurements from the 2007 International workshop on Comparing Ice nucleation Measuring Systems (ICIS-2007), Atmos. Chem. Phys., 11, 53-65, doi:10.5194/acp-11-53-2011, 2011.

Kabath, P., Stöckel, P., Lindinger, A., and Baumgärtel, H.: The nucleation of ice in supercooled $\mathrm{D}_{2} \mathrm{O}$ and $\mathrm{H}_{2} \mathrm{O}$, J. Mol. Liq., 125, 204-211, doi:10.1016/j.molliq.2005.11.025, 2006.

Kajava, A. V. and Lindow, S. E.: A model of the three-dimensional structure of ice nucleation proteins, J. Mol. Biol., 232, 709-717, doi:10.1006/jmbi.1993.1424, 1993.

Kandler, K., Schütz, L., Deutscher, C., Ebert, M., Hofmann, H., Jäckel, S., Jaenicke, R., Knippertz, P., Lieke, K., Massling, A., Petzold, A., Schladizt, A., Weinzierl, B., Wiedensohler, A., Zorn, S., and Weinbruch, S.: Size distribution, mass concentration, chemical and mineralogical composition and derived optical parameters of the boundary layer aerosol at Tinfou, Morocco, during SAMUM, Tellus B, 61, 32-50, doi:10.1111/j.16000889.2008.00385.x, 2009.

Kandler, K., Lieke, K., Benker, N., Emmel, C., Küpper, M., MüllerEbert, D., Ebert, M., Scheuvens, D., Schladitz, A., Schütz, L., and Weinbruch, S.: Electron microscopy of particles collected at Praia, Cape Verde, during the Saharan Mineral Dust Experiment: particle chemistry, shape, mixing state and complex refractive index, Tellus B, 63, 475-496, doi:10.1111/j.16000889.2011.00550.x, 2011a.

Kandler, K., Schütz, L., Jäckel, S., Lieke, K., Emmel, C., MüllerEbert, D., Ebert, M., Scheuvens, D., Schladitz, A., Šegvić, B., Wiedensohler, A., and Weinbruch, S.: Ground-based offline aerosol measurements at Praia, Cape Verde, during the Saharan Mineral Dust Experiment: microphysical properties and mineralogy, Tellus B, 63, 459-474, doi:10.1111/j.16000889.2011.00546.x, 2011b.
Kanji, Z. A. and Abbatt, J. P. D.: Laboratory studies of ice formation via deposition mode nucleation onto mineral dust and n-hexane soot samples, J. Geophys. Res., 111, D16204, doi:10.1029/2005JD006766, 2006.

Kanji, Z. A. and Abbatt, J. P. D.: The University of Toronto continuous flow diffusion chamber (UT-CFDC): A simple design for ice nucleation studies, Aerosol. Sci. Tech., 43, 730-738, doi:10.1080/02786820902889861, 2009.

Kanji, Z. A. and Abbatt, J. P. D.: Ice nucleation onto Arizona Test Dust at cirrus temperatures: Effect of temperature and aerosol size on onset relative humidity, J. Phys. Chem. A, 114, 935-941, doi:10.1021/jp908661m, 2010.

Kanji, Z. A., Florea, O., and Abbatt, J. P. D.: Ice formation via deposition nucleation on mineral dust and organics: dependence of onset relative humidity on total particulate surface area, Environ. Res. Lett., 3, 025004, doi:10.1088/1748-9326/3/2/025004, 2008.

Kanji, Z. A., DeMott, P. J., Möhler, O., and Abbatt, J. P. D.: Results from the University of Toronto continuous flow diffusion chamber at ICIS 2007: instrument intercomparison and ice onsets for different aerosol types, Atmos. Chem. Phys., 11, 31-41, doi:10.5194/acp-11-31-2011, 2011.

Kärcher, B., Möhler, O., DeMott, P. J., Pechtl, S., and Yu, F.: Insights into the role of soot aerosols in cirrus cloud formation, Atmos. Chem. Phys., 7, 4203-4227, doi:10.5194/acp-7-4203-2007, 2007.

Kittaka, S., Ishimaru, S., Kuranishi, M., Matsuda, T., and Yamaguchi, T.: Enthalpy and interfacial free energy changes of water capillary condensed in mesoporous silica, MCM-41 and SBA-15, Phys. Chem. Chem. Phys., 8, 3223-3231, 2006.

Kittaka, S., Ueda, Y., Fujisaki, F., Iiyama, T., and Yamaguchi, T.: Mechanism of freezing of water in contact with mesoporous silicas MCM-41, SBA-15 and SBA-16: role of boundary water of pore outlets in freezing, Phys. Chem. Chem. Phys., 13, 1722217233, doi:10.1039/c1cp21458f, 2011.

Knopf, D. A. and Koop, T.: Heterogeneous nucleation of ice on surrogates of mineral dust, J. Geophys. Res., 111, D12201, doi:10.1029/2005JD006894, 2006.

Knopf, D. A., Wang, B., Laskin, A., Moffet, R. C., and Gilles, M. K.: Heterogeneous nucleation of ice on anthropogenic organic particles collected in Mexico City, Geophys. Res. Lett., 37, L11803, doi:10.1029/2010GL043362, 2010.

Koehler, K. A., Kreidenweis, S. M., DeMott, P. J., Prenni, A. J., and Petters, M. D.: Potential impact of Owens (dry) Lake dust on warm and cold cloud formation, J. Geophys. Res., 112, D12210, doi:10.1029/2007JD008413, 2007.

Koehler, K. A., DeMott, P. J., Kreidenweis, S. M., Popovicheva, O. B., Petters, M. D., Carrico, C. M., Kireeva, E. D., Khokhlova, T. D., and Shonija, N. K.: Cloud condensation nuclei and ice nucleation activity of hydrophobic and hydrophilic soot particles, Phys. Chem. Chem. Phys., 11, 79067920, doi:10.1039/b905334b, 2009.

Koehler, K. A., Kreidenweis, S. M., DeMott, P. J., Petters, M. D., Prenni, A. J., and Möhler, O.: Laboratory investigations of the impact of mineral dust aerosol on cold cloud formation, Atmos. Chem. Phys., 10, 11955-11968, doi:10.5194/acp10-11955-2010, 2010.

Koga, K., Gao, G. T., Tanaka, H., and Zeng, X. C.: Formation of ordered ice nanotubes inside carbon nanotubes, Nature, 412, 802 805, doi:10.1038/35090532, 2001. 
Koop, T. and Zobrist, B.: Parameterizations for ice nucleation in biological and atmospheric systems, Phys. Chem. Chem. Phys., 11, 10839-10850, doi:10.1039/b914289d, 2009.

Koop, T., Luo, B. P., Tsias, A., and Peter, T.: Water activity as the determinant for homogeneous ice nucleation in aqueous solutions, Nature, 406, 611-614, doi:10.1038/35020537, 2000.

Krämer, B., Hübner, O., Vortisch, H., Wöste, L., Leisner, T., Schwell, M., Rühl, E., and Baumgärtel, H.: Homogeneous nucleation rates of supercooled water measured in single levitated microdroplets, J. Chem. Phys., 111, 6521-6527, 1999.

Krämer, M., Schiller, C., Afchine, A., Bauer, R., Gensch, I., Mangold, A., Schlicht, S., Spelten, N., Sitnikov, N., Borrmann, S., de Reus, M., and Spichtinger, P.: Ice supersaturations and cirrus cloud crystal numbers, Atmos. Chem. Phys., 9, 3505-3522, doi:10.5194/acp-9-3505-2009, 2009.

Kulkarni, G. and Dobbie, S.: Ice nucleation properties of mineral dust particles: determination of onset RHi, IN active fraction, nucleation time-lag, and the effect of active sites on contact angles, Atmos. Chem. Phys., 10, 95-105, doi:10.5194/acp-10-95-2010, 2010.

Kulkarni, G., Fan, J., Comstock, J. M., Liu, X., and Ovchinnikov, M.: Laboratory measurements and model sensitivity studies of dust deposition ice nucleation, Atmos. Chem. Phys., 12, 72957308, doi:10.5194/acp-12-7295-2012, 2012.

Kumar, P., Jasra, R. V., and Bhat, T. S. G.: Evolution of porosity and surface acidity in montmorillonite clay on acid activation, Ind. Eng. Chem. Res., 34, 1440-1448, doi:10.1021/ie00043a053, 1995.

Kyakuno, H., Matsuda, K., Yahiro, H., Inami, Y., Fukuoka, T., Miyata,Y., Yanagi, K., Maniwa, Y., Kataura, H., Saito, T., Yumura, M., and Iijima, S.: Confined water inside single-walled carbon nanotubes: Global phase diagram and effect of finite length, J. Chem. Phys. 134, 244501, doi:10.1063/1.3593064, 2011.

Lagriffoul, A., Boudenne, J. L., Absi, R., Ballet, J. J., Berjeaud, J. M., Chevalier, S., Creppy, E. E, Gilli, E., Gadonna, J. P., Gadonna-Widehem, P., Morris, C. E., and Zini, S.: Bacterialbased additives for the production of artificial snow: What are the risks to human health?, Sci. Total. Environ., 408, 1659-1666, doi:10.1016/j.scitotenv.2010.01.009, 2010.

Li, T., Donadio, D., Russo, G., and Galli, G.: Homogeneous ice nucleation from supercooled water, Phys. Chem. Chem. Phys., 13, 19807-19813, doi:10.1039/c1cp22167a, 2011.

Liu, E., Dore, J. C., Webber, J. B. W., Khushalani, D., Jähnert, S., Findenegg, G. H., and Hansen, T.: Neutron diffraction and NMR relaxation studies of structural variation and phase transformations for water/ice in SBA-15 silica: I. The over-filled case, J. Phys.-Condens. Mat., 18, 10009-10028, doi:10.1088/09538984/18/44/003, 2006.

Liu, J., Nicholson, C. E., and Cooper, S. J.: Direct measurement of critical nucleus size in confined volumes, Langmuir, 23, 72867292, doi:10.1021/la063650a, 2007.

Lüönd, F., Stetzer, O., Welti, A., and Lohmann, U.: Experimental study on the ice nucleation ability of size-selected kaolinite particles in the immersion mode, J. Geophys. Res., 115, D14201, doi:10.1029/2009JD012959, 2010.

Majewski, J., Margulis, L., Weissbuch, I., Popovitz-Biro, R., Arad, T., Talmon, Y., Lahav, M., and Leiserowitz, L.: Electronmicroscopy studies of amphiphilic self-assemblies on vitreous ice, Adv. Mater., 7, 26-35, doi:10.1002/adma.19950070104, 1995.

Mangold, A., Wagner, R., Saathoff, H., Schurath, U., Giesemann, C., Ebert, V., Krämer, M., and Möhler, O.: Experimental investigation of ice nucleation by different types of aerosols in the aerosol chamber AIDA: implications to microphysics of cirrus clouds, Meteorol. Z., 14, 485-497, doi:10.1127/09412948/2005/0053, 2005.

Maniwa, Y., Kataura, H., Abe, M., Udaka, A., Suzuki, S., Achiba, Y., Kira, H., Matsuda, K., Kadowaki, H., and Okabe, Y.: Ordered water inside carbon nanotubes: formation of pentagonal to octagonal ice-nanotubes, Chem. Phys. Lett., 401, 534-538, doi:10.1016/j.cplett.2004.11.112, 2005.

Marcolli, C., Gedamke, S., Peter, T., and Zobrist, B.: Efficiency of immersion mode ice nucleation on surrogates of mineral dust, Atmos. Chem. Phys., 7, 5081-5091, doi:10.5194/acp-7-50812007, 2007.

Möhler, O., Büttner, S., Linke, C., Schnaiter, M., Saathoff, H., Stetzer, O., Wagner, R., Krämer, M., Mangold, A., Ebert, V., and Schurath, U.: Effect of sulfuric acid coating on heterogeneous ice nucleation by soot aerosol particles, J. Geophys. Res., 110, D11210, doi:10.1029/2004JD005169, 2005a.

Möhler, O., Linke, C., Saathoff, H., Schnaiter, M.,Wagner, R., Mangold, A., Krämer, M., and Schurath, U.: Ice nucleation on flame soot aerosol of different organic carbon content, Meteorol. Z., 14, 477-484, doi:10.1127/0941-2948/2005/0055, 2005 b.

Möhler, O., Field, P. R., Connolly, P., Benz, S., Saathoff, H., Schnaiter, M., Wagner, R., Cotton, R., Krämer, M., Mangold, A., and Heymsfield, A. J.: Efficiency of the deposition mode ice nucleation on mineral dust particles, Atmos. Chem. Phys., 6, 30073021, doi:10.5194/acp-6-3007-2006, 2006.

Möhler, O., Benz., S., Saathoff, H., Schnaiter, M., Wagner, R., Schneider, J., Walter, S., Ebert, V., and Wagner, S.: The effect of organic coating on the heterogeneous ice nucleation efficiency of mineral dust aerosols, Environ. Res. Lett., 3, 025007, doi:10.1088/1748-9326/3/2/025007, 2008a.

Möhler, O., Georgakopoulos, D. G., Morris, C. E., Benz, S., Ebert, V., Hunsmann, S., Saathoff, H., Schnaiter, M., and Wagner, R.: Heterogeneous ice nucleation activity of bacteria: new laboratory experiments at simulated cloud conditions, Biogeosciences, 5, 1425-1435, doi:10.5194/bg-5-1425-2008, 2008b.

Moore, E. B., Allen, J. T., and Molinero, V.: Liquid-ice coexistence below the melting temperature for water confined in hydrophilic and hydrophobic nanopores, J. Phys. Chem. C, 116, 7507-7514, doi:10.1021/jp3012409, 2012.

Morishige, K. and Iwasaki, H.: X-ray study of freezing and melting of water confined within SBA-15, Langmuir, 19, 2808-2811, doi:10.1021/la0208474, 2003.

Morishige, K. and Kawano, K.: Freezing and melting of water in a single cylindrical pore: The pore-size dependence of freezing and melting behavior, J. Chem. Phys., 110, 4867-4872, doi:10.1063/1.481742, 1999.

Morishige, K. and Nobuoka, K.: X-ray diffraction studies of freezing and melting of water confined in a mesoporous adsorbent (MCM-41), J. Chem. Phys., 107, 6965-6969, doi:10.1063/1.474936, 1997.

Morishige, K. and Uematsu, H.: The proper structure of cubic ice confined in mesopores, J. Chem. Phys., 122, 044711, doi:10.1063/1.1836756, 2005. 
Morishige, K., Yasunaga, H., Denoyel, R., and Wernert, V.: Poreblocking-controlled freezing of water in cagelike pores of KIT5, J. Phys. Chem. C, 111, 9488-9495, doi:10.1021/jp072022e, 2007.

Morishige, K., Yasunaga, H., and Uematsu, H.: Stability of cubic ice in mesopores, J. Phys. Chem. C, 113, 3056-3061, doi:10.1021/jp8088935, 2009.

Mossop, S. C.: The freezing of supercooled water, P. Phys. Soc. B, 68, 193-208, doi:10.1088/0370-1301/68/4/301, 1955.

Murphy, D. M.: Something in the air, Science, 307, 1888-1890, doi:10.1126/science.1108160, 2005.

Murphy, D. M. and Koop, T.: Review of the vapour pressures of ice and supercooled water for atmospheric applications, Q. J. Roy. Meteor. Soc., 131, 1539-1565, doi:10.1256/qj.04.94, 2005.

Murphy, D. M. and Thomson, D. S.: Chemical composition of single aerosol particles at Idaho Hill: Negative ion measurements, J. Geophys. Res., 102, 6353-6368, doi:10.1029/96jd00858, 1997.

Murr, L. E. and Guerrero, P. A.: Carbon nanotubes in wood soot, Atmos. Sci. Lett., 7, 93-95, doi:10.1002/asl.138, 2006.

Murr, L. E. and Soto, K. F.: A TEM study of soot, carbon nanotubes, and related fullerene nanopolyhedra in common fuel-gas combustion sources, Mater. Charact., 55, 50-65, doi:10.1016/j.matchar.2005.02.008, 2005.

Murr, L. E., Bang J. J., Esquivel E. V., Guerrero P. A., and Lopez D. A.: Carbon nanotubes, nanocrystal forms, and complex nanoparticle aggregates in common fuel-gas combustion sources and the ambient air, J. Nanopart. Res., 6, 241-51, doi:10.1023/B:NANO.0000034651.91325.40, 2004.

Murray, B. J., Broadley S. L., Wilson, T. W., Bull, S. J., Wills, R. H., Christenson, H. K., and Murray E. J.: Kinetics of the homogeneous freezing of water, Phys. Chem. Chem. Phys., 12, 1038010387, doi:10.5194/acp-12-9275-2012, 2010a.

Murray, B. J., Wilson, T. W., Dobbie, S., Cui, Z., Al-Jumur, S. M. R. K., Möhler, O., Schnaiter, M., Wagner, R., Benz, S., Niemand, M., Saathoff, H., Ebert, V., Wagner, S., and Kärcher, B.: Heterogeneous nucleation of ice particles on glassy aerosols under cirrus conditions, Nat. Geosci., 3, 233-237, doi:10.1038/ngeo817, $2010 b$.

Murray, B. J., O’Sullivan, D., Atkinson, J. D., and Webb, M. E.: Ice nucleation by particles immersed in supercooled cloud droplets, Chem. Soc. Rev., 41, 6519-6554, doi:10.1039/c2cs35200a, 2012.

Niedermeier, D., Hartmann, S., Clauss, T., Wex, H., Kiselev, A., Sullivan, R. C., DeMott, P. J., Petters, M. D., Reitz, P., Schneider, J., Mikhailov, E., Sierau, B., Stetzer, O., Reimann, B., Bundke, U., Shaw, R. A., Buchholz, A., Mentel, T. F., and Stratmann, F.: Experimental study of the role of physicochemical surface processing on the IN ability of mineral dust particles, Atmos. Chem. Phys., 11, 11131-11144, doi:10.5194/acp-11-11131-2011, 2011.

Parsons, M. T., Mak, J., Lipetz, S. R., and Bertram, A. K., Deliquescence of malonic, succinic, glutaric, and adipic acid particles, J. Geophys. Res., 109, D06212, doi:10.1029/2003JD004075, 2004.

Peter, T., Marcolli, C., Spichtinger, P., Corti, T., Baker, M. B., and Koop, T.: When dry air is too humid, Science, 314, 1399-1401, doi:10.1126/science.1135199, 2006.

Pinti, V., Marcolli, C., Zobrist, B., Hoyle, C. R., and Peter, T.: Ice nucleation efficiency of clay minerals in the immersion mode, Atmos. Chem. Phys., 12, 5859-5878, doi:10.5194/acp-12-58592012, 2012.
Popovitz-Biro, R., Wang, J. L., Majewski, J., Shavit, E., Leiserowitz, L., and Lahav, M.: Induced freezing of supercooled water into ice by self-assembled crystalline monolayers of amphiphilic alcohols at the air-water interface, J. Am. Chem. Soc., 116, 1179-1191, doi:10.1021/ja00083a003, 1994.

Pradzynski, C. C., Forck, R. M., Zeuch, T., Slavíček, P., and Buck, U.: A fully size-resolved perspective on the crystallization of water clusters, Science, 337, 1529-1532, doi:10.1126/science.1225468, 2012.

Pruppacher, H. R.: A new look at homogeneous ice nucleation in supercooled water drops, J. Atmos. Sci., 52, 1924-1933, doi:10.1175/1520-0469(1995)052<1924:ANLAHI>2.0.CO;2, 1995.

Pruppacher, H. R. and Klett, J. D.: Microphysics of clouds and precipitation, Kluwer Academic Publishers, Dordrecht, 1997.

Reinhardt, A. and Doye, J. P. K.: Free energy landscapes for homogeneous nucleation of ice for a monatomic water model, J. Chem. Phys., 136, 054501, doi:10.1063/1.3677192, 2012.

Riechers, B., Wittbracht, F., Hütten, A., and Koop, T.: The homogeneous ice nucleation rate of water droplets produced in a microfluidic device and the role of temperature uncertainty, Phys. Chem. Chem. Phys., 15, 5873-5887, doi:10.1039/c3cp42437e, 2013.

Roberts, P. and Hallett, J.: A laboratory study of the ice nucleating properties of some mineral particulates, Q. J. Roy. Meteor. Soc., 94, 25-34, doi:10.1002/qj.49709439904, 1968.

Rutherford, D. W., Chiou, C. T., and Eberl, D. D.: Effects of exchanged cation on the microporosity of montmorillonite, Clay. Clay Miner., 45, 534-543, doi:10.1346/CCMN.1997.0450405, 1997.

Salam, A., Lohmann, U., Crenna, B., Lesins, G., Klages, P., Rogers, D., Irani, R., MacGillivray, A., and Coffin, M.: Ice nucleation studies of mineral dust particles with a new continuous flow diffusion chamber, Aerosol Sci. Tech., 40, 134-143, doi:10.1080/02786820500444853, 2006.

Salles, F., Beurroies, I., Bildstein, O., Jullien, M., Raynal, J., Denoyel, R., and Van Damme, H.: A calorimetric study of mesoscopic swelling and hydration sequence in solid Na-montmorillonite, Appl. Clay Sci., 39, 186-201, doi:10.1016/j.clay.2007.06.001, 2008.

Salles, F., Douillard, J.-M., Denoyel, R., Bildstein, O., Jullien, M., Beurroies, I., and Van Damme, H.: Hydration sequence of swelling clays: Evolutions of specific surface area and hydration energy, J. Colloid Interf. Sci., 333, 510-522, doi:10.1016/j.jcis.2009.02.018, 2009.

Schaller, R. C. and Fukuta, N.: Ice nucleation by aerosol-particles: Experimental studies using a wedge-shaped ice thermal diffusion chamber, J. Atmos. Sci., 36, 1788-1802, doi: 10.1175/15200469(1979)036<1788:INBAPE>2.0.CO;2, 1979.

Schreiber, A., Ketelsen, I., and Findenegg, G. H.: Melting and freezing of water in ordered mesoporous silica materials, Phys. Chem. Chem. Phys., 3, 1185-1195, doi:10.1039/b010086m, 2001.

Seyed-Yazdi, J., Farman, H., Dore, J. C., Webber, J. B. W., Findenegg, G. H., and Hansen, T.: Structural characterization of water and ice in mesoporous SBA-15 silicas: II. The "almost-filled" case for $86 \AA$ A pore diameter, J. Phys.-Condens. Mat., 20, 205107 , doi:10.1088/0953-8984/20/20/205107, 2008. 
Shilling, J. E., Fortin, T. J., and Tolbert, M. A.: Depositional ice nucleation on crystalline organic and inorganic solids, J. Geophys. Res., 111, D12204, doi:10.1029/2005JD006664, 2006.

Sills, I. D., Aylmore, L. A. G., and Quirk, J. P.: An analysis of pore size in illite-kaolinite mixtures, J. Soil Sci., 24, 480-490, 1973.

Sjogren, S., Gysel, M., Weingartner, E., Baltensperger, U., Cubison, M. J., Coe, H., Zardini, A. A., Marcolli, C., Krieger, U. K., and Peter, T.: Hygroscopic growth and water uptake kinetics of two-phase aerosol particles consisting of ammonium sulfate, adipic and humic acid mixtures, J. Aerosol Sci., 38, 157-171, doi:10.1016/j.jaerosci.2006.11.005, 2007.

Solveyra, E. G., de la Llave, E., Scherlis, D. A., and Molinero, V.: Melting and crystallization of ice in partially filled nanopores, J. Phys. Chem. B, 115, 14196-14204, doi:10.1021/jp205008w, 2011.

Steinke, I., Möhler, O., Kiselev, A., Niemand, M., Saathoff, H., Schnaiter, M., Skrotzki, J., Hoose, C., and Leisner, T.: Ice nucleation properties of fine ash particles from the Eyjafjallajökull eruption in April 2010, Atmos. Chem. Phys., 11, 12945-12958, doi:10.5194/acp-11-12945-2011, 2011.

Stetzer, O., Baschek, B., Lüönd, F., and Lohmann, U.: The Zurich Ice Nucleation Chamber (ZINC) - A new instrument to investigate atmospheric ice formation, Aerosol Sci. Technol., 42, 6474, doi:10.1080/02786820701787944, 2008.

Szyrmer, W. and Zawadzki, I.: Biogenic and anthropogenic sources of ice-forming nuclei: a review, B. Am. Meteorol. Soc., 78, 209-228, doi:10.1175/15200477(1997)078<0209:BAASOI>2.0.CO;2, 1997.

Tcheurekdjian, N., Zettlemoyer, A. C., and Chessick, J. J.: The adsorption of water vapor onto silver iodide, J. Phys. Chem., 68, 773-777, doi:10.1021/j100786a010, 1964.

Textor, C., Schulz, M., Guibert, S., Kinne, S., Balkanski, Y., Bauer, S., Berntsen, T., Berglen, T., Boucher, O., Chin, M., Dentener, F., Diehl, T., Feichter, J., Fillmore, D., Ginoux, P., Gong, S., Grini, A., Hendricks, J., Horowitz, L., Huang, P., Isaksen, I. S. A., Iversen, T., Kloster, S., Koch, D., Kirkevåg, A., Kristjansson, J. E., Krol, M., Lauer, A., Lamarque, J. F., Liu, X., Montanaro, V., Myhre, G., Penner, J. E., Pitari, G., Reddy, M. S., Seland, Ø., Stier, P., Takemura, T., and Tie, X.: The effect of harmonized emissions on aerosol properties in global models an AeroCom experiment, Atmos. Chem. Phys., 7, 4489-4501, doi:10.5194/acp-7-4489-2007, 2007.

Tobo, Y., DeMott, P. J., Raddatz, M., Niedermeier, D., Hartmann, S., Kreidenweis, S. M., Stratmann, F., and Wex, H.: Impacts of chemical reactivity on ice nucleation of kaolinite particles: A case study of levoglucosan and sulfuric acid, Geophys. Res. Lett., 39, L19803, doi:10.1029/2012GL053007, 2012.

Tomić, Z. P., Logar, V. P. Babic, B. M., Rogan J. R., and Makreski, P.: Comparison of structural, textural and thermal characteristics of pure and acid treated bentonites from Aleksinac and Petrovac (Serbia), Spectrochim. Acta A, 82, 389-395, doi:10.1016/j.saa.2011.07.068, 2011.

Vonnegut, B.: The nucleation of ice formation by silver iodide, J. Appl. Phys., 18, 593-595, doi:10.1063/1.1697813, 1947.

Vuković, Z., Milutinović-Nikolić, A., Krstić, J., Abu-Rabi, A., Novaković, T., and Jovanović, D.: The influence of acid treatment on the nanostructure and textural properties of bentonite clays, Mater. Sci. Forum, 494, 339-344, doi:10.4028/www.scientific.net/MSF.494.339, 2005.
Wagner, R., Möhler, O., Saathoff, H., Schnaiter, M., and Leisner, T.: High variability of the heterogeneous ice nucleation potential of oxalic acid dihydrate and sodium oxalate, Atmos. Chem. Phys., 10, 7617-7641, doi:10.5194/acp-10-7617-2010, 2010.

Wagner, R., Möhler, O., Saathoff, H., Schnaiter, M., and Leisner, T.: New cloud chamber experiments on the heterogeneous ice nucleation ability of oxalic acid in the immersion mode, Atmos. Chem. Phys., 11, 2083-2110, doi:10.5194/acp-11-2083-2011, 2011.

Wang, B. and Knopf, D. A.: Heterogeneous ice nucleation on particles composed of humic-like substances impacted by $\mathrm{O}_{3}$, J. Geophys. Res., 116, D03205, doi:10.1029/2010JD014964, 2011.

Wang, B., Lambe, A. T., Massoli, P., Onasch, T. B., Davidovits, P., Worsnop, D. R., and Knopf, D. A.: The deposition ice nucleation and immersion freezing potential of amorphous secondary organic aerosol: Pathways for ice and mixed-phase cloud formation, J. Geophys. Res., 117, D16209, doi:10.1029/2012JD018063, 2012.

Webber, B. and Dore, J.: Structural and dynamic studies of water in mesoporous silicas using neutron scattering and nuclear magnetic resonance, J. Phys.-Condens. Mat., 16, S5449-S5470, doi:10.1088/0953-8984/16/45/009, 2004.

Webber, J. B. W., Dore, J. C., Strange, J. H., Anderson, R., and Tohidi, B.: Plastic ice in confined geometry: the evidence from neutron diffraction and NMR relaxation, J. Phys.-Condens. Mat., 19, 415117, doi:10.1088/0953-8984/19/41/415117, 2007.

Welti, A., Lüönd, F., Stetzer, O., and Lohmann, U.: Influence of particle size on the ice nucleating ability of mineral dusts, Atmos. Chem. Phys., 9, 6705-6715, doi:10.5194/acp-9-6705-2009, 2009.

Welti, A., Kanji, Z., Stetzer, O., Lohmann U., and Lüönd, F.: Exploring the mechanisms of ice nucleation: From deposition nucleation to condensation freezing, J. Atmos. Sci., 71, 16-36, doi:10.1175/JAS-D-12-0252.1, 2014.

Wilson, T. W., Murray, B. J., Wagner, R., Möhler, O., Saathoff, H., Schnaiter, M., Skrotzki, J., Price, H. C., Malkin, T. L., Dobbie, S., and Al-Jumur, S. M. R. K.: Glassy aerosols with a range of compositions nucleate ice heterogeneously at cirrus temperatures, Atmos. Chem. Phys., 12, 8611-8632, doi:10.5194/acp-128611-2012, 2012.

Wise, M. E., Baustian, K. J., and Tolbert, M. A.: Internally mixed sulfate and organic particles as potential ice nuclei in the tropical tropopause region, P. Natl. Acad. Sci. USA, 107, 6693-6698, doi:10.1073/pnas.0913018107, 2010.

Zender, C. S., Miller, R. L., and Tegen, I.: Quantifying mineral dust mass budgets: Terminology, constraints, and current estimates, Eos Trans. AGU, 85, 509-512, doi:10.1029/2004EO480002, 2004.

Zimmermann, F., Ebert, M., Worringen, A., Schütz, L., and Weinbruch, S.: Environmental scanning electron microscopy (ESEM) as a new technique to determine the ice nucleation capability of individual atmospheric aerosol particles, Atmos. Environ., 41, 8219-8227, doi:10.1016/j.atmosenv.2007.06.023, 2007.

Zimmermann, F., Weinbruch, S., Schütz, L., Hofmann, H., Ebert, M., Kandler, K., and Worringen, A.: Ice nucleation properties of the most abundant mineral dust phases, J. Geophys. Res., 113, D23204, doi:10.1029/2008JD010655, 2008.

Zobrist, B., Marcolli, C., Koop, T., Luo, B. P., Murphy, D. M., Lohmann, U., Zardini, A. A., Krieger, U. K., Corti, T., Cziczo, D. J., Fueglistaler, S., Hudson, P. K., Thomson, D. S., and Peter, 
T.: Oxalic acid as a heterogeneous ice nucleus in the upper troposphere and its indirect aerosol effect, Atmos. Chem. Phys., 6, 3115-3129, doi:10.5194/acp-6-3115-2006, 2006.

Zobrist, B., Koop, T., Luo, B. P., Marcolli, C., and Peter, T.: Heterogeneous ice nucleation rate coefficient of water droplets coated by a nonadecanol monolayer, J. Phys. Chem. C, 111, 2149-2155, doi:10.1021/jp066080w, 2007.

Zobrist, B., Marcolli, C., Peter, T., and Koop, T.: Heterogeneous ice nucleation in aqueous solutions: the role of water activity, J. Phys. Chem. A, 112, 3965-3975, doi:10.1021/jp7112208, 2008a.

Zobrist, B., Marcolli, C., Pedernera, D. A., and Koop, T.: Do atmospheric aerosols form glasses?, Atmos. Chem. Phys., 8, 52215244, doi:10.5194/acp-8-5221-2008, 2008b.
Zuberi, B., Bertram, A. K., Koop, T., Molina, L. T., and Molina, M. J.: Heterogeneous freezing of aqueous particles induced by crystallized $\left(\mathrm{NH}_{4}\right)_{2} \mathrm{SO}_{4}$, ice and letovicite, J. Phys Chem. A, 105, 6458-6464, doi:10.1021/jp010094e, 2001.

Zuberi, B., Bertram, A. K., Cassa, C. A., Molina, L. T., and Molina, M. J.: Heterogeneous nucleation of ice in $\left(\mathrm{NH}_{4}\right)_{2} \mathrm{SO}_{4}-\mathrm{H}_{2} \mathrm{O}$ particles with mineral dust immersions, Geophys. Res. Lett., 29, 1504, doi:10.1029/2001GL014289, 2002. 